\title{
Creep-Fatigue Behavior and Damage Accumulation of a Candidate Structural Material for Concentrating Solar Power Thermal Receiver Quarter 6 Report
}

Michael D McMurtrey, Ryann E Rupp, Bipul Barua, Mark Messner

August 2019

The INL is a U.S. Department of Energy National Laboratory operated by Battelle Energy Alliance

Idaho National Laboratory 


\title{
Creep-Fatigue Behavior and Damage Accumulation of a Candidate Structural Material for Concentrating Solar Power Thermal Receiver Quarter 6 Report
}

\author{
Michael D McMurtrey, Ryann E Rupp, Bipul Barua, Mark Messner
}

August 2019

Idaho National Laboratory Idaho Falls, Idaho 83415

http://www.inl.gov

Prepared for the U.S. Department of Energy

Office of Energy Efficiency and Renewable Energy

Under DOE Idaho Operations Office

Contract DE-AC07-05ID14517 


\section{Research Performance Progress Report (RPPR) - DOE Solar Program}

Project Title: $\quad$ Creep-fatigue Behavior and Damage Accumulation of a Candidate Structural Material for Concentrating Solar Power Solar Thermal Receiver

Project Period: $\quad$ 2/01/18 $-1 / 31 / 20$

Budget Period: $\quad$ 5/01/19 - 7/31/19

Reporting Period: $\quad$ 5/01/19 - 7/31/119

Reporting Frequency: Quarterly

Submission Date: 8/15/19

Recipient: $\quad$ Idaho National Laboratory

Address: $\quad 2525$ Fremont Ave

Idaho Falls, ID 83402

Website (if available) Www.inl.gov

Project Number: $\quad 33872$

Project Team: $\quad$ Idaho National Laboratory

Argonne National Laboratory

Principal Investigator: Michael McMurtrey, Materials Scientist

Phone: (208) 526-2327

Email: michael.mcmurtrey@inl.gov

Business Contact: Gabriel Ilevbare, Materials Science \& Engineering Manager

Phone: 208-526-3735

Email: gabriel.ilevbare@inl.gov

HQ Tech Manager: Mark Lausten

HQ Project Officer: Christine Bing

GO Grant Specialist: GS name

GO Contracting Officer: CO name

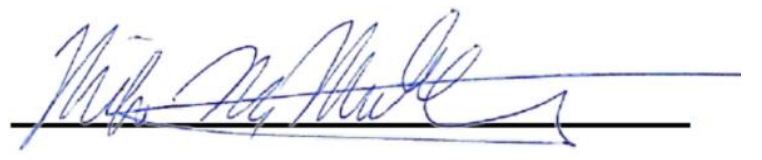

8/15/19

Signature

Date 


\section{Information from Statement of Project Objectives (SOPO)}

Project Objective: Creep-fatigue deformation is an important consideration for a thermal receiver in Concentrating Solar Power (CSP) systems due to the constant static stress or pressure, diurnal cycling, and elevated service temperatures required for efficient operation. An accurate description of the creep-fatigue behavior, not available for five of the six candidate materials, is important for assessment of preliminary designs. This project will provide a detailed analysis of the creep-fatigue behavior and damage accumulation of a candidate structural material for a CSP solar thermal receiver to address a critical knowledge barrier for receiver designs identified in the CSP Gen3 Demonstration Roadmap. This effort includes the development of rules for the design of solar receiver components against high temperature creep-fatigue and ratcheting failure modes. The ASME Code rules for high temperature nuclear components will form the basis of the method but adjustments will be made to reflect the generally shorter, diurnal operating cycles of thermal receivers and the relative consequences of failure, comparing nuclear to solar components.

\section{Work Planned for this Quarter:}

Task 1 - All initial planned fatigue conditions were previously, however some additional fatigue and creep-fatigue data was generated this quarter to strengthen design curves.

Task 2 - Not much was changed in the design models, though some new data was added. Test/example cases were performed to demonstrate use of the model.

Task 3 - Force controlled testing was performed on Alloy $740 \mathrm{H}$ plate for comparison to the upcoming sheet testing that will need to be run in force control.

\section{Plans for Next Quarter:}

Task 1 - Creep-fatigue testing will be finalized with additional data to ensure confidence in the Task 2 design models..

Task 2 - Design rules and models will continue to be refined and finalized with data generated by INL.

Task 3 - Additional force controlled plate testing will be performed $\left(\right.$ at $\left.750^{\circ} \mathrm{C}\right)$, as well as initial sheet specimen tests. 


\section{Narrative Report and Update:}

\section{Project Results and Discussion:}

\section{Task 1}

No additional data was generated in creep or tensile testing this quarter. The completed datasets for tensile and creep testing are shown in the previous (Q5) report. New fatigue and creep-fatigue testing generated this quarter was limited by required maintenance affecting two frames, resulting in fewer than expected available test frames. This issue has been resolved and a significant effort is underway to complete tests during Q7. In this quarter, a new fatigue and creep fatigue test were completed, as well as three load control tests that are related to Task 3 and will be covered in more detail within that section.

\section{Fatigue and Creep-Fatigue Testing}

Cyclic testing (including both fatigue and creep-fatigue) was performed using three-zone furnaces. Each zone may be controlled independently to ensure minimal temperature gradients over the gage section. Extensometers are used to measure stain directly in the gage section (through use of ceramic posts that connect to the specimen over the gage section). A window has been cut in the furnace insulation to allow the extensometer posts to reach the sample. Tests for Task 1 are all strain controlled, with a strain rate of $0.001 / \mathrm{s}$.

Fatigue and creep-fatigue testing will be shown jointly in this report to better highlight the detrimental effects of creep in cyclic testing. The creep portion of creep-fatigue occurs during holds at peak tensile strain. A hold at the minimum compressive strain was examined previously and found to be less detrimental to the fatigue life. Tensile dwell times were chosen to ensure more conservative results for the design models. Two new tests were performed this quarter for this task, a fatigue test at $750^{\circ} \mathrm{C}$ and a delta strain of $0.6 \%$ and a creep-fatigue test at $850^{\circ} \mathrm{C}$, with a $0.4 \%$ delta strain and a 10 minute hold time.

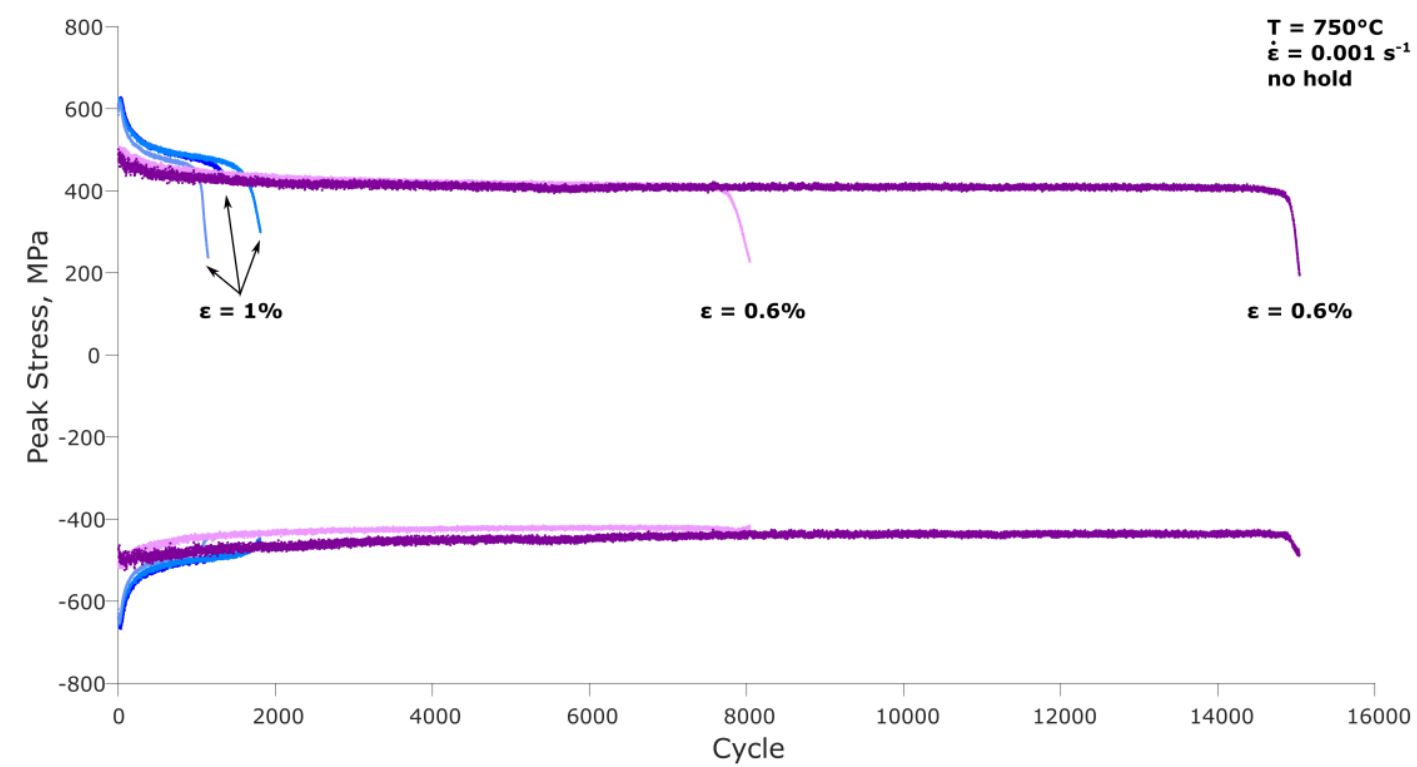

Figure 1. Fatigue curves for all strain controlled, $750^{\circ} \mathrm{C}$ tests. 


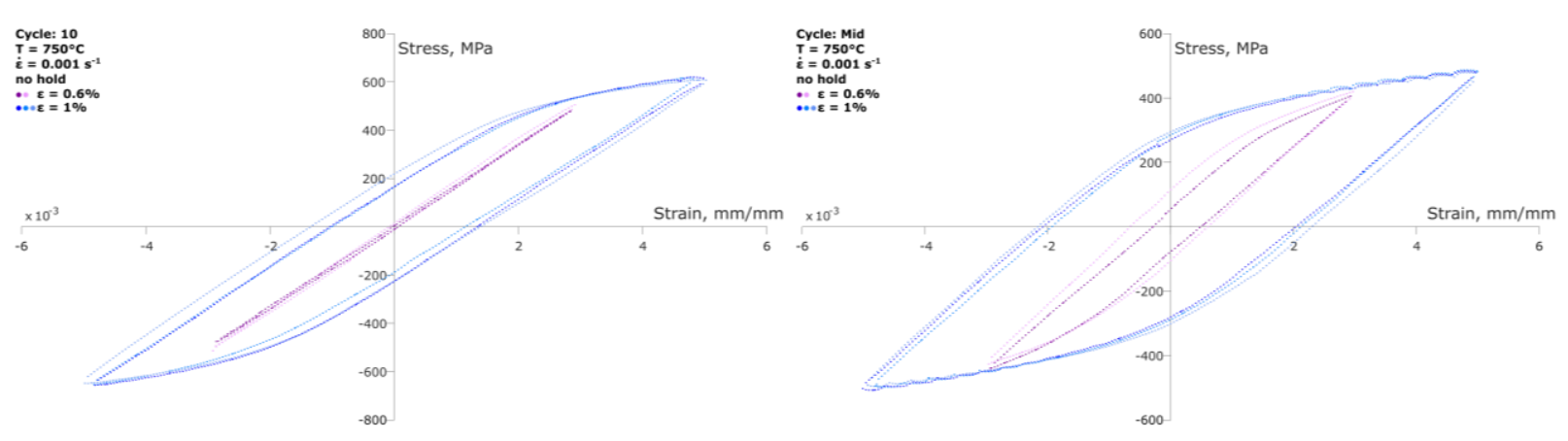

Figure 2. Hysteresis loops for cycle 10 (left) and the mid-cycle (right) for all strain controlled, $750^{\circ} \mathrm{C}$ fatigue tests

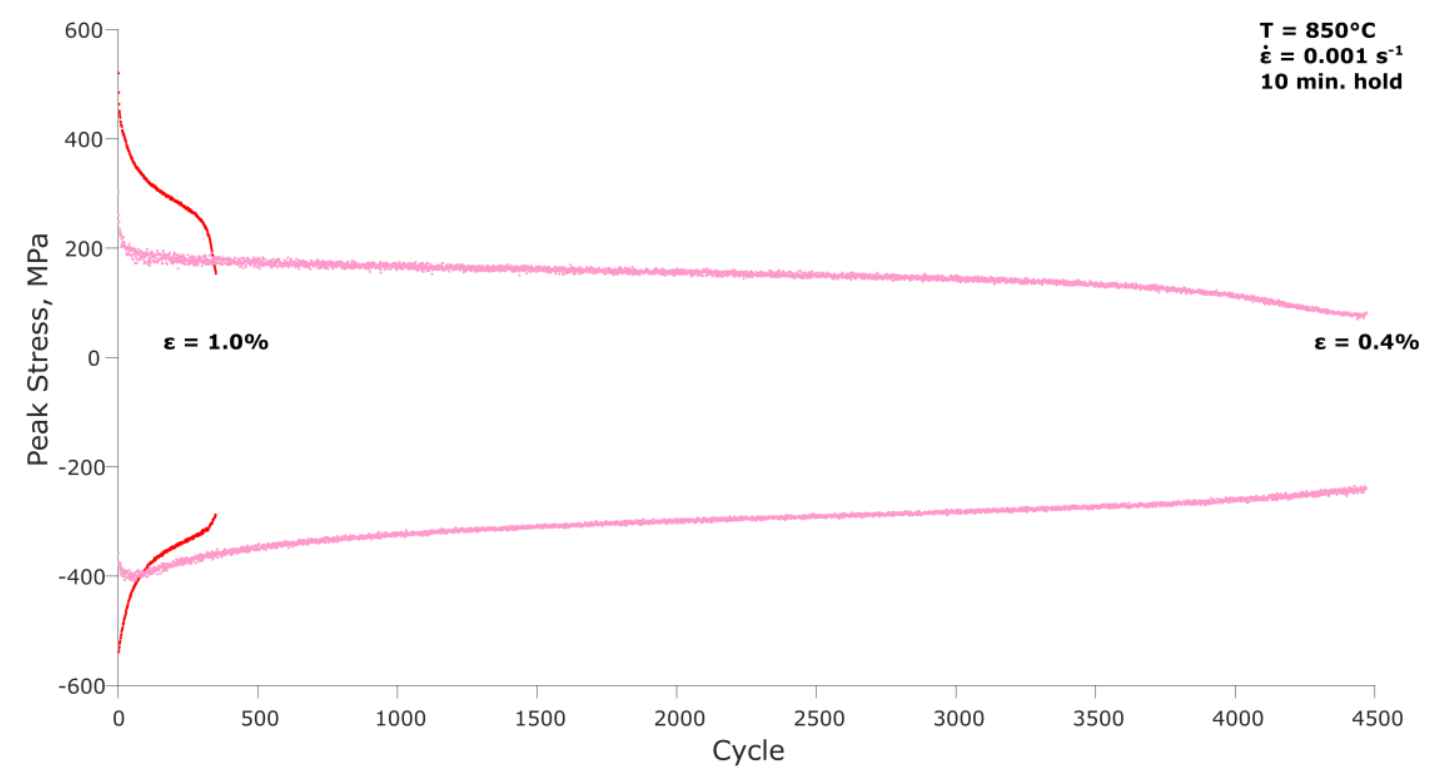

Figure 3. Creep-fatigue curves for both strain controlled, $850^{\circ} \mathrm{C}$ tests with a 10 minute hold in tension.

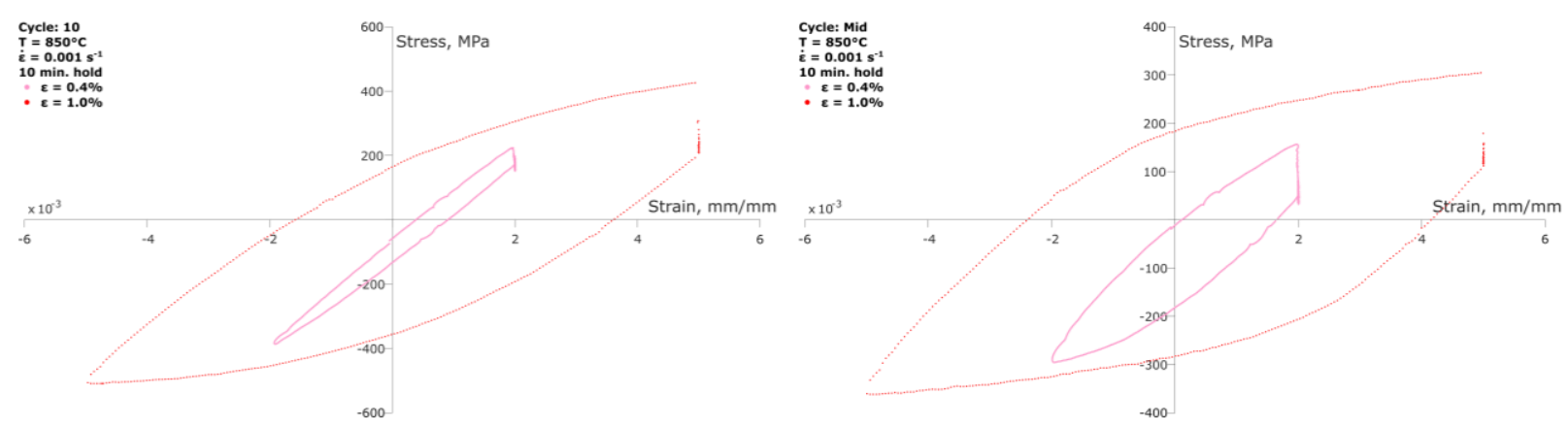

Figure 4. Hysteresis loops for cycle 10 (left) and mid-cycle (right) of both strain controlled, $850^{\circ} \mathrm{C}$ tests with a 10 minute hold in tension 


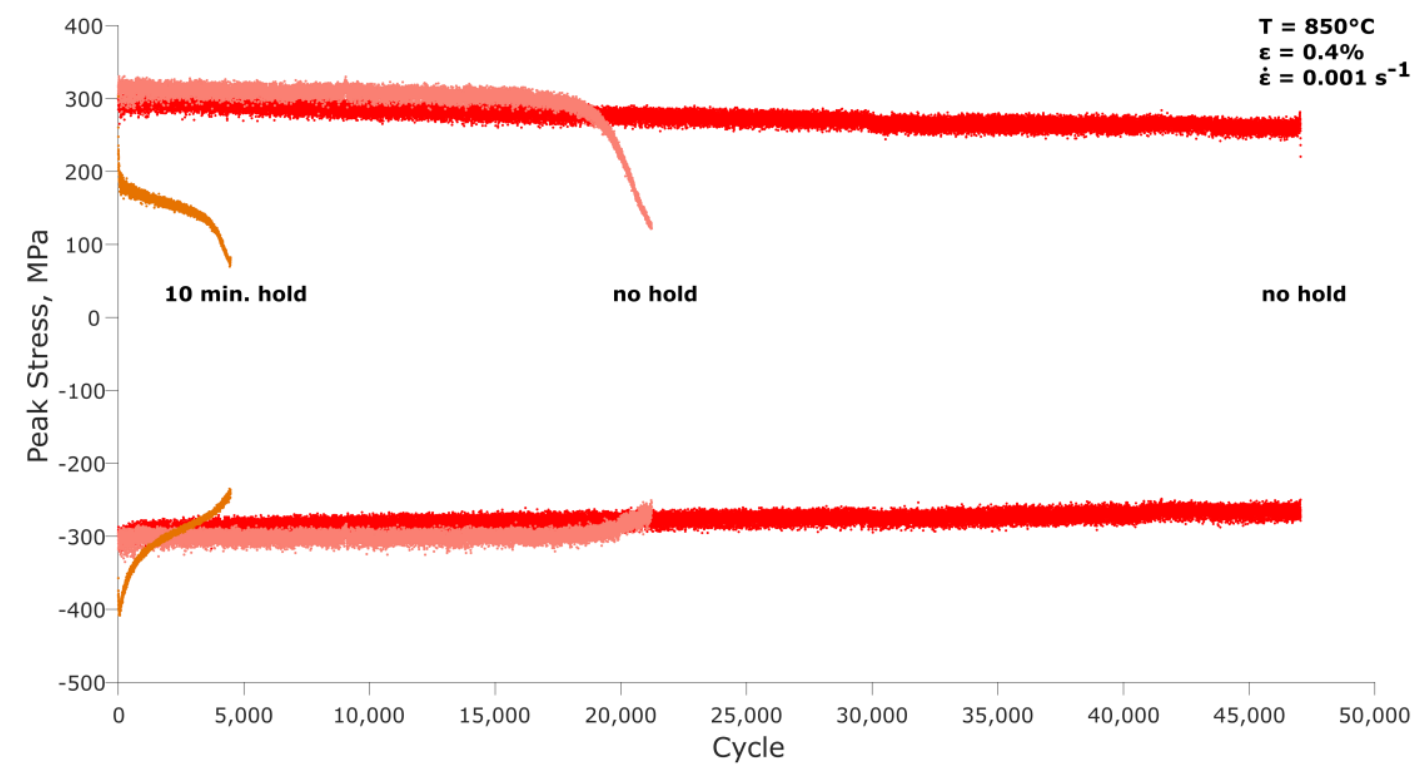

Figure 5. Stress vs. cycle for all strain controlled, $850^{\circ} \mathrm{C}$ with $0.4 \%$ total delta strain cyclic tests.

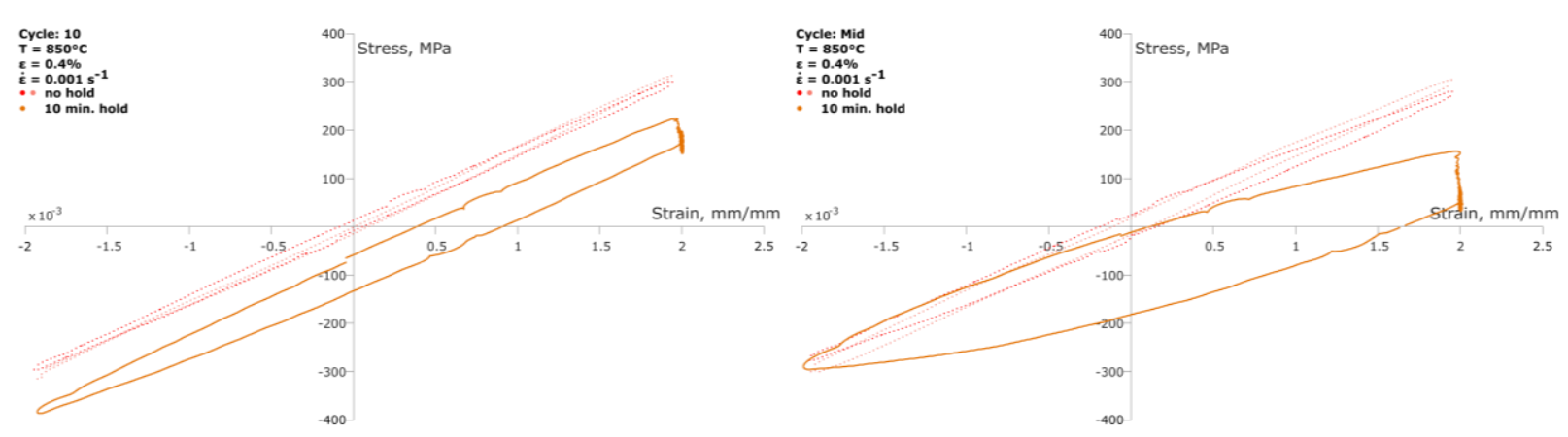

Figure 6. Hysteresis loops comparing $850^{\circ} \mathrm{C}$ fatigue and creep fatigue tests with a total delta strain of $0.4 \%$. Cycle 10 is shown on the left and the mid-cycle to the right.

\section{Summary}

All of the fatigue and creep-fatigue testing is summarized in Table 1. The completed tests have been provided to ANL so that the design models may begin to be refined using actual test data. Significant testing, particularly creep-fatigue, will be performed in Q7 to ensure that the final design model has enough test data to provide confidence in the results. With additional test frames now available, no issues are expected with accomplishing the remaining tests. 


\begin{tabular}{|c|c|c|c|c|c|c|c|c|c|c|c|c|c|c|}
\hline Temp. & Strain Rate & Hold time $^{1}$ & $\Delta \varepsilon_{\mathrm{t}}$ & \multicolumn{4}{|c|}{ At Cycle 10} & \multicolumn{5}{|c|}{ Midlife } & \multirow[b]{2}{*}{\begin{tabular}{|c|} 
Cycles \\
to \\
Initiation \\
\end{tabular}} & \multirow[b]{2}{*}{\begin{tabular}{|c} 
Cycles \\
to Failure
\end{tabular}} \\
\hline & & & & $\sigma_{\max }$ & $\sigma_{\min }$ & $\sigma_{\mathrm{h} \text {-start }}$ & $\sigma_{\text {h-end }}$ & $\begin{array}{l}\text { cycle } \\
\text { used }\end{array}$ & $\sigma_{\max }$ & $\sigma_{\min }$ & $\sigma_{\text {h-start }}$ & $\sigma_{\text {h-end }}$ & & \\
\hline$\left({ }^{\circ} \mathrm{C}\right)$ & $(/ \mathrm{s})$ & (min) & $(\%)$ & (MPa) & (MPa) & (MPa) & (MPa) & $\left(\mathrm{N}_{25} / 2\right)$ & (MPa) & $(\mathrm{MPa})$ & $(\mathrm{MPa})$ & $(\mathrm{MPa})$ & $\left(\mathrm{N}_{0}\right)$ & $\left(\mathrm{N}_{25}\right)$ \\
\hline \multicolumn{15}{|c|}{ Fatigue testing } \\
\hline 750 & 0.001 & 0 & 0.6 & 508 & -500 & - & - & 4000 & 420 & -425 & - & - & 7827 & 7950 \\
\hline 750 & 0.001 & 0 & 0.6 & 483 & -479 & - & - & 7500 & 406 & -440 & - & - & 14875 & 14987 \\
\hline 750 & 0.001 & 0 & 1.0 & 610 & -650 & - & - & 550 & 479 & -496 & - & - & 1038 & 1095 \\
\hline 750 & 0.001 & 0 & 1.0 & 620 & -656 & - & - & 900 & 484 & -508 & - & - & - & - \\
\hline 750 & 0.001 & 0 & 1.0 & 616 & -654 & - & - & 900 & 487 & -498 & - & - & 1541 & 1767 \\
\hline 800 & 0.001 & 0 & 1.0 & 554 & -583 & & & 350 & 436 & -450 & & & 637 & 653 \\
\hline 850 & 0.001 & 0 & 0.4 & 313 & -301 & - & - & 10000 & 305 & -305 & - & - & 18619 & 19969 \\
\hline 850 & 0.001 & 0 & 0.4 & 301 & -297 & - & - & 20000 & 280 & -277 & - & - & - & $47048^{3,4}$ \\
\hline 850 & 0.001 & 0 & 1.0 & 516 & -540 & - & - & 200 & 413 & -428 & - & - & 398 & 409 \\
\hline 850 & 0.001 & 0 & 1.0 & 514 & -535 & - & - & 200 & 409 & -417 & - & - & 370 & 402 \\
\hline \multicolumn{15}{|c|}{ Discarded Fatigue tests ${ }^{2}$} \\
\hline 850 & 0.001 & 0 & 1.0 & 423 & -453 & - & - & 190 & 382 & -403 & - & - & 353 & 377 \\
\hline 750 & 0.001 & 0 & 1.0 & 579 & -620 & - & - & 420 & 448 & -475 & - & - & 821 & 848 \\
\hline 750 & 0.001 & 0 & 1.0 & & & & & & & & & & & $747^{3}$ \\
\hline 750 & 0.001 & 0 & 1.0 & & & & & & & & & & & $981^{3}$ \\
\hline 750 & 0.001 & 0 & 1.0 & & & & & & & & & & & $693^{3}$ \\
\hline \multicolumn{15}{|c|}{ Creep-Fatigue testing } \\
\hline 750 & 0.001 & $60 \mathrm{~T}$ & 1.0 & 578 & -698 & 578 & 352 & 61 & 513 & -676 & 513 & 274 & 111 & 122 \\
\hline 750 & 0.001 & $60 \mathrm{C}$ & 1.0 & 665 & -607 & -607 & -355 & 94 & 652 & -527 & -526 & -275 & 181 & 187 \\
\hline 750 & 0.001 & 600 & 1.0 & \multicolumn{11}{|c|}{ Ongoing } \\
\hline 850 & 0.001 & $10 \mathrm{~T}$ & 0.4 & 224 & -386 & 224 & 173 & 2100 & 156 & -296 & 155 & 48 & 3791 & 4147 \\
\hline 850 & 0.001 & $10 \mathrm{~T}$ & 1.0 & 426 & -509 & 426 & 193 & 150 & 305 & -362 & 305 & 104 & 320 & 342 \\
\hline 850 & 0.001 & $10 \mathrm{~T}$ & 1.0 & 456 & -532 & 456 & 202 & 69 & 364 & -422 & 363 & 132 & -4 & $138^{3,4}$ \\
\hline 850 & 0.001 & $600 \mathrm{~T}$ & 1.0 & 311 & -390 & 310 & 82 & 116 & 245 & -299 & 244 & 51 & 209 & 231 \\
\hline
\end{tabular}

1) In the case of hold times, $T$ refers to a hold at peak tension stress and $C$ refers to a hold at peak compressive stress

2) Testing using alternative methods of heating were found to vary the results and the data was not used in developing the design models

3) These cycles to failure are the total number of cycles performed by the test frame rather than the calculated $25 \%$ load drop from $\mathrm{N}_{0}$ )

4) Specimen cracked and failed outside the extensometer region

Table 1. Summary of Alloy $740 \mathrm{H}$ fatigue and creep-fatigue testing performed at INL. Tests that were not used in the design models are highlighted in red.

\section{Task 2}

\section{Updated Alloy $740 \mathrm{H}$ design data}

This section updates the design data for $740 \mathrm{H}$ based on the tests completed at INL in the current quarter. As mentioned in the previous quarterly report, the design information is essentially stable at this point. The only changes this quarter are to the fatigue diagram (negligible change) and to the creep-fatigue interaction diagram.

\section{Young's modulus}

No changes from our Q5 report. These values are from the material datasheet [1]. 


\begin{tabular}{ll}
\hline $\begin{array}{l}\text { Temperature } \\
\left({ }^{\circ} \mathrm{C}\right)\end{array}$ & $\begin{array}{l}\text { Modulus } \\
(\mathrm{GPa})\end{array}$ \\
\hline 20 & 221 \\
100 & 218 \\
200 & 212 \\
300 & 206 \\
400 & 200 \\
500 & 193 \\
600 & 186 \\
700 & 178 \\
800 & 169 \\
900 & 160 \\
\hline
\end{tabular}

Table 2. Design Young's modulus.

\section{Poisson's ratio}

Based on the ASME Section II Part D values we elect to use a constant value of 0.31. This is the same value recommended in our Q5 report.

\section{Coefficient of thermal expansion}

These values are from the material datasheet [1]. No change from our Q5 report.

\begin{tabular}{lll}
\hline $\begin{array}{l}\text { Temperature } \\
\left({ }^{\circ} \mathrm{C}\right)\end{array}$ & $\begin{array}{l}\text { Mean CTE } \\
\left(\mu \mathrm{m} / \mathrm{mm} /{ }^{\circ} \mathrm{C}\right)\end{array}$ & $\begin{array}{l}\text { Instantaneous CTE } \\
\left(\mu \mathrm{m} / \mathrm{mm} /{ }^{\circ} \mathrm{C}\right)\end{array}$ \\
\hline 20 & & 12.38 \\
100 & 12.38 & 12.38 \\
200 & 13.04 & 13.55 \\
300 & 13.5 & 14.32 \\
400 & 13.93 & 15.12 \\
500 & 14.27 & 15.55 \\
600 & 14.57 & 16 \\
700 & 15.03 & 17.68 \\
800 & 15.72 & 20.39 \\
900 & 16.41 & 16.51 \\
\hline
\end{tabular}

Table 3. Design coefficients of thermal expansion.

\section{Thermal conductivity}

No change from our Q5 report. These values are from the material datasheet [1]. 


\begin{tabular}{ll}
\hline $\begin{array}{l}\text { Temperature } \\
\left({ }^{\circ} \mathrm{C}\right)\end{array}$ & $\begin{array}{l}\text { Conductivity } \\
\left(\mathrm{W} /\left(\mathrm{m}^{\circ} \mathrm{C}\right)\right)\end{array}$ \\
\hline 20 & 10.2 \\
100 & 11.7 \\
200 & 13 \\
300 & 14.5 \\
400 & 15.7 \\
500 & 17.1 \\
600 & 18.4 \\
700 & 20.2 \\
800 & 22.1 \\
900 & 23.8 \\
\hline
\end{tabular}

Table 4. Design values of thermal conductivity.

Specific heat

No change from our Q5 report. These values are from the material datasheet [1].

\begin{tabular}{ll}
\hline $\begin{array}{l}\text { Temperature } \\
\left({ }^{\circ} \mathrm{C}\right)\end{array}$ & $\begin{array}{l}\text { Specific heat } \\
\left(\mathrm{J} /\left(\mathrm{kg}{ }^{\circ} \mathrm{C}\right)\right)\end{array}$ \\
\hline 20 & 449 \\
100 & 476 \\
200 & 489 \\
300 & 496 \\
400 & 503 \\
500 & 513 \\
600 & 519 \\
700 & 542 \\
800 & 573 \\
900 & 635 \\
\hline \multicolumn{2}{c}{ Table 5. Design values of specific heat }
\end{tabular}

Yield strength

No change from our Q5 report. These values are from the ASME Code Case [2]. 
Creep-fatigue Behavior and Damage Accumulation of a Candidate Structural Material for Concentrating Solar Power Solar Thermal Receiver Michael McMurtrey

\begin{tabular}{ll}
\hline $\begin{array}{l}\text { Temperature } \\
\left({ }^{\circ} \mathrm{C}\right)\end{array}$ & $\begin{array}{c}S_{y} \\
(\mathrm{MPa})\end{array}$ \\
\hline 40 & 621 \\
100 & 594 \\
150 & 577 \\
200 & 562 \\
250 & 548 \\
300 & 538 \\
350 & 531 \\
400 & 529 \\
450 & 529 \\
500 & 529 \\
550 & 529 \\
600 & 529 \\
650 & 529 \\
700 & 529 \\
750 & 508 \\
800 & 463 \\
850 & 418 \\
900 & 373 \\
\hline Table 6. Design values of yield strength $\left(S_{y}\right)$.
\end{tabular}

Table 6. Design values of yield strength $\left(S_{y}\right)$.

Ultimate tensile strength

No change from the Q5 report. These values are from the ASME Code Case [2]. 


\begin{tabular}{ll}
\hline $\begin{array}{l}\text { Temperature } \\
\left({ }^{\circ} \mathrm{C}\right)\end{array}$ & $\begin{array}{c}S_{u} \\
(\mathrm{MPa})\end{array}$ \\
\hline 40 & 1034 \\
100 & 1034 \\
150 & 1034 \\
200 & 1030 \\
250 & 998 \\
300 & 976 \\
350 & 967 \\
400 & 966 \\
450 & 966 \\
500 & 966 \\
550 & 966 \\
600 & 957 \\
650 & 921 \\
700 & 860 \\
750 & 771 \\
800 & 651 \\
850 & 531 \\
900 & 411 \\
\hline Table 7. Design values of tensile strength $\left(S_{w}\right)$.
\end{tabular}

\section{Minimum rupture stress}

No change from the Q5 report. These values were calculated from a rupture model developed at ANL using data from [3]. The line on the table indicates the region where the rupture stress is controlled by the material's ultimate tensile strength, instead of the creep rupture strength. 
33872

Creep-fatigue Behavior and Damage Accumulation of a Candidate Structural Material for Concentrating Solar Power Solar Thermal Receiver Michael McMurtrey

\begin{tabular}{|c|c|c|c|c|c|c|c|c|c|c|c|}
\hline & \multicolumn{10}{|c|}{ Time (hours) } \\
\hline & & 1 & 10 & 30 & 100 & 300 & 1000 & 3000 & 10000 & 30000 & 100000 \\
\hline \multirow{20}{*}{$\begin{array}{c}\text { Temp. } \\
\left({ }^{\circ} \mathrm{C}\right)\end{array}$} & 425 & 966 & 966 & 966 & 966 & 966 & 966 & 966 & 966 & 966 & 966 \\
\hline & 450 & 966 & 966 & 966 & 966 & 966 & 966 & 966 & 966 & 966 & 966 \\
\hline & 475 & 966 & 966 & 966 & 966 & 966 & 966 & 966 & 966 & 966 & 966 \\
\hline & 500 & 966 & 966 & 966 & 966 & 966 & 966 & 966 & 966 & 966 & 966 \\
\hline & 525 & 966 & 966 & 966 & 966 & 966 & 966 & 966 & 966 & 966 & 938 \\
\hline & 550 & 966 & 966 & 966 & 966 & 966 & 966 & 966 & 966 & 876 & 749 \\
\hline & 575 & 962 & 962 & 962 & 962 & 962 & 957 & 957 & 814 & 703 & 598 \\
\hline & 600 & 957 & 957 & 957 & 957 & 957 & 902 & 775 & 656 & 563 & 476 \\
\hline & 625 & 939 & 939 & 939 & 939 & 870 & 733 & 627 & 528 & 451 & 380 \\
\hline & 650 & 921 & 921 & 921 & 834 & 710 & 595 & 507 & 424 & 361 & 302 \\
\hline & 675 & 891 & 891 & 819 & 684 & 580 & 483 & 409 & 341 & 289 & 240 \\
\hline & 700 & 860 & 800 & 675 & 561 & 473 & 392 & 331 & 274 & 231 & 191 \\
\hline & 725 & 816 & 662 & 556 & 459 & 386 & 318 & 267 & 220 & 184 & 152 \\
\hline & 750 & 771 & 548 & 458 & 376 & 314 & 258 & 215 & 176 & 147 & 120 \\
\hline & 775 & 665 & 453 & 377 & 308 & 256 & 209 & 173 & 141 & 117 & 96 \\
\hline & 800 & 555 & 374 & 310 & 252 & 208 & 169 & 140 & 113 & 94 & 76 \\
\hline & 825 & 463 & 309 & 255 & 206 & 169 & 137 & 112 & 91 & 74 & 60 \\
\hline & 850 & 386 & 255 & 209 & 168 & 138 & 111 & 90 & 73 & 59 & 48 \\
\hline & 875 & 322 & 211 & 172 & 137 & 112 & 89 & 73 & 58 & 47 & 38 \\
\hline & 900 & 268 & 174 & 141 & 112 & 91 & 72 & 58 & 46 & 38 & 30 \\
\hline
\end{tabular}

\section{Allowable stress $S_{0}$}

No change from our Q5 report. These values are from the ASME Code Case [2]. 


\begin{tabular}{ll}
\hline $\begin{array}{l}\text { Temperature } \\
\left({ }^{\circ} \mathrm{C}\right)\end{array}$ & $\begin{array}{l}S_{0} \\
(\mathrm{MPa})\end{array}$ \\
\hline 40 & 295 \\
100 & 295 \\
150 & 295 \\
200 & 279 \\
250 & 276 \\
300 & 276 \\
350 & 276 \\
400 & 276 \\
450 & 276 \\
500 & 276 \\
550 & 276 \\
600 & 274 \\
650 & 226 \\
700 & 146 \\
750 & 84.1 \\
800 & 34.5 \\
850 & 21.8 \\
900 & 13.8 \\
\hline
\end{tabular}

Allowable stress $S_{m}$

Table 10 is provided for use with the Section III, Division 5, Nonmandatory Appendix T rules for ratcheting and creep-fatigue design by inelastic analysis. These values are the minimum of $0.9 S_{y}$ and $S_{u} / 3$ for the indicated temperatures. 


\begin{tabular}{ll}
\hline $\begin{array}{l}\text { Temperature } \\
\left({ }^{\circ} \mathrm{C}\right)\end{array}$ & $\begin{array}{l}S_{m} \\
(\mathrm{MPa})\end{array}$ \\
\hline 40 & 345 \\
100 & 345 \\
150 & 345 \\
200 & 343 \\
250 & 333 \\
300 & 325 \\
350 & 322 \\
400 & 322 \\
450 & 322 \\
500 & 322 \\
550 & 322 \\
600 & 319 \\
650 & 307 \\
700 & 287 \\
750 & 257 \\
800 & 217 \\
850 & 177 \\
900 & 137 \\
\hline
\end{tabular}

Table 10. Allowable stress $S_{m}$.

\section{Isochronous stress-strain curves}

The model remains the same as in the Q5 report. The curves are based on an additive, historyindependent decomposition of the total strain, $\varepsilon$ into elastic strain, $\varepsilon_{\varepsilon}$, time-independent plastic strain, $\varepsilon_{p}$, and time-dependent creep strain, $\varepsilon_{c}$.

$\varepsilon=\varepsilon_{e}+\varepsilon_{p}+\varepsilon_{c}$

The hot tensile curves are the outcome of this model when $\varepsilon_{c}=0$, i.e. when $t=0$, whereas the isochronous curves are the output of the model for some fixed, non-zero time. The elastic strain is calculated using the temperature dependent values of Young's modulus, E (Table 2) for Alloy $740 \mathrm{H}$.

$\varepsilon_{e}=\frac{\sigma}{E}$

The plastic response of Alloy $740 \mathrm{H}$ was divided into two regions based on temperature. At temperatures below and equal to $800^{\circ} \mathrm{C}$ the composite model uses a Ramberg-Osgood model for the plastic strain to capture the experimentally-observed smooth transition from elastic to work hardening plastic behavior. Above this temperature the model uses a Voce hardening model to capture a quick transition to a nearly perfectly-plastic response. The composite model for the plastic strain is then 


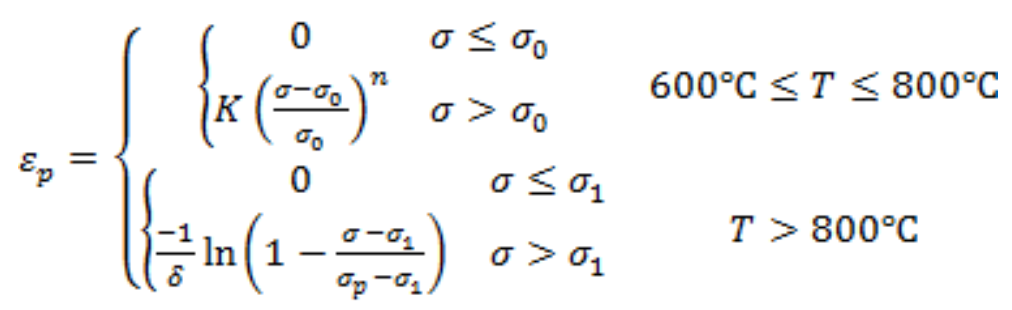

Table 11 lists all the model constants for Ramberg-Osgood and Voce Hardening models for temperature range between $600^{\circ} \mathrm{C}$ and $850^{\circ} \mathrm{C}$.

\begin{tabular}{ccccccc}
\hline \multirow{2}{*}{ Temperatures } & \multicolumn{2}{c}{ Ramberg-Osgood model parameters } & \multicolumn{5}{c}{ Voce hardening model parameters } \\
& $\sigma_{0}(\mathrm{MPa})$ & $\mathrm{K}$ & $\mathrm{n}$ & $\sigma_{\mathrm{p}}(\mathrm{MPa})$ & $\sigma_{1}(\mathrm{MPa})$ & $\delta$ \\
\hline $600^{\circ} \mathrm{C}-700^{\circ} \mathrm{C}$ & 400.24 & 0.0704 & 6.6480 & & & \\
$725^{\circ} \mathrm{C}$ & 374.20 & 0.0357 & 7.1315 & & & \\
$750^{\circ} \mathrm{C}$ & 348.16 & 0.0181 & 7.6150 & & & \\
$775^{\circ} \mathrm{C}$ & 312.255 & 0.0055 & 10.971 & & & \\
$800^{\circ} \mathrm{C}$ & 276.35 & 0.0017 & 14.327 & 574.991 & 455.850 & 908.324 \\
$825^{\circ} \mathrm{C}$ & & & & 521.631 & 319.315 & 2212.205 \\
$850^{\circ} \mathrm{C}$ & & & & 468.271 & 182.780 & 3516.087 \\
\hline
\end{tabular}

Table 11. Parameters for plasticity models for $\varepsilon_{\mathrm{p}}$.

To model the time-dependent strain, $\varepsilon_{c}$ we adopt a simple creep model for alloy $740 \mathrm{H}$.

$\varepsilon_{c}=\dot{\varepsilon}_{c}(T, \sigma) t$

where $\dot{\varepsilon}_{c}$ is some constant, average creep rate, which is a function of temperature and stress.

We adopt a form developed by Kocks [6] and Mecking [7] for the creep rate model. Their model posits a linear relation between the $\log$-normalized material flow stress $\log \frac{\sigma}{\mu}$ and the normalized activation energy $\frac{k T}{\mu b^{\mathrm{a}}} \ln \frac{\vec{s}_{0}}{\vec{s}}$. If this log-linear relation exists, the Kocks-Mecking model can be converted into a model for the deformation strain rate as a function of the linear fit slope $A$ and intercept $B$

$\dot{\varepsilon}=\dot{\varepsilon}_{0} e^{B \mu b^{\mathrm{s}} /(A k T)}\left(\frac{\sigma}{\mu}\right)^{-\mu b^{\mathrm{s}} /(A k T)}$

Here $\mu$ is the material shear stress given as $\mu=\frac{E}{2(1+v)}, k$ is the Boltzmann constant, $T$ is absolute temperature, $b$ is a characteristic Burgers vector, and $\dot{\varepsilon}_{0}$ is some reference strain rate. Figure 7 plots the available Alloy $740 \mathrm{H}$ creep data using the average rate to $1 \%$ creep strain as the deformation strain rate and the applied values of stress and temperature. 


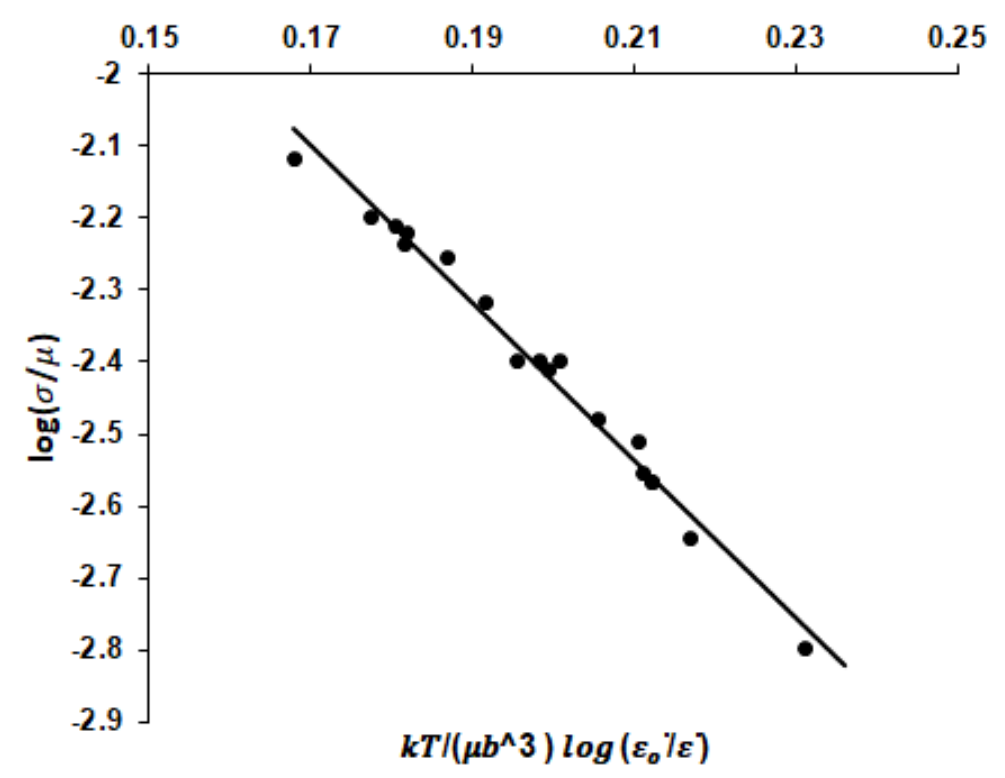

Figure 7. Kocks-Mecking diagram used to construct the model for $\varepsilon_{\varepsilon}$.

As the Figure 7 shows, the Alloy 740 creep data nearly obeys the Kocks-Mecking form. Based on this diagram, the model for the creep strain adopted here is

$\varepsilon_{c}=\dot{\varepsilon}_{0} e^{\frac{B \mu b^{\mathrm{a}}}{A k T}}\left(\frac{\sigma}{\mu}\right)^{\frac{-\mu b^{\mathrm{a}}}{A k T}} t$

The parameters for the creep model are given in Table 12. Figures 8-18 plot the isochronous stress-strain curves for alloy $740 \mathrm{H}$ for temperatures in the range between $600^{\circ} \mathrm{C}$ and $850^{\circ} \mathrm{C}$ with an interval of $25^{\circ} \mathrm{C}$. 


\begin{tabular}{|c|c|}
\hline$\dot{\varepsilon}_{o}$ & $1.19 \times 10^{10} \mathrm{hr}^{-1}$ \\
\hline $\mathrm{k}$ & $1.38064 \times 10^{-20} \mathrm{~mJ} / \mathrm{K}$ \\
\hline $\mathrm{b}$ & $2.53 \times 10^{-07} \mathrm{~mm}$ \\
\hline $\mathrm{A}$ & -10.98557 \\
\hline $\mathrm{B}$ & -0.53098 \\
\hline
\end{tabular}

Table 12. Parameters for creep model of alloy $740 \mathrm{H}$.

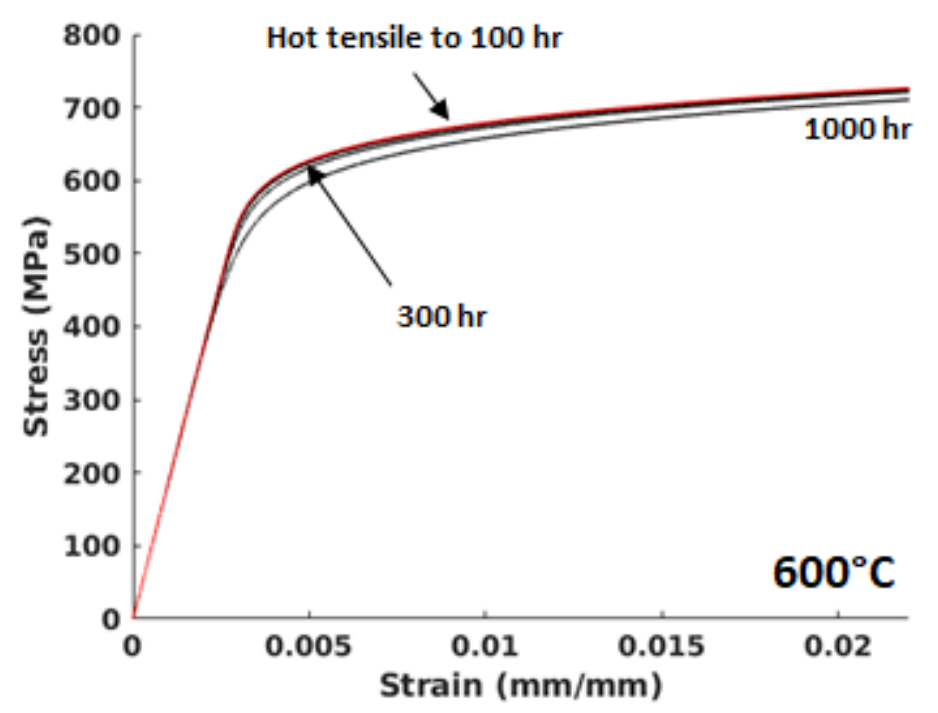

Figure 8. Isochronous stress strain curves at $600^{\circ} \mathrm{C}$.

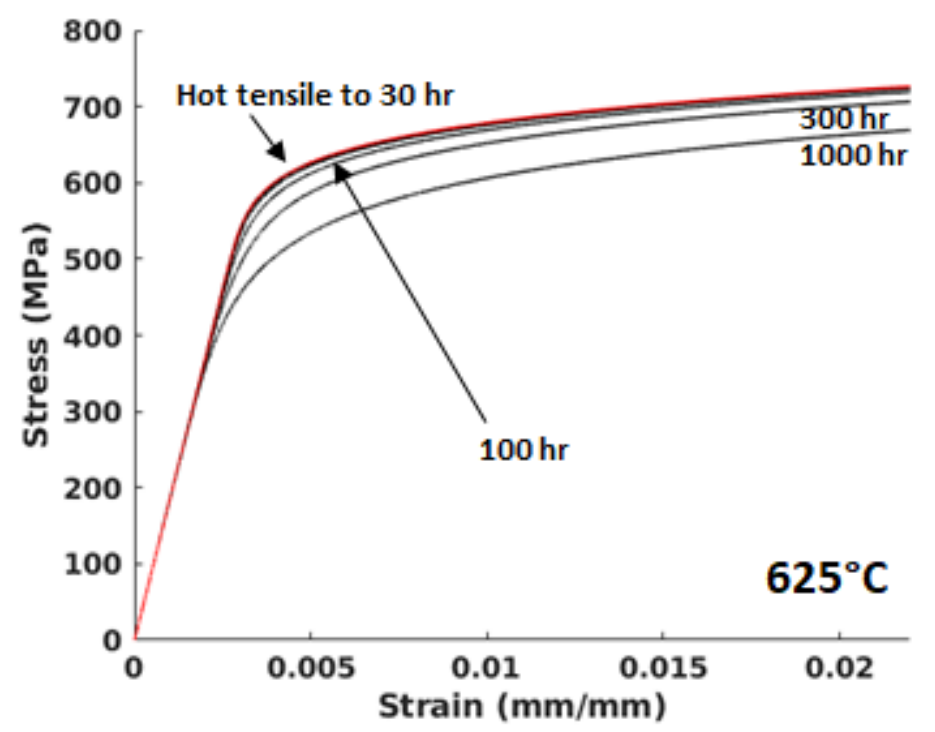

Figure 9. Isochronous stress strain curves at $625^{\circ} \mathrm{C}$. 


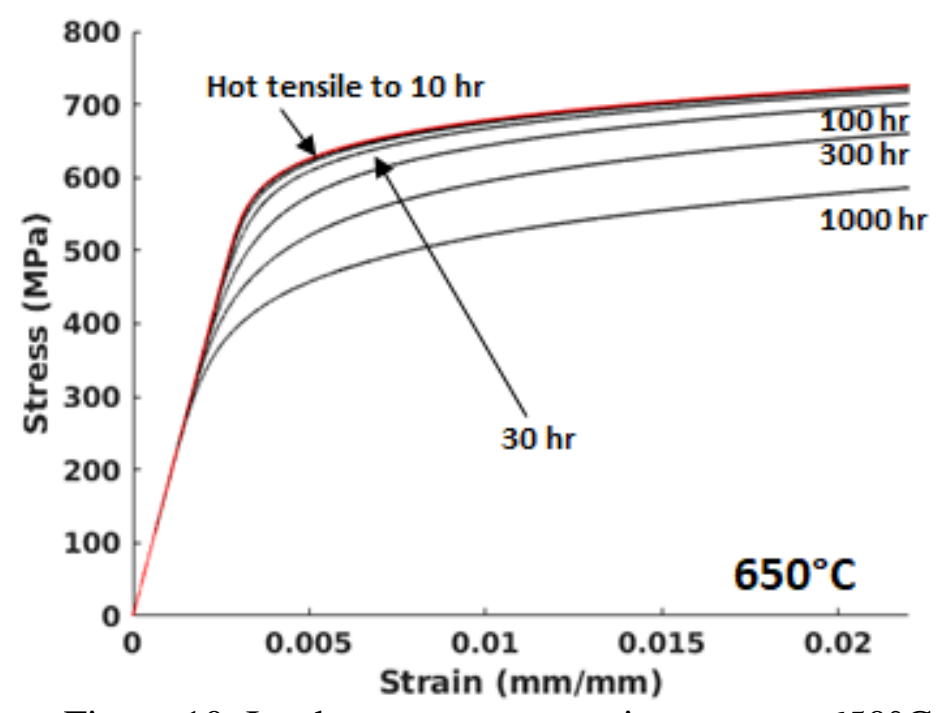

Figure 10. Isochronous stress strain curves at $650^{\circ} \mathrm{C}$.

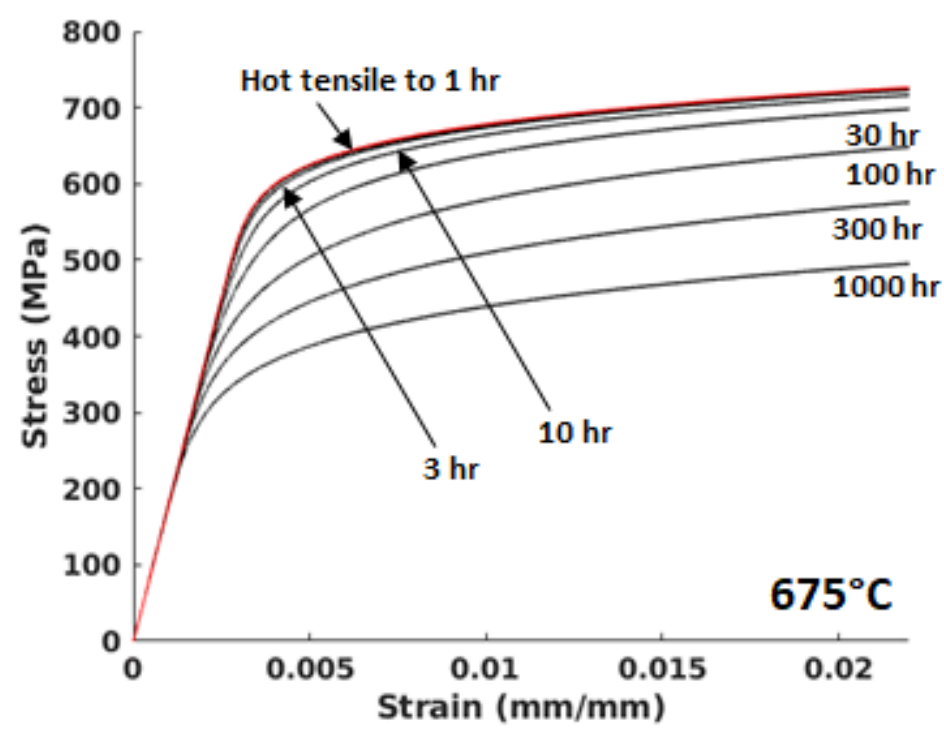

Figure 11. Isochronous stress strain curves at $675^{\circ} \mathrm{C}$. 


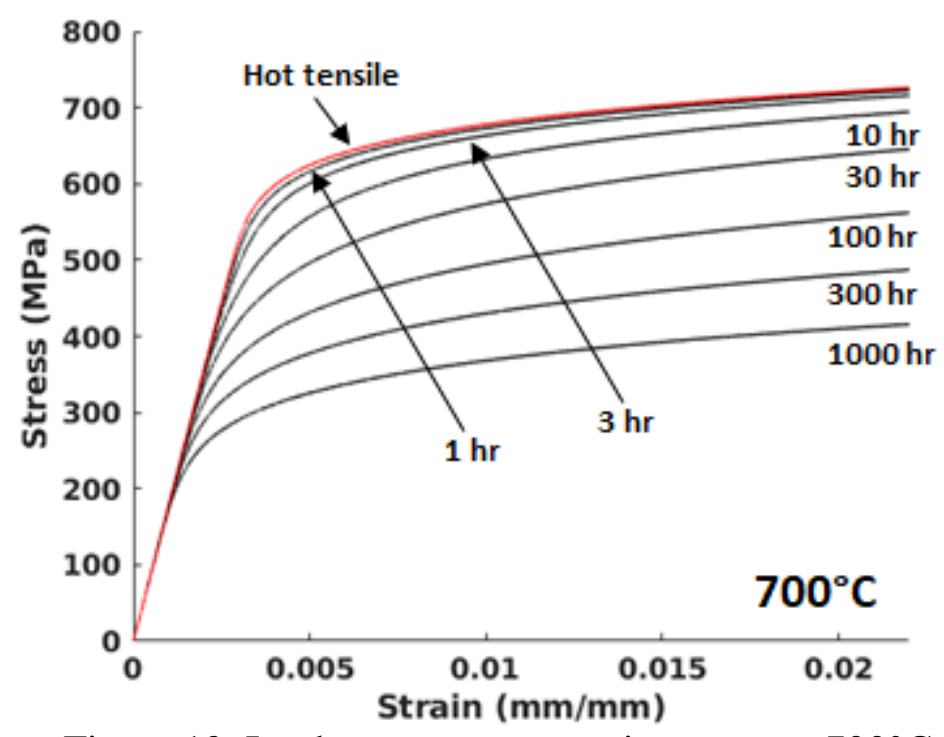

Figure 12 . Isochronous stress strain curves at $700^{\circ} \mathrm{C}$.

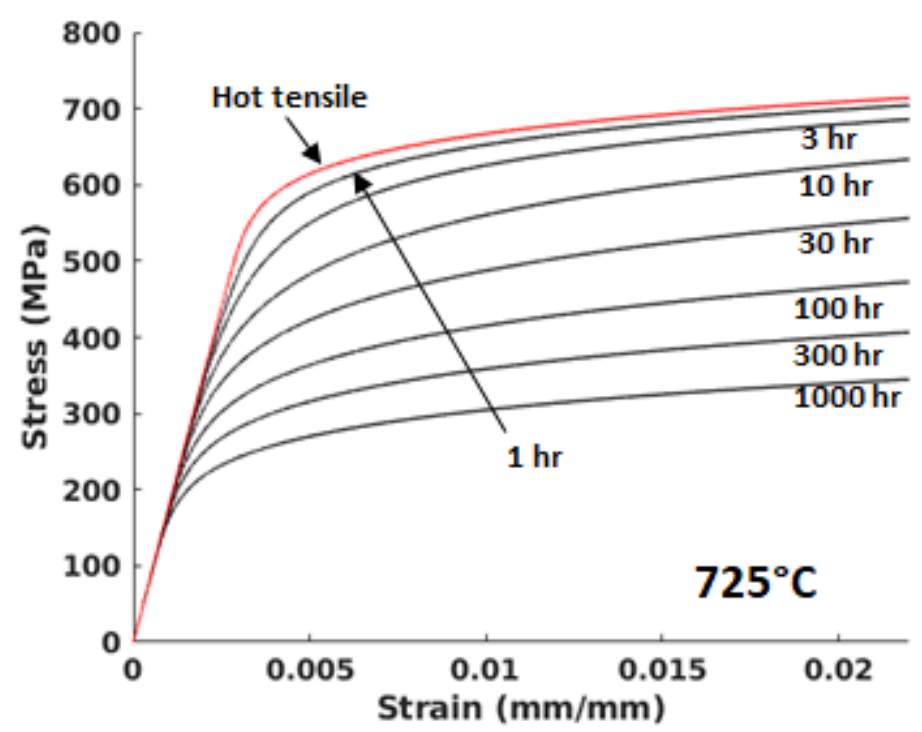

Figure 13. Isochronous stress strain curves at $725^{\circ} \mathrm{C}$. 


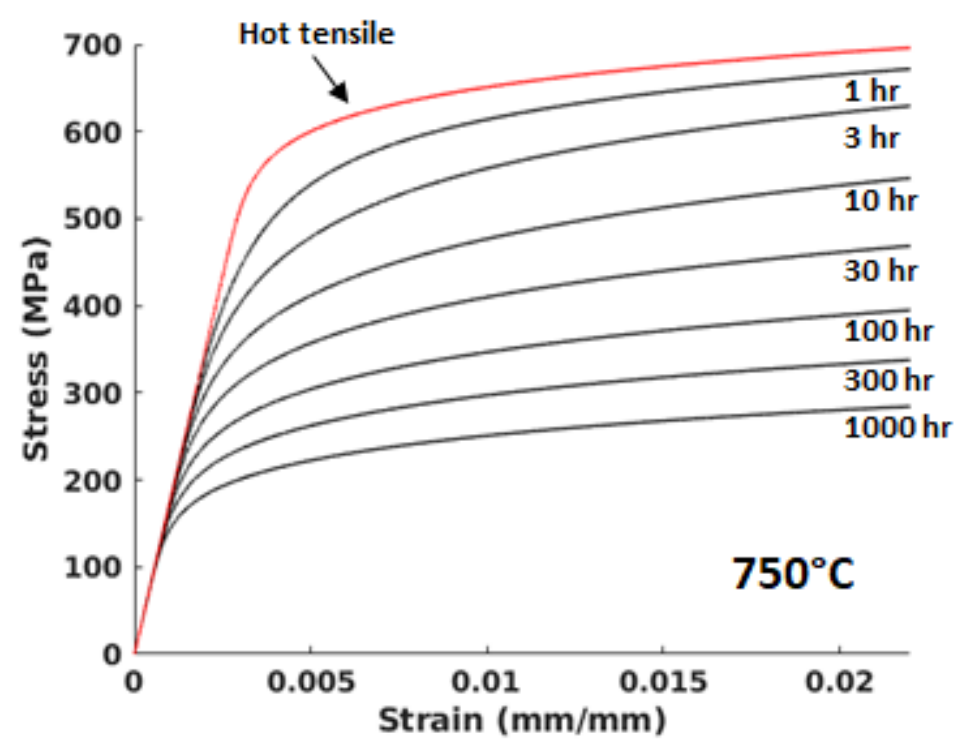

Figure 14 . Isochronous stress strain curves at $750^{\circ} \mathrm{C}$.

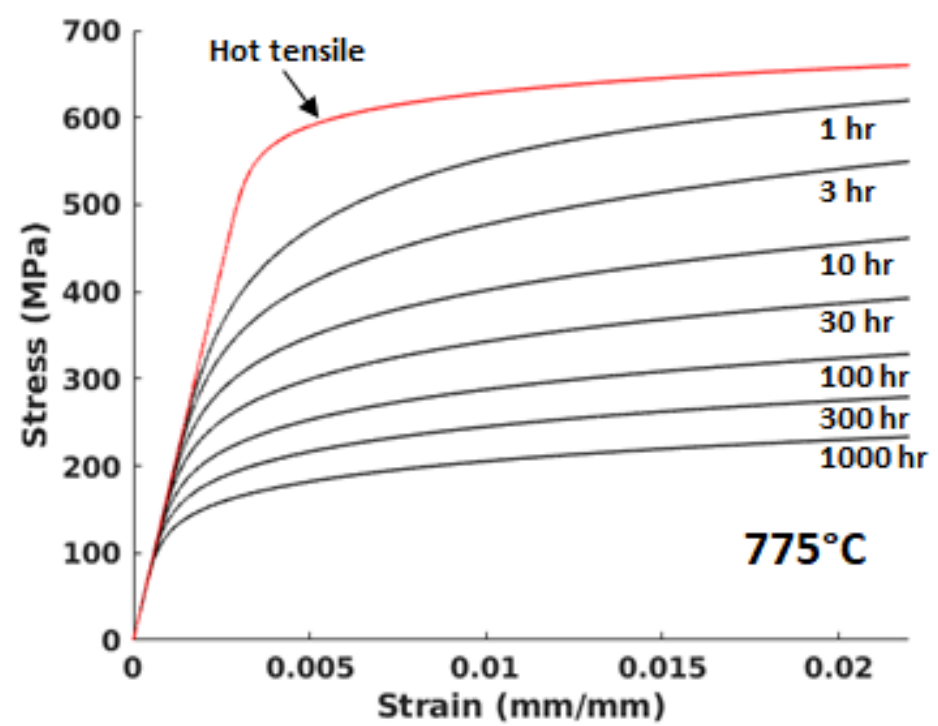

Figure 15. Isochronous stress strain curves at $775^{\circ} \mathrm{C}$. 


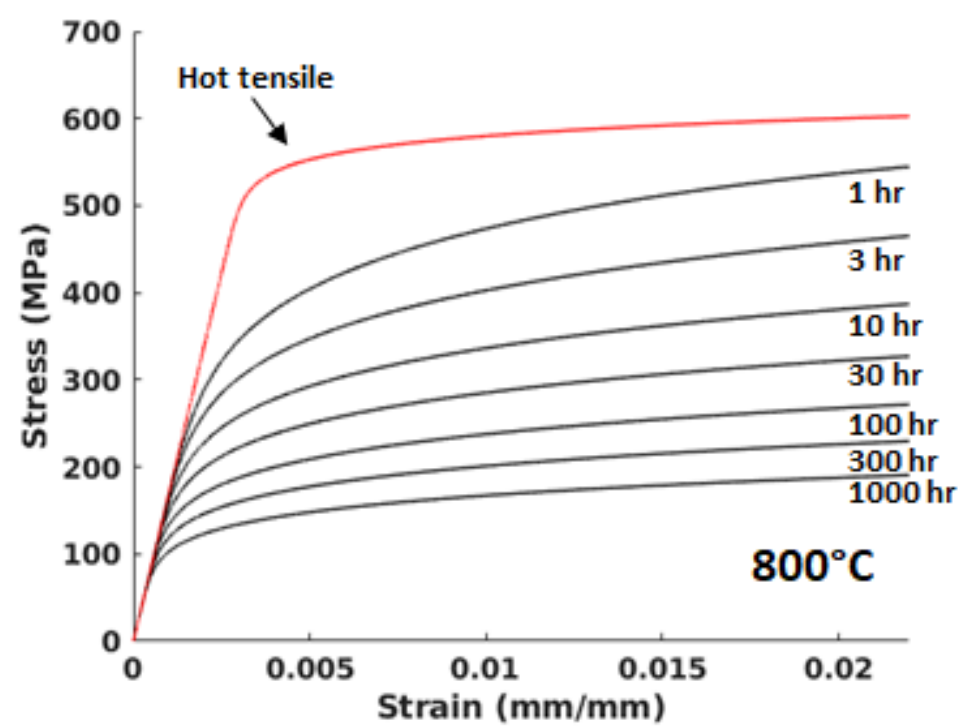

Figure 16. Isochronous stress strain curves at $800^{\circ} \mathrm{C}$.

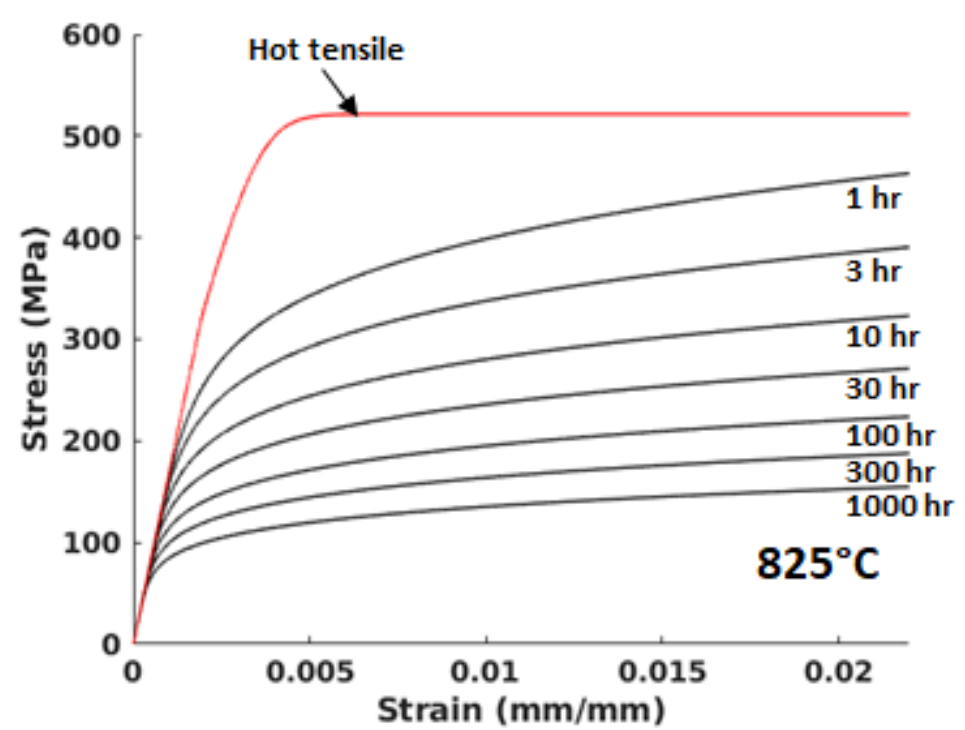

Figure 17. Isochronous stress strain curves at $825^{\circ} \mathrm{C}$. 


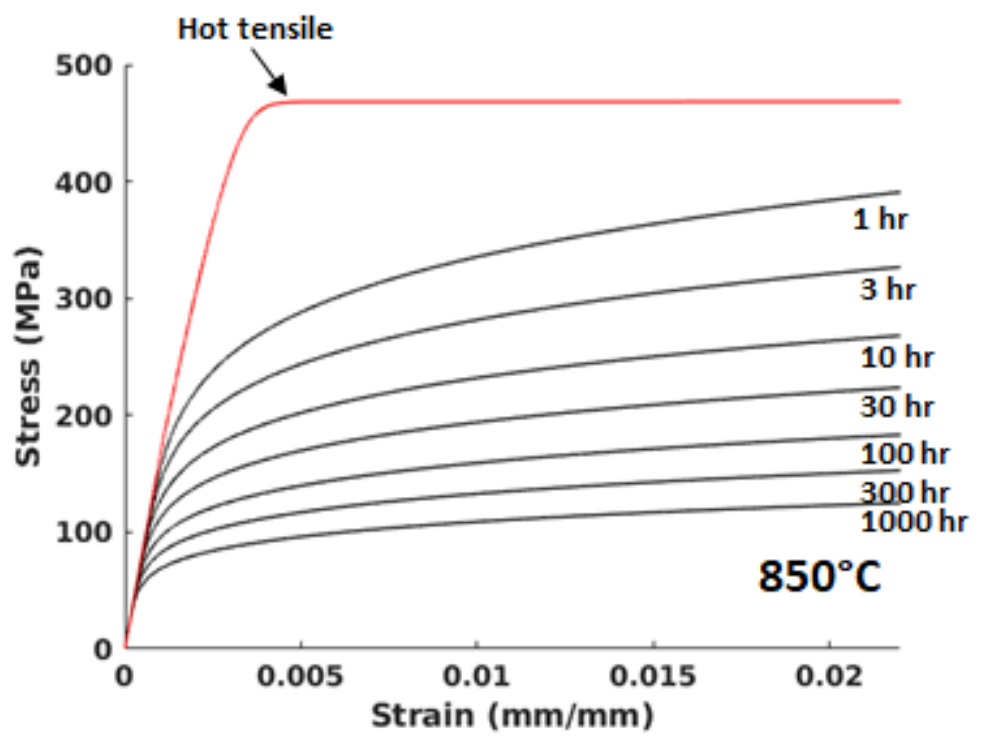

Figure 18. Isochronous stress strain curves at $850^{\circ} \mathrm{C}$.

\section{Relaxation strength}

Section III, Division 5, Subsection HB, Subpart B, Nonmandatory Appendix T-1324 requires the use of a relaxation strength $S_{r L}$ and $S_{r H}$. These values are not provided in the Code. For Alloy $740 \mathrm{H}$ designers may use the values tabulated in Table 13, which are based on stress relaxation using the creep model discussed above starting from a stress of $1.5 S_{m}$.

\begin{tabular}{cl|llllllll}
\multicolumn{1}{c|}{} & & \multicolumn{2}{l}{ Time (hours) } & & & & & \\
\multicolumn{1}{c|}{} & 1 & 10 & 30 & 100 & 300 & 1000 & 3000 & 10000 \\
\hline Temp. & 425 & 483 & 483 & 483 & 483 & 483 & 483 & 483 & 483 \\
& 450 & 483 & 483 & 483 & 483 & 483 & 483 & 483 & 483 \\
& 475 & 483 & 483 & 483 & 483 & 483 & 483 & 483 & 483 \\
& 500 & 483 & 483 & 483 & 483 & 483 & 483 & 483 & 483 \\
& 525 & 483 & 483 & 483 & 483 & 483 & 483 & 483 & 483 \\
& 550 & 483 & 483 & 483 & 483 & 483 & 483 & 483 & 483 \\
& 575 & 481 & 481 & 481 & 481 & 481 & 481 & 481 & 481 \\
600 & 478 & 478 & 478 & 478 & 478 & 476 & 472 & 459 \\
625 & 469 & 469 & 469 & 468 & 466 & 460 & 445 & 412 \\
& 650 & 460 & 460 & 459 & 456 & 449 & 428 & 394 & 345 \\
675 & 445 & 444 & 441 & 432 & 412 & 374 & 328 & 278 \\
& 700 & 430 & 425 & 417 & 395 & 360 & 310 & 265 & 221 \\
725 & 406 & 395 & 377 & 340 & 296 & 248 & 208 & 172 \\
& 750 & 382 & 358 & 326 & 280 & 237 & 195 & 162 & 132 \\
775 & 348 & 308 & 270 & 224 & 186 & 151 & 124 & 101 \\
800 & 312 & 256 & 217 & 176 & 145 & 116 & 95 & 76 \\
& 825 & 272 & 207 & 171 & 137 & 111 & 88 & 71 & 57 \\
850 & 231 & 164 & 133 & 105 & 84 & 66 & 53 & 42
\end{tabular}

Table 13. Relaxation strength as a function of time and temperature. Values are in MPa. 


\section{Fatigue curves}

One additional test from INL was included versus the Q5 report. This additional test did not significantly shift the design fatigue curves. The fatigue data comes from INL tests and the literature [4-5].

The fatigue curves are based on the correlations:

$$
\Delta \varepsilon=\left\{\begin{array}{cc}
0.0125 N^{-0.08}+0.0765 N^{-0.44} & T \leq 700^{\circ} \mathrm{C} \\
0.0393 N^{-0.08} & 700^{\circ} \mathrm{C}<T \leq 850^{\circ} \mathrm{C}
\end{array}\right.
$$

to the available experimental data. The low temperature correlation was suggested by [5] and matches both the author's data and the new tests. The high temperature correlation is based on the INL test database. For both temperature ranges the recommended design fatigue curve are based on margins of 1.5 on strain range and 10 on cycles, i.e. if the nominal correlation is given by $\Delta \varepsilon(N)$ then the design correlation is based on $\Delta \varepsilon_{\text {design }}(N)=\min \{\Delta \varepsilon(N) / 1.5, \Delta \varepsilon(N / 10)\}$. Tables 14 and 15 list points along both the nominal and design fatigue curves.

\begin{tabular}{lll}
\hline Cycles & $\begin{array}{l}\text { Strain range, } \\
\text { nominal } \\
(\mathrm{mm} / \mathrm{mm})\end{array}$ & $\begin{array}{l}\text { Strain range, } \\
\text { design } \\
(\mathrm{mm} / \mathrm{mm})\end{array}$ \\
\hline 10 & 0.03817 & 0.025448 \\
20 & 0.03031 & 0.020207 \\
40 & 0.02440 & 0.016265 \\
100 & 0.01873 & 0.012488 \\
200 & 0.01562 & 0.010410 \\
400 & 0.01322 & 0.008813 \\
1000 & 0.01085 & 0.007236 \\
2000 & 0.00950 & 0.006336 \\
4000 & 0.00843 & 0.005618 \\
10000 & 0.00731 & 0.004875 \\
20000 & 0.00664 & 0.004427 \\
40000 & 0.00608 & 0.004051 \\
100000 & 0.00546 & 0.003639 \\
\hline Table 14. Fatigue curve for use below $700^{\circ} \mathrm{C}$.
\end{tabular}




\begin{tabular}{lll}
\hline Cycles & $\begin{array}{l}\text { Strain range, } \\
\text { nominal } \\
(\mathrm{mm} / \mathrm{mm})\end{array}$ & $\begin{array}{l}\text { Strain range, } \\
\text { design } \\
(\mathrm{mm} / \mathrm{mm})\end{array}$ \\
\hline 10 & 0.02368154 & 0.01578769 \\
20 & 0.0205589 & 0.01370593 \\
40 & 0.01784801 & 0.01189867 \\
100 & 0.01480505 & 0.00987004 \\
200 & 0.01285286 & 0.00856857 \\
400 & 0.01115809 & 0.00743872 \\
1000 & 0.00925571 & 0.00617048 \\
2000 & 0.00803526 & 0.00535684 \\
4000 & 0.00697573 & 0.00465049 \\
10000 & 0.00578642 & 0.00385761 \\
20000 & 0.00502342 & 0.00334895 \\
40000 & 0.00436104 & 0.00290736 \\
100000 & 0.00361751 & 0.00241167 \\
\hline
\end{tabular}

Table 15. Fatigue curve for use between $700^{\circ} \mathrm{C}$ and $850^{\circ} \mathrm{C}$.

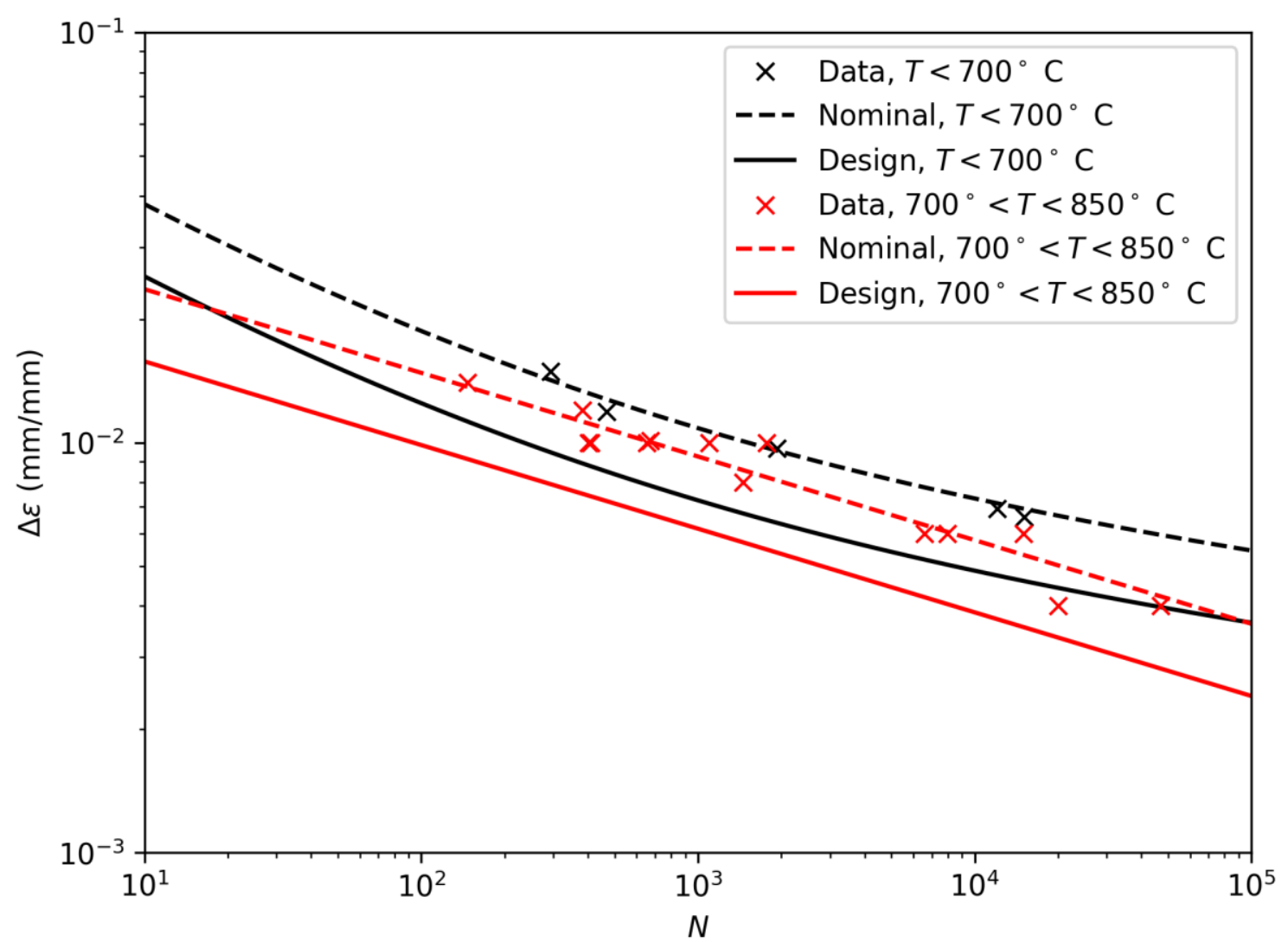

Figure 19. Nominal and design fatigue curves overlaid with fatigue data.

\section{Creep-fatigue interaction diagram}


The interaction diagram is based on creep-fatigue tests from INL and an additional data point gathered from the literature [8]. The literature datapoint is the outlier, falling underneath even the $(0.1,0.1)$ intersection point plotted on the figure, drawn from the ASME A617 Code Case. This diagram was updated from Q5 with an additional test completed at INL. This additional test supports a more severe creep-fatigue interaction diagram, in line with the single datapoint collected from the literature. The final creep-fatigue interaction diagram will be determined once all the INL testing is complete.

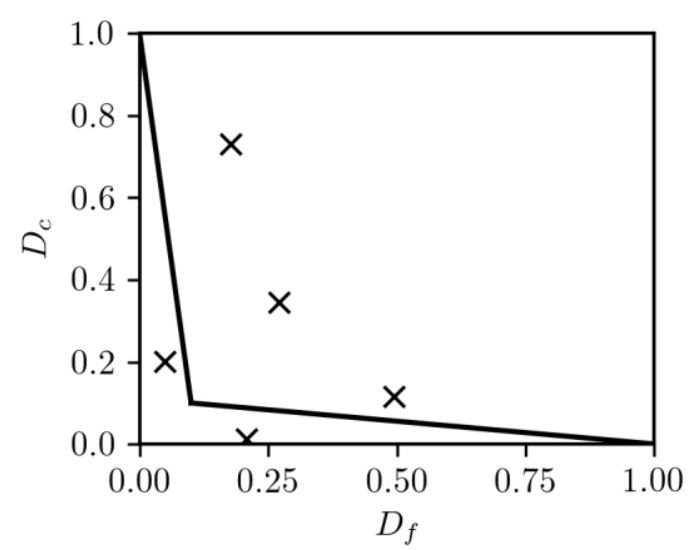

Figure 20. Creep fatigue-interaction diagram overlaid with experimental data

\section{Sample problems illustrating the high temperature receiver design methods}

The previous quarterly report identified three design methods suitable for the design of high temperature CSP components using Alloy $740 \mathrm{H}$.

Method 1 is the classical ASME Section III, Division 5 design by elastic analysis method with a reduced design margin, making it suitable for use in CSP systems. This method is the most general in terms of materials and component types but the most difficult to execute.

Method 2 simplifies the ASME Section III, Division 5 method based on the high yield strength of Alloy $740 \mathrm{H}$. Method 2 will produce comparable results to Method 1, but with much simpler design calculations.

Method 3 uses a simple inelastic analysis to analyze axisymmetric receiver structures. This method is relatively simple to execute but will produce the most accurate design calculations of high temperature life and therefore produce the most efficient designs. However, the method is limited to Alloy $740 \mathrm{H}$ and to certain types of load cycles, representative of CSP receivers but not of a broader class of components.

The below reproduces the description of each method provided in the Q5 report to aid the reader in following the sample problem calculations. 


\section{Method 1: ASME Section III, Division 5}

The most general methods proposed here to use for design is the high temperature evaluation procedure described in Section III, Division 5, Subsection HB, Subpart B of the ASME Boiler and Pressure Vessel Code. This methodology was created to design safety-critical high temperature nuclear reactor components and so the provisions contain a large design margin to ensure safe performance. This design margin has been reduced somewhat for the Alloy $740 \mathrm{H}$ design data described above, to reflect the reduced safety requirements of CSP systems.

The specific design method proposed for use for CSP receivers is a simplification of the full Section III, Division 5 rules. In all cases the design data for $740 \mathrm{H}$ given above should be used in the analysis.

1. Define a series of service loads in terms of time-dependent mechanical and thermal boundary conditions on the structure. Each service case should define periodic loading conditions as well as provide an expected number of repetitions of this particular cycle type in service. Additionally, define a design loading based on enveloping the worst combinations of temperatures, pressures, and mechanical forces from the aggregate of all the service loading conditions, as described in HBB-3113.

2. Perform a transient elastic thermo-mechanical analysis of the component for each service load case. Follow the stress classification guidelines in Section III, Division 5, HBB3213 to divide the loads in primary, local primary, secondary, and peak categories. Perform the same process for the design loading.

3. Check the primary stress from the design load analysis against the allowable stress $S_{\text {o }}$ given above, as described in HBB-3222.1. The intent of this check is to replicate nonnuclear allowable stress design in Section VIII or Section I and so these Sections may be alternately used as a basis for primary load design, replacing this step.

4. Check the structure against the ratcheting criteria described in HBB-1332 (the O'Donnell-Porowski approach), with the following changes:

a. The strain limit is increased to $2 \%$ for base metal and $1 \%$ for weld metal.

b. The applicable temperature limit from Table HBB-T-1323 for $740 \mathrm{H}$ is $600^{\circ} \mathrm{C}$. We anticipate that the receiver temperatures will fall below this threshold during the night periods and so the method should be universally applicable.

c. The strain calculation may be based on a stress of $1.0 \sigma_{c}$ rather than the $1.25 \sigma_{c}$ specified in the Code. The strain value need not exceed $2 \%$ divided by the total number of cycles.

5. Evaluate the structure against the creep-fatigue criteria described in HBB-1430 with the following modifications:

a. When calculating the creep strain increment in HBB-1432 the stress intensity used is $1.0 \sigma_{c}$ rather than the $1.25 \sigma_{c}$ specified in the Code.

b. When using HBB-1433 option (b) to determine a stress relaxation profile, the lower bound stress $S_{L B}$ may be taken as $1.0 \sigma_{c}$, rather than the $1.25 \sigma_{c}$ specified in the Code. 
6. The buckling exemption charts described in HBB-T-1520 deal with load-controlled buckling which is not applicable to CSP receivers, as the load-controlled compressive stresses are expected to be minimal. Furthermore, time-dependent strain-controlled buckling is generally not a significant concern and so for CSP receivers only straincontrolled time independent buckling is relevant. Buckling may be checked by analyzing the structure assuming a constitutive response given by the hot tensile curves described above and a load factor of 1.5. This is a slight reduction from the HBB factor of 1.67, reflecting the lower consequences of failure for CSP systems.

\section{Method 2: Simplified elastic design for high strength materials}

This method is a simplification of the ASME Section III, Division 5 method described above for Alloy $740 \mathrm{H}$. One characteristic of this material is its high yield point, even at elevated temperatures. This means that the response of a receiver is likely to be well represented by an elastic-creep constitutive model, which simplifies the creep-fatigue evaluation using the Division 5 approach. Furthermore, hold times in the creep regime are short for CSP systems because of the diurnal cycling pattern and so it is conservative to assume no stress relaxation occurs during the loading. Steps 1, 2, 3, 4, and 6 remain the same as with Method 1. Step 5 is replaced with the following procedure.

This method is applicable only if the primary plus secondary stress intensity $(\mathrm{P}+\mathrm{Q})$ remains less than $S_{y}$ for all service loading cycles and if the peak stresses are minimal.

For each service load cycle:

1. Calculate the transient stress versus time profile via elastic analysis.

2. Convert these stresses into elastic strains using the Young's modulus and Poisson's ratio provided above.

3. Compute creep damage

a. Calculate an effective strain range $\Delta \varepsilon_{1}$ using HBB-T-1413.

b. Calculate a strain due to creep, $\Delta \varepsilon_{2}$ by using the isochronous curves to calculate the creep-ratcheting strain accumulated through a single cycle period at a stress of $\sigma_{c}$, where $\sigma_{c}$ is the O'Donnell-Porowski core stress determined in Method 1, Step 4.

c. Determine the total strain range for this cycle as $\Delta \varepsilon=\Delta \varepsilon_{1}+\Delta \varepsilon_{2}$.

4. Determine the stress versus time profile used to calculate creep damage for this cycle by calculating the von Mises stress from the elastically-calculated stresses derived in step 1. This effective stress versus time profile may be used in determining the creep damage attributed to this load cycle.

This process produces, at each material point, an effective strain range and a stress relaxation history. These individual cycle effective strains can be converted into a total fatigue damage using a rainflow counting approach and the definition of fatigue damage given in HBB-T-1411 (Miner's rule). The individual stress relaxation profiles can be combined using the procedure given in HBB-T-1433. Creep damage can be calculated from this composite history using the 
definition given in HBB-T-1411 and the resulting creep and fatigue damages assessed against the creep-fatigue interaction diagram.

If the loading cycles correspond to full daily receiver cycles so that the total number of service loading cycles, $N$, equals the plant operating life in days then the creep strain increment in step $3 \mathrm{~b}$ may be estimated as $\Delta \varepsilon_{2}=0.02 / N$, which will be negligible for many receiver designs.

\section{Method 3: Simplified inelastic design for high strength materials}

This approach is again limited to situations where the elastically-calculated stresses remain below the material yield stress $S_{y}$ for all service cycles. Furthermore, this approach is limited to design situations where the service cycles correspond to full daily receiver loadings. Some small number of representative loadings may be used, however each of these representative cycles must correspond to a full daily loading. This provision means separate weather-related loads cannot be separated from a standard daily cycle - if any such loadings exist they must be incorporated into daily load cycles.

With these conditions met, an elastic-creep constitutive response reasonably describes the material. For small creep strains, this response can be characterized with the simple model determined above for use in constructing the material isochronous curves. This model is defined by:

$$
\dot{\boldsymbol{\sigma}}=\boldsymbol{C}:\left(\dot{\varepsilon}-\dot{\varepsilon}_{c r}-\dot{\varepsilon}_{t h}\right)
$$

where $\dot{\boldsymbol{\sigma}}$ is the stress rate, $\boldsymbol{C}$ is the isotropic elasticity tensor, defined through the elastic constants above, $\dot{\varepsilon}$ is the total strain rate, $\dot{\varepsilon}_{t h}$ is the thermal strain rate, defined through the thermal expansion coefficients above, and $\dot{\varepsilon}_{c r}$ is defined as

$\dot{\varepsilon}_{c r}=\dot{\varepsilon}\left(\sigma_{\text {eff }}\right) \frac{\boldsymbol{s}}{\|s\|}$

where $s$ is the deviatoric stress, $\sigma_{\text {eff }}$ is the von Mises effective stress, and $\dot{\varepsilon}(\sigma)$ is the scalar creep strain rate equation defined above as:

$$
\dot{\varepsilon}=\dot{\varepsilon}_{0} e^{B \mu b^{\mathrm{a}} /(A K T)}\left(\frac{\sigma}{\mu}\right)^{-\mu b^{\mathrm{a}} /(A K T)} .
$$

These expressions extend the scalar model developed above to $3 \mathrm{D}$ using standard $\mathrm{J}_{2}$ flow theory.

This design method follows Method 1 steps 1 to 3 for assessing primary load design. Additionally, the designer must check these elastically-calculated stresses to ensure the total primary + secondary $(\mathrm{P}+\mathrm{Q})$ stress intensity does not exceed $S_{y}$ at any point during the service history. Buckling is assessed using step 6 from Method 1. However, ratcheting and creepfatigue are assessed using the following modified procedure. This process must be applied at each material point in order to assess the suitability of the entire component.

For each load cycle:

1. Perform an elastic-creep analysis of the structure using the model defined above. Repeat this analysis for as many cycles as are required to achieve a steady cyclic response, defined by the stresses becoming periodic with the applied loads (see notes below). 
2. Extract the stress/strain/time history for a single cycle of the periodic loading after the structure achieves a steady-state response.

a. Calculate the effective strain range $\Delta \varepsilon$ using the definition given in HBB-T-1413.

b. Extract the stress relaxation profile $\sigma_{\text {eff }}(t)$ given by plotting the von Mises effective stress versus time over this load cycle.

c. Extract the effective ratcheting rate for this load cycle, $\Delta r$, by subtracting calculating the effective strain $\sqrt{\frac{2}{3} \varepsilon: \varepsilon}$ at the beginning $\left(r_{1}\right)$ and end $\left(r_{2}\right)$ of the cycle. Calculate the effective ratcheting rate as $\Delta r=\left|r_{2}-r_{1}\right|$.

This process produces a histogram giving an effective strain range, effective stress history, and effective ratcheting rate for each cycle, along with the cycle frequency. The effective strain ranges are combined into a total fatigue damage using rainflow counting and Miner's rule. The effective stress histories are combined using the approach described in HBB-T-1411 and creep damage calculated from this history using HBB-T-1411, dividing the effective stress by a factor of 0.9 rather than the 0.67 specified in HBB-T-1411-1 of the ASME Code. The creep-fatigue diagram can then be consulted as an acceptance criteria.

The total ratcheting strain can be determined by

$\varepsilon_{r}=\sum_{i=1}^{n_{\text {type }}} \Delta r_{i} N_{i}$

where $\Delta r_{i}$ is the effective ratcheting strain of cycle type i, $N_{i}$ is the number of repetitions of this cycle type, and the sum proceeds over each service cycle. This sum must be less than $10 \%$ for base metal and 5\% for welds at each material point. Note the ratcheting check is an integral part of this procedure because the creep model determined above is only valid up to a few percent strain.

The number of cycles required to achieve the cyclic steady state can be determined by plotting the effective von Mises stress as a function of time, shifted by the cycle period so that all the simulated cycles overlap. When the cycle stresses fall on top of one another sufficient cycles have been completed to achieve the cyclic steady-state solution.

\section{Sample Problems}

The remainder of this chapter then walks through two sample design problems, applying all three design methods to each problem. For the first sample problem the details provided in this report should be sufficient to provide a complete tutorial for designers describing how to execute the required design analysis and calculations.

\section{Sample problem 1}

Figure 21 illustrates the first problem considered for evaluating design methods developed for CSP systems. This problem is an axisymmetric representation of a tube in a cavity receiver. The tube is $500 \mathrm{~mm}$ long and $2 \mathrm{~mm}$ thick. The outer diameter is $40 \mathrm{~mm}$. For simplicity, we assumed uniform the heat flux on the outer surface of the tube and that the heat conduction analysis is done in the steady state. This results in linear temperature gradient along the length, 
circumference, and thickness of the tube and therefore this problem can be treated as an axisymmetric problem. This linear temperature distribution can be fully described by providing the inner and outer tube metal temperatures as a function of time and axial position. Only two points are required to define the axial gradient. Figure 21 shows the temperature and pressure loading considered for this problem. The loading cycle includes warming up of the system in the morning, steady state operation, five cloud events each with 8 minutes hold, cooling down in the evening, and no operation during night. The design life of the tube is 30 years.

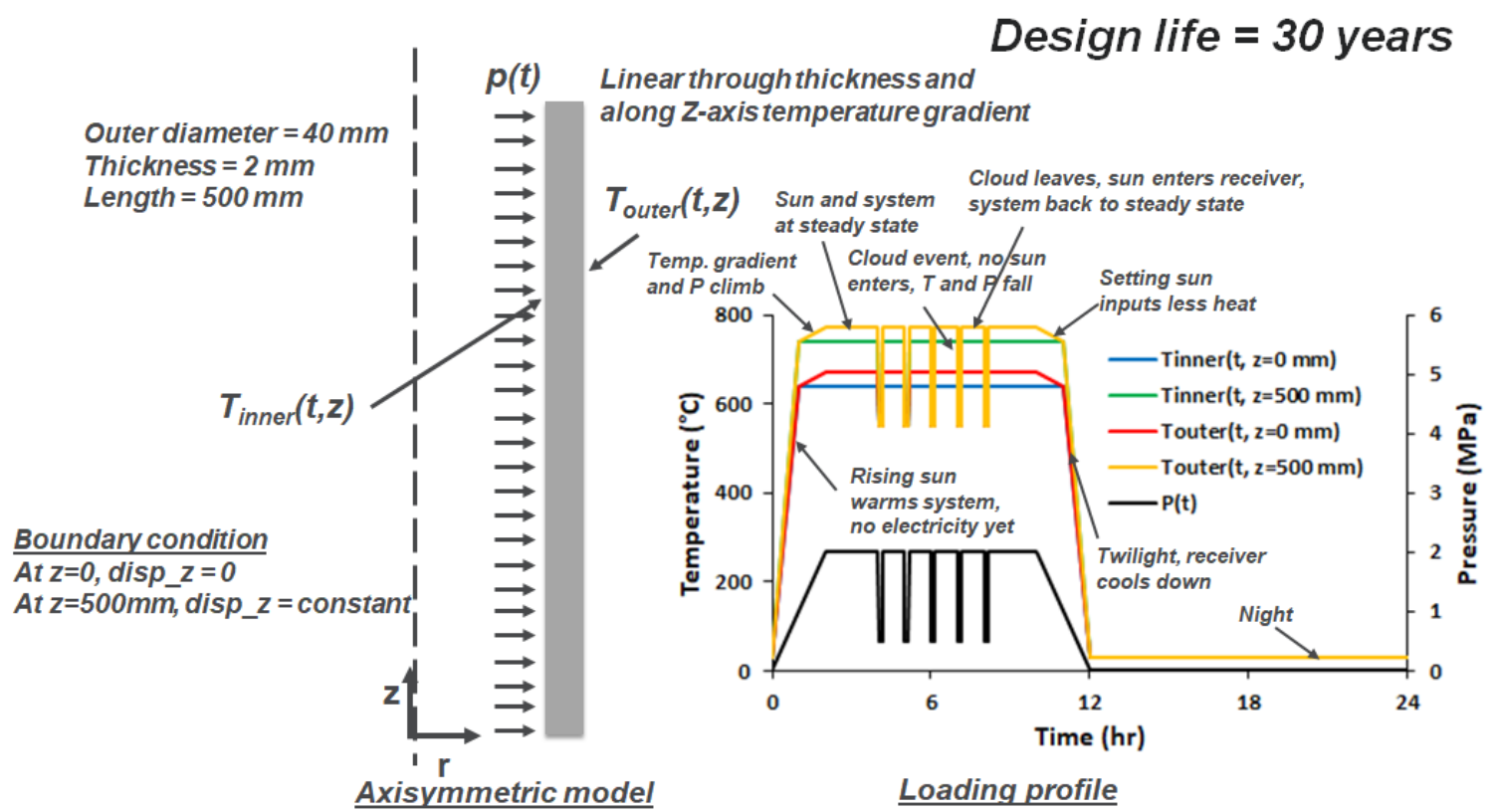

Figure 21: Sample problem 1. An axisymmetric representation of a single tube. Loading profile shows the inner and outer wall temperature at the bottom $(\mathrm{z}=0 \mathrm{~mm})$ and top $(\mathrm{z}=500 \mathrm{~mm})$ ends of the tube, respectively, and pressure exerted on the inner wall by the salt flowing inside the tube.

\section{Design calculations based on Method 1}

Step 1: Defining service loads and design loads

As we considered only one type of loading condition, the loading profile shown in Figure 21 can be considered as the design load. The daily load cycle can be divided into two service load types - start-up/shut-down cycle and cloud event. Table 16 provides the details of each service loads.

\begin{tabular}{|c|c|c|}
\hline Service load types & Associated load points and time & Frequency per design cycle \\
\hline start-up/shut-down cycle & $\begin{array}{c}\text { Load point-1: } 12 \text { hours } \\
\text { Load point-2: } 12 \text { hours }\end{array}$ & 1 \\
\hline cloud event & $\begin{array}{c}\text { Load point-2: } 0 \text { hours } \\
\text { Load point-3: } 0.133 \text { hours }\end{array}$ & 5 \\
\hline
\end{tabular}

Table 16: Service load cycles and associated load points (illustrated in Figure 22) in the daily load cycle and corresponding hold times. 


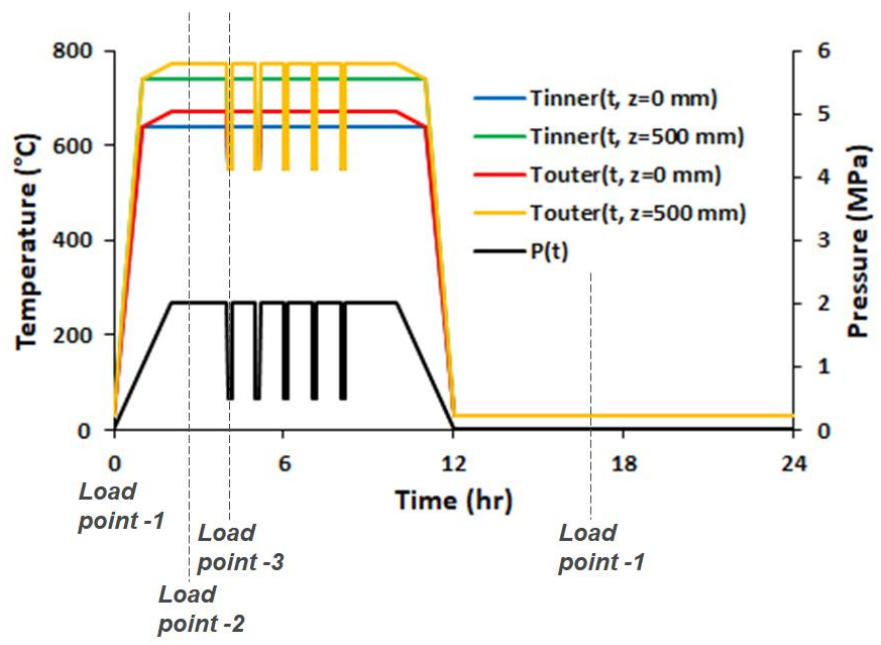

Figure 22: Different load points during the loading cycle considered.

Step 2: Transient elastic thermo-mechanical analysis for each service load case and stress classification

We used MOOSE (Multiphysics Object Oriented Simulation Environment), an open source finite element solver to perform the elastic thermo-mechanical analyses. We classify stresses due to pressure as primary load and thermal stresses caused by the temperature gradient as secondary load. There is no peak load.

Step 3: Primary load design check

Maximum primary load occurs at load point-2. Figure 23 shows the temperature distribution in the tube and stress components along the thickness of the tube at maximum wall averaged temperature location. Table 17 reports details of the primary load checks. First, all the stress components were linearized to divide into membrane and bending components along the stress classification line. The membrane and bending stress tensors were then used to determine the stress intensities in Table 17.

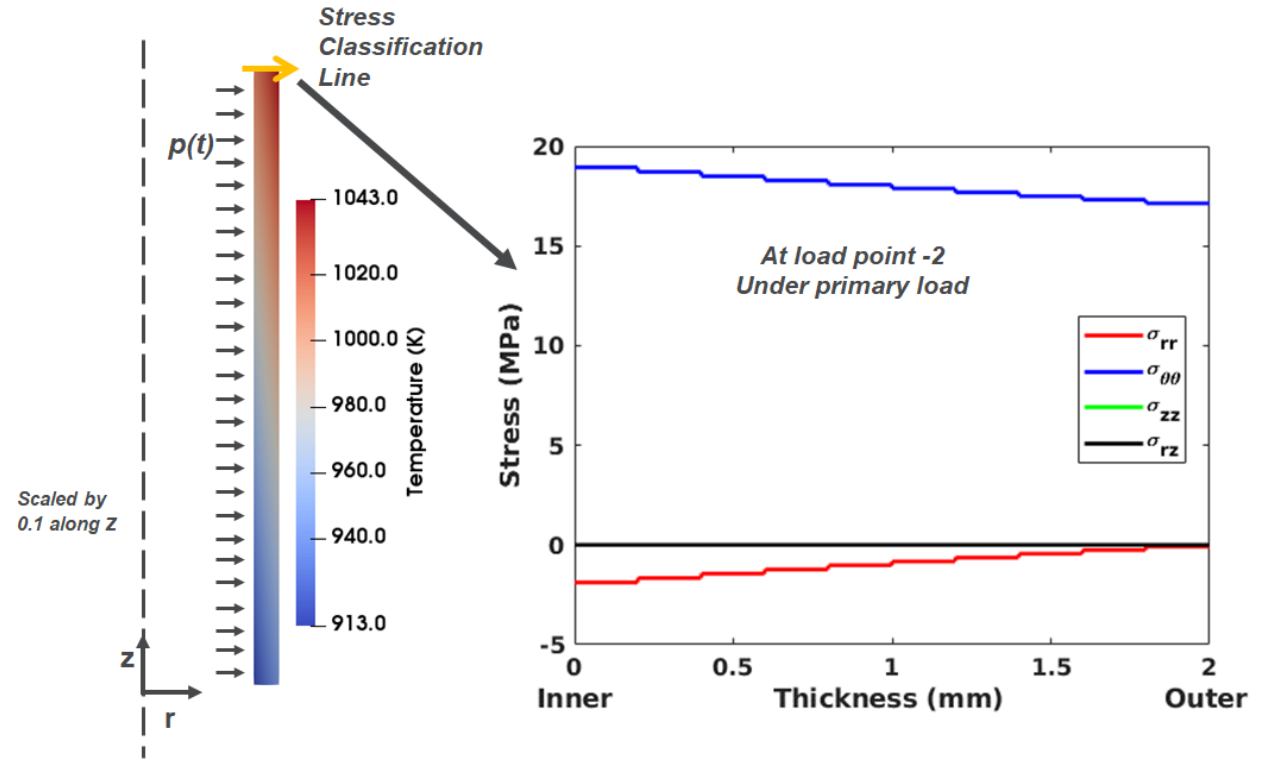


Figure 23: Temperature distribution in the tube and through thickness elastic stress components at maximum wall averaged temperature location under primary load at load point -2 .

\begin{tabular}{|l|c|}
\hline Max. General primary membrane stress intensity, $P_{m}$ & $18.95 \mathrm{MPa}$ \\
\hline Max. Combined primary membrane plus bending stress intensity, $P_{L}+P_{b}$ & $20.92 \mathrm{MPa}$ \\
\hline Maximum metal temperature, $T_{\max }$ & $770{ }^{\circ} \mathrm{C}$ \\
\hline Allowable stress, $S_{\bullet}$ at $T_{\max }$ & $64.26 \mathrm{MPa}$ \\
\hline Design criteria $-1: P_{\mathrm{m}} \leq S_{\bullet}$ & $\boldsymbol{P A S S} !$ \\
\hline Design criteria $-2: P_{L}+P_{b} \leq 1.5 S_{0}$ & $\boldsymbol{P A S S} !$ \\
\hline
\end{tabular}

Table 17: Primary load design checks.

Step 4: Ratcheting check

Design Method 1 uses the O'Donnell-Porowski approach, described in Section III, Division 5, HBB-1332 for ratcheting checks. In this approach, an effective creep stress parameter, $\mathrm{Z}$ is determined from a primary stress parameter, $\mathrm{X}$ and a secondary stress parameter, $\mathrm{Y}$ as shown in Figure 24. The effective creep stress parameter is used to calculate the effective creep stress which is then used to determine the ratcheting creep strain using isochronous stress-strain curves. The definition of $\mathrm{X}$ and $\mathrm{Y}$ are

$X=\left(P_{L}+\frac{P_{b}}{K_{\mathrm{t}}}\right)_{\max } / S_{y}$

$Y=\left(Q_{R}\right)_{\max } / S_{y}$

where,

$\left(P_{L}+\frac{P_{b}}{K_{\mathrm{t}}}\right)_{\max } / S_{y}=$ the maximum value of the primary stress intensity, adjusted for bending via $K_{t}$, during the cycle being evaluated.

$\left(Q_{R}\right)_{\max }=$ the maximum range of the secondary stress intensity during the cycle being considered

$S_{y}=$ is the average of the $S_{y}$ values at the maximum and minimum wall averaged temperatures during the cycle

$K_{t}=(K+1) / 2$

$K$ is 1.5 for across-the-wall bending of shell structures or rectangular sections, see HBB-3223 (c)

(6) in Section III Division 5.

Once $\mathrm{Z}$ is found, effective core, $\sigma_{c}$ stress is determined from

$Z=\frac{\sigma_{e}}{s_{y L}}$

where $S_{y L}=S_{y}$ at the cold end of the cycle being considered.

It should be noted that, the average wall temperature at one of the stress extremes defining the secondary stress intensity range must be below the temperature listed in Section III, Division 5, HBB-T-1323, given as $600^{\circ} \mathrm{C}$ for $740 \mathrm{H}$ in the description of the design method above.

The creep ratcheting strain increment for a load cycle is evaluated by entering the isochronous stress strain curves at the maximum wall temperature and effective core, $\sigma_{c}$ stress during the load cycle with the stress held constant for the entire service life. An example of creep ratcheting strain determination is shown in Figure 25. 


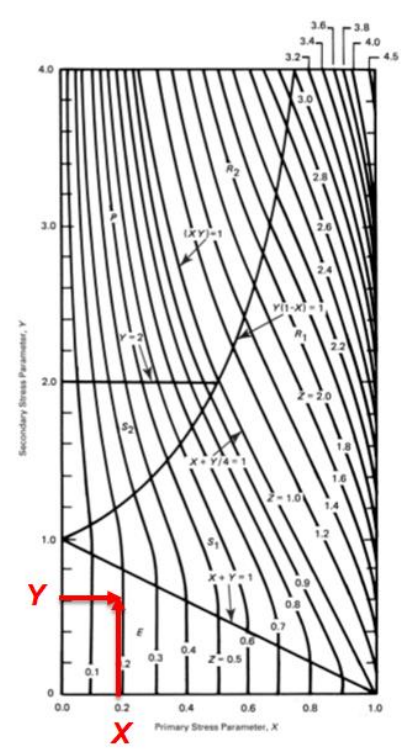

Figure 24: Determination of effective creep stress parameters from Section III, Division 5, Figure HBB-T-1332-1.

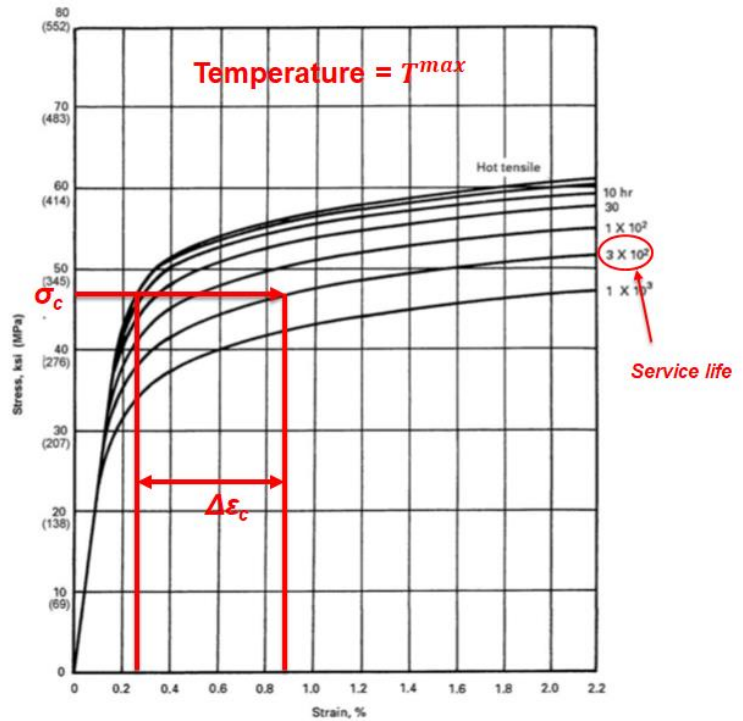

Figure 25: Determination of creep ratcheting strain increment from isochronous stress strain curves.

Since the start-up/shut-down service load includes the extreme temperature profile and the total time of the day, considering only the start-up/shut-down load should provide conservative estimation for ratcheting design. Table 18 provides all the calculation details of the ratcheting design check. Figure 26 shows the stress components under secondary loading at load point -2 . Stress components are shown at two different locations - maximum wall averaged temperature and maximum von Mises stress. The maximum ratcheting strain in the structure is $5.82 \mathrm{e}-9 \%$ which is less than $2 \%$, thus the design passes the ratcheting check. Note that, a design must pass the ratcheting design check before it is checked for creep-fatigue damage. 

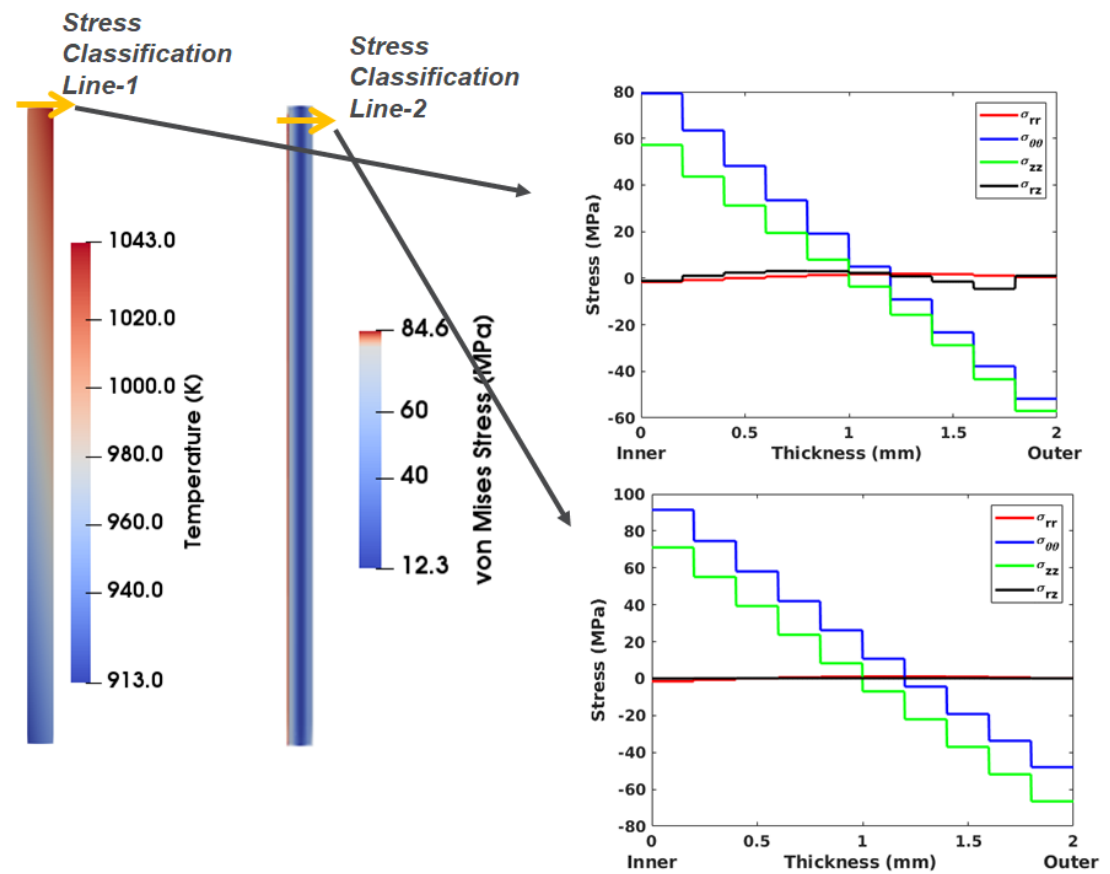

Figure 26: Temperature and von Mises stress distribution in the tube and through thickness stress components at maximum wall averaged temperature and maximum von Mises stress locations under secondary load at load point-2.

\begin{tabular}{|c|c|c|}
\hline & $\begin{array}{l}\text { Stress classification } \\
\text { shown in Figure } 26\end{array}$ & $\begin{array}{l}\text { Stress classification } \\
\text { shown in Figure } 26\end{array}$ \\
\hline$T_{\text {wall averaged }}^{\text {max }}$ & $755.2^{\circ} \mathrm{C}$ & $752.6^{\circ} \mathrm{C}$ \\
\hline$T_{\text {wail averaged }}^{\text {min }}$ & $30^{\circ} \mathrm{C}$ & $30^{\circ} \mathrm{C}$ \\
\hline$T^{\max }$ & $770^{\circ} \mathrm{C}$ & $767.3^{\circ} \mathrm{C}$ \\
\hline$S_{y H}\left(\right.$ at $\left.T_{\text {waill averaged }}^{\text {max }}\right)$ & $503.3 \mathrm{MPa}$ & $505.4 \mathrm{MPa}$ \\
\hline$S_{y L}\left(\right.$ at $\left.T_{\text {wail averaged }}^{\min }\right)$ & $621.0 \mathrm{MPa}$ & $621.0 \mathrm{MPa}$ \\
\hline$S_{y}=\left(S_{y H}+S_{y L}\right) / 2$ & $562.2 \mathrm{MPa}$ & $563.2 \mathrm{MPa}$ \\
\hline$K$ & 1.5 & 1.5 \\
\hline$K_{\mathrm{t}}=(K+1) / 2$ & 1.25 & 1.25 \\
\hline$\left(P_{L}+\frac{P_{b}}{K_{t}}\right)_{\max }$ & 20.53 & 20.53 \\
\hline$\left(Q_{R}\right)_{\max }$ & 85.06 & 96.81 \\
\hline$X=\left(P_{L}+\frac{P_{b}}{K_{\mathrm{t}}}\right)_{\max } / S_{y}$ & 0.037 & 0.036 \\
\hline$Y=\left(Q_{R}\right)_{\max } / S_{y}$ & 0.151 & 0.172 \\
\hline $\begin{array}{l}Z \text { using Section III, Division 5, Figure } \\
\text { HBB-T-1332-1 }\end{array}$ & 0.037 & 0.036 \\
\hline$\sigma_{c}$ from $Z=\frac{\sigma_{c}}{s_{y L}}$ & 22.67 & 22.63 \\
\hline $\begin{array}{l}\text { Service life (considering whole day as } \\
\text { service time per day) }\end{array}$ & 30 years $=262800$ hours & 30 years $=262800$ hours \\
\hline Ratcheting strain at the end of service life & $2.45 \mathrm{e}-8 \%$ & $6.41 \mathrm{e}-9 \%$ \\
\hline $\begin{array}{l}\text { Ratcheting design criteria: } 2 \% \text { for base } \\
\text { metal }\end{array}$ & PASS! & PASS! \\
\hline
\end{tabular}

Table 18: Ratcheting design check according to Method 1. 
Step 5: Creep-fatigue damage check

According to Section III, Division 5, a design is acceptable if the creep and fatigue damage satisfy the following relation:

$\sum_{j}\left(\frac{n}{N_{d}}\right)_{j}+\sum_{k}\left(\frac{\Delta t}{T_{d}}\right)_{k} \leq D$

where $\mathrm{D}$ is the total creep-fatigue damage and the first and second terms on the left side are fatigue damage, $D_{f}$ and creep damage, $D_{c}$, respectively. In the fatigue damage term, $(n)_{j}$ is the number of repetitions of cycle type $\mathrm{j}$ and $\left(N_{d}\right)_{j}$ is the number of design allowable cycles for respective cycle type; while in the creep damage term, $\left(T_{d}\right)_{k}$ is the allowable time duration for a given stress at the maximum temperature occurring in the time interval $\mathrm{k}$ and $(\Delta t)_{k}$ is the duration of the time interval $\mathrm{k}$.

The design allowable cycles for fatigue damage is determined by entering fatigue curves at total strain range, $\epsilon_{t}$. Total strain range, $\epsilon_{t}$ is calculated using equation HBB-T-1432-16:

$\epsilon_{t}=K_{v} \Delta \epsilon_{\text {mod }}+K \Delta \epsilon_{c}$ where $K$ is the local geometric concentration or equivalent stress concentration factor determined by dividing effective primary plus secondary plus peak stress divided by the effective primary plus secondary stress, $K_{v}$ is the multiaxial plasticity and Poisson ratio adjustment factor, $\Delta \epsilon_{c}$ is the creep strain increment, and $\Delta \epsilon_{\text {mod }}$ is the modified maximum equivalent strain range.

$\Delta \epsilon_{\text {mod }}$ is calculated using equation Section III, Division 5, HBB-T-1432-12:

$\Delta \epsilon_{\text {mod }}=\left(\frac{s^{*}}{s}\right) K^{2} \Delta \epsilon_{\max }$

where $\Delta \epsilon_{\max }$ is the maximum equivalent strain range calculated from the elastic analysis of under primary and secondary loading together. $\Delta \epsilon_{\max }$ is calculated according to Section III, Division 5, HBB-T-1413 with $v^{*}=0.3$ for elastic analysis. $S^{*}$ and $\bar{S}$ are stresses determined by entering the isochronous stress-strain curves at $\Delta \epsilon_{\max }$ and $K \Delta \epsilon_{\max }$, respectively.

$K_{v}$ is determined using equation Section III, Division 5, HBB-T-1432-15:

$K_{v}=1.0+f\left(K_{v}^{\prime}-1.0\right)$

where $f$ is the inelastic multiaxial adjustment factor determined using Section III, Division 5, Figure HBB-T-1432-2 and triaxiality factor, T.F.

T. F. $=\frac{\left\|\sigma_{1}+\sigma_{2}+\sigma_{\mathrm{g}}\right\|}{\frac{1}{\sqrt{2}}\left[\left(\sigma_{1}-\sigma_{2}\right)^{2}+\left(\sigma_{2}-\sigma_{\mathrm{g}}\right)^{2}+\left(\sigma_{\mathrm{g}}-\sigma_{1}\right)^{\mathrm{x}}\right]}$

where $\sigma$ 's are principals stresses at the extreme of the stress cycle.

$K_{v}^{\prime}$ is the adjustment for inelastic biaxial Poisson's ratio determined from Section III, Division 5, Figure HBB-T-1432-3 using $K_{e}$.

$K_{e}=\left\{\begin{array}{c}1 ; K \Delta \epsilon_{\max } \leq 3 \bar{S}_{m} / E \\ \frac{K \Delta \epsilon_{\max } E}{3 S_{m}} ; K \Delta \epsilon_{\max }>3 \bar{S}_{m} / E\end{array}\right.$

where

$3 \bar{S}_{m}=\left\{\begin{array}{c}1.5 S_{m}+S_{r H} ; \text { when only one of the extreme of the stress difference occurs ata } \\ \text { temperature above those covered by Division 1, Subsection NB rules } \\ S_{r H}+S_{r L} ; \text { when both of the extreme of the stress difference occur at a } \\ \text { temperature above those covered by Division 1, Subsection NB rules }\end{array}\right.$

Here $S_{r H}$ and $S_{r L}$ are relaxation strengths associated with the temperatures at the hot and cold extremes of the stress cycle. These values are provided above in the $740 \mathrm{H}$ design data. The hot temperature condition is defined as the maximum operating temperature of the stress cycle. The 
hot time is equal to the portion of service life when wall averaged temperatures exceed $425^{\circ} \mathrm{C}$. The cold temperature is defined as the colder of the two temperatures corresponding to the two stress extremes in the stress cycle. The cold time is again equal to the portion of service life when wall averaged temperatures exceed $425^{\circ} \mathrm{C}$.

The creep strain increment per stress cycle, $\Delta \epsilon_{c}$ is determined by entering the isochronous stressstrain curves at $\sigma_{c}$ and maximum metal temperature for the stress cycle time, including hold times between transient (instead of total service life). Alternatively, the creep accumulated during the entire service life divided by the number of stress cycles during the entire service life can also be used for calculating creep strain increment per stress cycle, $\Delta \epsilon_{c}$. We used the latter option.

The design allowable cycles, $N_{d}$ is then calculated from design fatigue curve at maximum metal temperature and using total strain range, $\epsilon_{t}$, as illustrated in Figure 27. Fatigue damage fraction, $D_{f}$ is then determined from the ratio between design cycles and design allowable cycles for each cycle type and then adding them together.

Figure 28 shows the equivalent strain from elastic analysis between load points $1 \& 2$ and between load points $2 \& 3$ along two stress classification lines. Table 19 shows the details of all the relevant calculations to determine fatigue damage fraction.

Creep damage evaluation is done in accordance to HBB-T1433(b) but with one exception. The lower bound stress $S_{L B}$ is taken as $1.0 \sigma_{c}$, rather than the $1.25 \sigma_{c}$ specified in the Code. First, stress relaxation profile is determined by entering the isochronous stress-strain curves at a strain level equal to $\epsilon_{t}$ and at hold-time temperature and determining the corresponding stress levels at varying times. However, this stress relaxation process should not be permitted to a stress level less than $S_{L B}$. This stress relaxation procedure results in a stress-time history similar to that illustrated in Figure 29. Using the stress-time history and hold-time temperature during the cycle creep damage fraction can be calculated according to the illustration in Figure 30. For creep damage fraction calculation, we only considered the start-up/shut-down service load cycle and the day time (12 hr) during the cycle. The time duration of the cloud events is already included in the start-up/shut-down service load cycle. Creep damage is not expected during night time (12 hr) of the start-up/shut-down service load cycle. Table 20 and 21 show the details of determining creep damage fraction, $D_{c}$ from stress relaxation profile.

To determine whether the design passes the creep-fatigue damage check, the fatigue damage fraction, $D_{f}$ and creep damage fraction, $D_{c}$ are plotted on creep-fatigue interaction diagram as shown in Figure 30. If the $\left(D_{f}, D_{c}\right)$ point falls inside the creep-fatigue damage envelop the design passes. As seen in Figure 31, the $\left(D_{f}, D_{c}\right)$ points fall inside the creep-fatigue damage envelop which means the design passes for creep-fatigue damage check. 


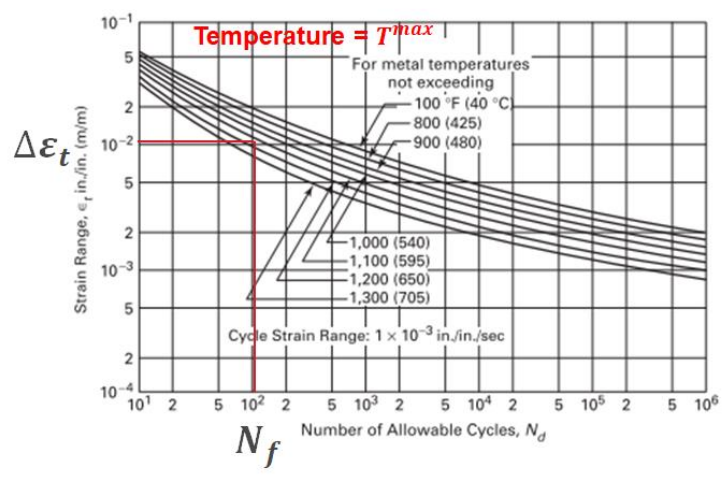

Figure 27: Illustration of determining design allowable cycles, $N_{d}$.
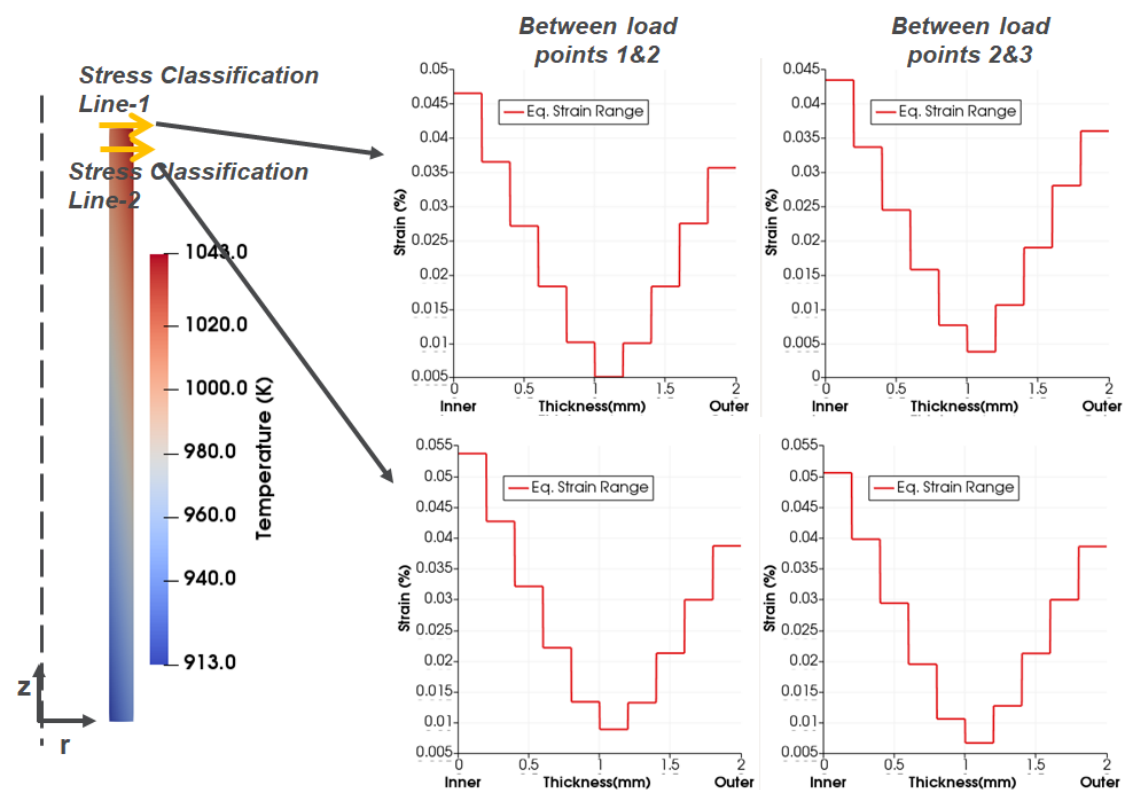

Figure 28: Equivalent strain range from elastic analysis. 
33872

Creep-fatigue Behavior and Damage Accumulation of a Candidate Structural Material for Concentrating Solar Power Solar Thermal Receiver Michael McMurtrey

\begin{tabular}{|c|c|c|c|c|}
\hline & \multicolumn{2}{|c|}{$\begin{array}{l}\text { At OD on stress classification line-1 shown } \\
\text { in Figure } 28\end{array}$} & \multicolumn{2}{|c|}{$\begin{array}{l}\text { At OD on Stress classification line-2 shown } \\
\text { in Figure } 28\end{array}$} \\
\hline & $\begin{array}{l}\text { Start-up/shut-down } \\
\text { cycle }\end{array}$ & Cloud event & $\begin{array}{l}\text { Start-up/shut-down } \\
\text { cycle }\end{array}$ & Cloud event \\
\hline$T^{\max }$ & $770^{\circ} \mathrm{C}$ & $770^{\circ} \mathrm{C}$ & $767.3^{\circ} \mathrm{C}$ & $767.3^{\circ} \mathrm{C}$ \\
\hline Hot temperature & $770^{\circ} \mathrm{C}$ & $770^{\circ} \mathrm{C}$ & $767.3^{\circ} \mathrm{C}$ & $767.3^{\circ} \mathrm{C}$ \\
\hline Cold temperature & $30^{\circ} \mathrm{C}$ & $550^{\circ} \mathrm{C}$ & $30^{\circ} \mathrm{C}$ & $550^{\circ} \mathrm{C}$ \\
\hline Hot time & $\begin{array}{l}12 \mathrm{hr} *(30 * 365) \\
=131400 \mathrm{hr}\end{array}$ & 0 & $\begin{array}{l}12 \mathrm{hr} *(30 * 365) \\
=131400 \mathrm{hr}\end{array}$ & 0 \\
\hline Cold time & $\begin{array}{l}12 \mathrm{hr} *(30 * 365) \\
=131400 \mathrm{hr}\end{array}$ & $\begin{array}{l}8 \min *(30 * 365) \\
=1460 \mathrm{hr}\end{array}$ & $\begin{array}{l}12 \mathrm{hr} *(30 * 365) \\
=131400 \mathrm{hr}\end{array}$ & $\begin{array}{l}8 \min *(30 * 365) \\
=1460 \mathrm{hr}\end{array}$ \\
\hline$S_{Y H}$ & $107.2 \mathrm{MPa}$ & $354.8 \mathrm{MPa}$ & $110.5 \mathrm{MPa}$ & $358.9 \mathrm{MPa}$ \\
\hline$S_{r L}$ & Not required & $153.3 \mathrm{MPa}$ & Not required & $158.4 \mathrm{MPa}$ \\
\hline$S_{m}$ at $T^{\max }$ & 241.0 & Not required & 243.2 & Not required \\
\hline $3 \bar{S}_{\mathrm{m}}$ & $468.7 \mathrm{MPa}$ & $508.1 \mathrm{MPa}$ & $475.3 \mathrm{MPa}$ & $517.3 \mathrm{MPa}$ \\
\hline$\Delta \epsilon_{\max }$ & $0.0356 \%$ & $0.0360 \%$ & $0.0377 \%$ & $0.0376 \%$ \\
\hline$K$ & 1 (no peak stress) & 1 (no peak stress) & 1 (no peak stress) & 1 (no peak stress) \\
\hline$K \Delta \epsilon_{\max }$ & $0.0356 \%$ & $0.0360 \%$ & $0.0377 \%$ & $0.0376 \%$ \\
\hline$E$ & $171700 \mathrm{MPa}$ & $171700 \mathrm{MPa}$ & $171943 \mathrm{MPa}$ & $171943 \mathrm{MPa}$ \\
\hline $3 \bar{S}_{m / E}$ & $0.278 \%$ & $0.296 \%$ & $0.276 \%$ & $0.301 \%$ \\
\hline$K_{\theta}$ & 1 & 1 & 1 & 1 \\
\hline$K_{v}^{o}$ & 1 & 1 & 1 & 1 \\
\hline$K_{v}$ & 1 & 1 & 1 & 1 \\
\hline$\frac{5}{5}$ & 1 & 1 & 1 & 1 \\
\hline$\Delta \epsilon_{\text {mod }}$ & $0.0356 \%$ & $0.0360 \%$ & $0.0377 \%$ & $0.0376 \%$ \\
\hline$\Delta \epsilon_{c}$ & $2.23 \mathrm{e}-12 \%$ & 0 & $6.05 \mathrm{e}-13 \%$ & 0 \\
\hline$e_{t}$ & $0.0356 \%$ & $0.0360 \%$ & $0.0377 \%$ & $0.0376 \%$ \\
\hline $\begin{array}{l}\text { Design allowable } \\
\text { cycles, } N_{d}\end{array}$ & $>1 \mathrm{e} 12$ & $>1 \mathrm{e} 12$ & $>1 \mathrm{e} 12$ & $>1 \mathrm{e} 12$ \\
\hline Design cycles, $n$ & $30 * 365=10950$ & $30 * 365 * 5=54750$ & $30 * 365=10950$ & $30 * 365 * 5=54750$ \\
\hline $\begin{array}{l}\text { Fatigue damage } \\
\text { fraction, } D_{f}\end{array}$ & $6.57 e-8$ & & $6.57 e-8$ & \\
\hline
\end{tabular}

Table 19: Sample calculation of fatigue damage fraction, $D_{f}$ according to Method 1. 


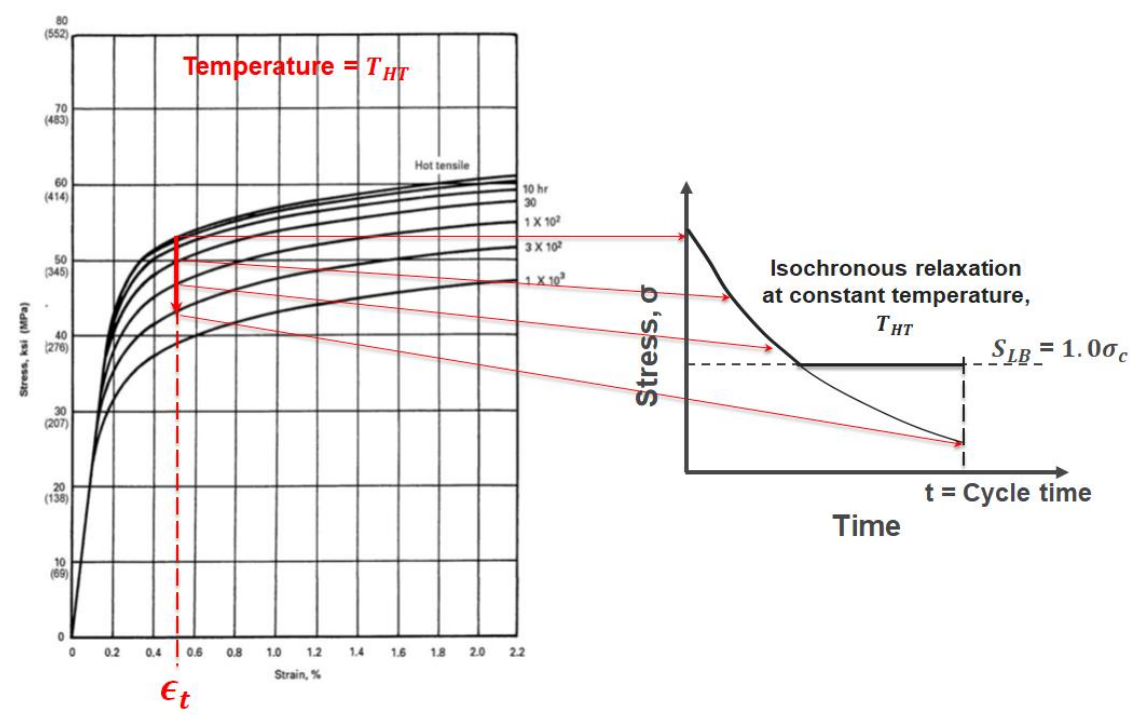

Figure 29: Illustration of determining Stress relaxation profile for creep damage calculation in Method 1.

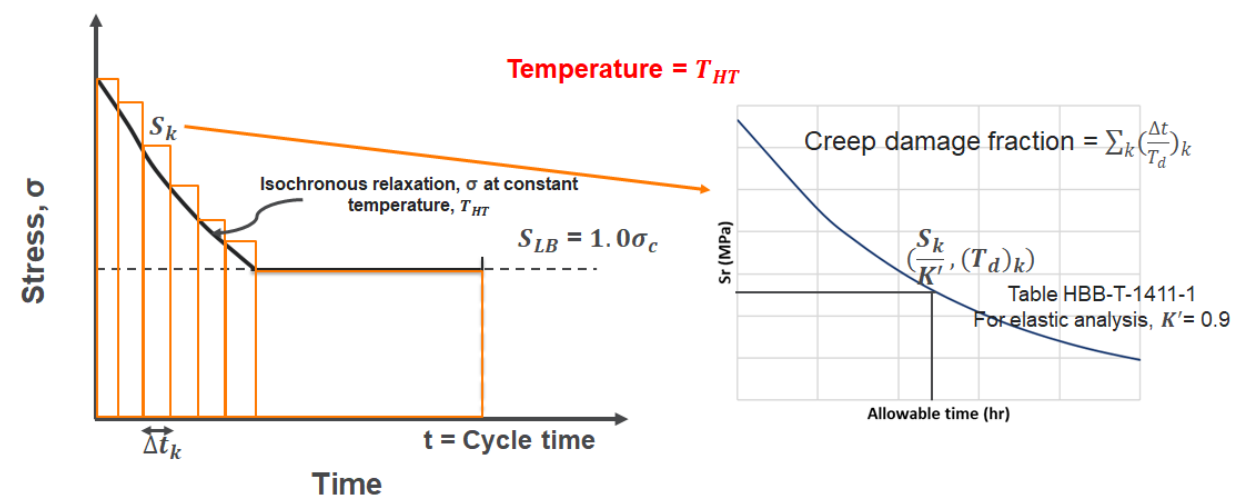

Figure 30: Illustration of calculating creep damage fraction in Method 1. 
33872

Creep-fatigue Behavior and Damage Accumulation of a Candidate Structural Material for Concentrating Solar Power Solar Thermal Receiver

Michael McMurtrey

\begin{tabular}{|c|c|c|c|c|}
\hline & $\begin{array}{l}\text { At OD on stress } \\
\text { classification line-1 } \\
\text { shown in Figure } 28\end{array}$ & $\begin{array}{l}\text { At ID on stress } \\
\text { classification line-1 } \\
\text { shown in Figure } 28\end{array}$ & $\begin{array}{l}\text { At OD on stress } \\
\text { classification line-2 } \\
\text { shown in Figure } 28\end{array}$ & $\begin{array}{l}\text { At ID on stress } \\
\text { classification line-2 } \\
\text { shown in Figure } 28\end{array}$ \\
\hline & $\begin{array}{l}\text { Start-up/shut-down } \\
\text { cycle }\end{array}$ & $\begin{array}{l}\text { Start-up/shut-down } \\
\text { cycle }\end{array}$ & $\begin{array}{l}\text { Start-up/shut-down } \\
\text { cycle }\end{array}$ & $\begin{array}{l}\text { Start-up/shut-down } \\
\text { cycle }\end{array}$ \\
\hline$\Delta \epsilon_{t}$ & $0.0356 \%$ & $0.0465 \%$ & $0.0387 \%$ & $0.0537 \%$ \\
\hline$T_{H T}$ & $770^{\circ} \mathrm{C}$ & $740^{\circ} \mathrm{C}$ & $767.3^{\circ} \mathrm{C}$ & $737.3^{\circ} \mathrm{C}$ \\
\hline$S_{L B}=\sigma_{c}$ & 22.67 & 22.67 & 22.63 & 22.63 \\
\hline $\begin{array}{l}K^{s} \text { (Table HBB-T- } \\
\text { 1411-1) for elastic } \\
\text { analysis }\end{array}$ & 0.9 & 0.9 & 0.9 & 0.9 \\
\hline $\begin{array}{l}\text { Creep damage } \\
\text { fraction per cycle } \\
\text { (from Table 21) }\end{array}$ & $5.89 \mathrm{e}-5$ & $5.91 e-5$ & $6.31 e-5$ & $6.82 \mathrm{e}-5$ \\
\hline Design cycles, $n$ & $30 * 365=10950$ & $30 * 365=10950$ & $30 * 365=10950$ & $30 * 365=10950$ \\
\hline $\begin{array}{l}\text { Creep damage } \\
\text { fraction, } D_{c}\end{array}$ & 0.65 & 0.65 & 0.69 & 0.75 \\
\hline
\end{tabular}

Table 20: Sample creep damage fraction, $D_{c}$ calculation according to Method 1. 
33872

Creep-fatigue Behavior and Damage Accumulation of a Candidate Structural Material for Concentrating Solar Power Solar Thermal Receiver Michael McMurtrey

\begin{tabular}{|c|c|c|c|c|c|c|c|c|c|c|c|}
\hline \multicolumn{6}{|c|}{ At OD on stress classification line-1 shown in Figure 28} & \multicolumn{6}{|c|}{ At OD on stress classification line-2 shown in Figure 28} \\
\hline $\begin{array}{c}\text { Time } \\
(\mathrm{hr})\end{array}$ & $\begin{array}{c}S_{k} \\
(M P a)\end{array}$ & $\begin{array}{c}\frac{3_{k}}{K^{F}} \\
(M P a)\end{array}$ & $\begin{array}{c}T_{d d_{k}} \\
(h r)\end{array}$ & $\begin{array}{l}t_{t_{k}} \\
(h r)\end{array}$ & $\left(\frac{\Delta T}{T_{d}}\right)_{k}$ & $\begin{array}{c}\text { Time } \\
(\mathrm{hr})\end{array}$ & $\begin{array}{c}S_{k_{k}} \\
(M P a)\end{array}$ & $\begin{array}{c}\frac{3_{k}}{K^{s}} \\
(M P a)\end{array}$ & $\begin{array}{c}\left.T_{d}\right)_{k} \\
(h r)\end{array}$ & $\begin{array}{l}\Delta t_{k} \\
(h r)\end{array}$ & $\left(\frac{\Delta T}{T_{a}}\right)_{k}$ \\
\hline 0 & $6.11 \mathrm{e} 1$ & $6.79 \mathrm{e} 1$ & $2.04 \mathrm{e} 5$ & 1 & $4.91 \mathrm{e}-6$ & 0 & $6.65 \mathrm{e} 1$ & $7.39 \mathrm{e} 1$ & $1.90 \mathrm{e} 5$ & 1 & $5.26 \mathrm{e}-6$ \\
\hline 1 & $6.11 \mathrm{e} 1$ & $6.79 \mathrm{e} 1$ & $2.04 \mathrm{e} 5$ & 1 & $4.91 \mathrm{e}-6$ & 1 & $6.65 \mathrm{e} 1$ & $7.39 \mathrm{e} 1$ & $1.90 \mathrm{e} 5$ & 1 & $5.26 \mathrm{e}-6$ \\
\hline 2 & $6.11 \mathrm{e} 1$ & $6.79 \mathrm{e} 1$ & $2.04 \mathrm{e} 5$ & 1 & $4.91 \mathrm{e}-6$ & 2 & $6.65 \mathrm{e} 1$ & $7.39 \mathrm{e} 1$ & $1.90 \mathrm{e} 5$ & 1 & $5.26 \mathrm{e}-6$ \\
\hline 3 & $6.11 \mathrm{e} 1$ & $6.79 \mathrm{e} 1$ & $2.04 \mathrm{e} 5$ & 1 & $4.91 \mathrm{e}-6$ & 3 & $6.65 \mathrm{e} 1$ & $7.39 \mathrm{e} 1$ & $1.90 \mathrm{e} 5$ & 1 & $5.26 \mathrm{e}-6$ \\
\hline 4 & $6.11 \mathrm{e} 1$ & $6.79 \mathrm{e} 1$ & $2.04 \mathrm{e} 5$ & 1 & $4.91 \mathrm{e}-6$ & 4 & $6.65 \mathrm{e} 1$ & $7.39 \mathrm{e} 1$ & $1.90 \mathrm{e} 5$ & 1 & $5.26 \mathrm{e}-6$ \\
\hline 5 & $6.11 \mathrm{e} 1$ & $6.79 \mathrm{e} 1$ & $2.04 \mathrm{e} 5$ & 1 & $4.91 \mathrm{e}-6$ & 5 & $6.65 \mathrm{e} 1$ & $\begin{array}{l}7.39 \mathrm{e} 1 \\
\end{array}$ & $1.90 \mathrm{e} 5$ & 1 & $5.26 \mathrm{e}-6$ \\
\hline 6 & $6.11 \mathrm{e} 1$ & $6.79 \mathrm{e} 1$ & $2.04 \mathrm{e} 5$ & 1 & $4.91 \mathrm{e}-6$ & 6 & $6.65 \mathrm{e} 1$ & $7.39 \mathrm{e} 1$ & $1.90 \mathrm{e} 5$ & 1 & $5.26 \mathrm{e}-6$ \\
\hline 7 & $6.11 \mathrm{e} 1$ & $6.79 \mathrm{e} 1$ & $2.04 \mathrm{e} 5$ & 1 & $4.91 \mathrm{e}-6$ & 7 & $6.65 \mathrm{e} 1$ & $7.39 \mathrm{e} 1$ & $1.90 \mathrm{e} 5$ & 1 & $5.26 \mathrm{e}-6$ \\
\hline 8 & $6.11 \mathrm{e} 1$ & $6.79 \mathrm{e} 1$ & $2.04 \mathrm{e} 5$ & 1 & $4.91 \mathrm{e}-6$ & 8 & $6.65 \mathrm{e} 1$ & $7.39 \mathrm{e} 1$ & $1.90 \mathrm{e} 5$ & 1 & $5.26 \mathrm{e}-6$ \\
\hline 9 & $6.11 \mathrm{e} 1$ & $6.79 \mathrm{e} 1$ & $2.04 \mathrm{e} 5$ & 1 & $4.91 \mathrm{e}-6$ & 9 & $6.65 \mathrm{e} 1$ & $7.39 \mathrm{e} 1$ & $1.90 \mathrm{e} 5$ & 1 & $5.26 \mathrm{e}-6$ \\
\hline 10 & $6.11 \mathrm{e} 1$ & $6.79 \mathrm{e} 1$ & $2.04 \mathrm{e} 5$ & 1 & $4.91 \mathrm{e}-6$ & 10 & $6.65 \mathrm{e} 1$ & $7.39 \mathrm{e} 1$ & $1.90 \mathrm{e} 5$ & 1 & $5.26 \mathrm{e}-6$ \\
\hline 11 & $6.11 \mathrm{e} 1$ & $6.79 \mathrm{e} 1$ & $2.04 \mathrm{e} 5$ & 1 & $4.91 \mathrm{e}-6$ & 11 & $6.65 \mathrm{e} 1$ & $7.39 \mathrm{e} 1$ & $1.90 \mathrm{e} 5$ & 1 & $5.26 \mathrm{e}-6$ \\
\hline 12 & 6.11e1 & $6.79 \mathrm{e} 1$ & $2.04 \mathrm{e} 5$ & & & 12 & $6.65 \mathrm{e} 1$ & $7.39 \mathrm{e} 1$ & $1.90 \mathrm{e} 5$ & & \\
\hline \multicolumn{5}{|c|}{ Creep damage fraction per cycle } & $5.89 e-5$ & \multicolumn{5}{|c|}{ Creep damage fraction per cycle } & $6.31 e-5$ \\
\hline \multicolumn{6}{|c|}{ At ID on stress classification line-1 shown in Figure 28} & \multicolumn{6}{|c|}{ At ID on stress classification line-2 shown in Figure 28} \\
\hline $\begin{array}{c}\text { Time } \\
(\mathrm{hr})\end{array}$ & $\begin{array}{c}S_{S_{k}} \\
(\boldsymbol{M P a})\end{array}$ & $\begin{array}{c}\frac{S_{\mathrm{k}}}{K^{s}} \\
(\mathrm{MPa})\end{array}$ & $\begin{array}{c}\left(I_{d}\right)_{k} \\
(h r)\end{array}$ & $\begin{array}{l}\Delta t_{k} \\
(h r)\end{array}$ & $\left(\frac{\Delta L}{T_{d}}\right)_{k}$ & $\begin{array}{c}\text { Time } \\
(\mathrm{hr})\end{array}$ & $\begin{array}{c}S_{k} \\
(M P a)\end{array}$ & $\begin{array}{c}\frac{J_{k}}{K^{s}} \\
(M P a)\end{array}$ & $\begin{array}{c}\left(I_{d}\right)_{k} \\
(h r)\end{array}$ & $\begin{array}{l}\Delta t_{\underline{k}} \\
(\boldsymbol{h r})\end{array}$ & $\left(\frac{\mu t}{T_{d}}\right)_{k}$ \\
\hline 0 & $8.11 \mathrm{e} 1$ & $9.01 \mathrm{e} 1$ & $2.03 \mathrm{e} 5$ & 1 & $4.92 \mathrm{e}-6$ & 0 & $9.38 \mathrm{e} 1$ & $1.04 \mathrm{e} 2$ & $1.76 \mathrm{e} 5$ & 1 & $5.68 \mathrm{e}-6$ \\
\hline 1 & $8.11 \mathrm{e} 1$ & $9.01 \mathrm{e} 1$ & $2.03 \mathrm{e} 5$ & 1 & $4.92 \mathrm{e}-6$ & 1 & $9.38 \mathrm{e} 1$ & $1.04 \mathrm{e} 2$ & $1.76 \mathrm{e} 5$ & 1 & $5.68 \mathrm{e}-6$ \\
\hline 2 & $8.11 \mathrm{e} 1$ & $9.01 \mathrm{e} 1$ & $2.03 \mathrm{e} 5$ & 1 & $4.92 \mathrm{e}-6$ & 2 & $9.38 \mathrm{e} 1$ & $1.04 \mathrm{e} 2$ & $1.76 \mathrm{e} 5$ & 1 & $5.68 \mathrm{e}-6$ \\
\hline 3 & $8.11 \mathrm{e} 1$ & $9.01 \mathrm{e} 1$ & $2.03 \mathrm{e} 5$ & 1 & $4.92 \mathrm{e}-6$ & 3 & $9.38 \mathrm{e} 1$ & $1.04 \mathrm{e} 2$ & $1.76 \mathrm{e} 5$ & 1 & $5.68 \mathrm{e}-6$ \\
\hline 4 & $8.11 \mathrm{e} 1$ & $9.01 \mathrm{e} 1$ & $2.03 \mathrm{e} 5$ & 1 & $4.92 \mathrm{e}-6$ & 4 & $9.38 \mathrm{e} 1$ & $1.04 \mathrm{e} 2$ & $1.76 \mathrm{e} 5$ & 1 & $5.68 \mathrm{e}-6$ \\
\hline 5 & $8.11 \mathrm{e} 1$ & $9.01 \mathrm{e} 1$ & $2.03 \mathrm{e} 5$ & 1 & $4.92 \mathrm{e}-6$ & 5 & $9.38 \mathrm{e} 1$ & $1.04 \mathrm{e} 2$ & $1.76 \mathrm{e} 5$ & 1 & $5.68 \mathrm{e}-6$ \\
\hline 6 & $8.11 \mathrm{e} 1$ & $9.01 \mathrm{e} 1$ & $2.03 \mathrm{e} 5$ & 1 & $4.92 \mathrm{e}-6$ & 6 & $9.38 \mathrm{e} 1$ & $1.04 \mathrm{e} 2$ & $1.76 \mathrm{e} 5$ & 1 & $5.68 \mathrm{e}-6$ \\
\hline 7 & $8.11 \mathrm{e} 1$ & $9.01 \mathrm{e} 1$ & $2.03 \mathrm{e} 5$ & 1 & $4.92 \mathrm{e}-6$ & 7 & $9.38 \mathrm{e} 1$ & $1.04 \mathrm{e} 2$ & $1.76 \mathrm{e} 5$ & 1 & $5.68 \mathrm{e}-6$ \\
\hline 8 & $8.11 \mathrm{e} 1$ & $9.01 \mathrm{e} 1$ & $2.03 \mathrm{e} 5$ & 1 & $4.92 \mathrm{e}-6$ & 8 & $9.38 \mathrm{e} 1$ & $1.04 \mathrm{e} 2$ & $1.76 \mathrm{e} 5$ & 1 & $5.68 \mathrm{e}-6$ \\
\hline 9 & $8.11 \mathrm{e} 1$ & $9.01 \mathrm{e} 1$ & $2.03 \mathrm{e} 5$ & 1 & $4.92 \mathrm{e}-6$ & 9 & $9.38 \mathrm{e} 1$ & $1.04 \mathrm{e} 2$ & $1.76 \mathrm{e} 5$ & 1 & $5.68 \mathrm{e}-6$ \\
\hline 10 & $8.11 \mathrm{e} 1$ & $9.01 \mathrm{e} 1$ & $2.03 \mathrm{e} 5$ & 1 & $4.92 \mathrm{e}-6$ & 10 & $9.38 \mathrm{e} 1$ & $1.04 \mathrm{e} 2$ & $1.76 \mathrm{e} 5$ & 1 & $5.68 \mathrm{e}-6$ \\
\hline 11 & $8.11 \mathrm{e} 1$ & $9.01 \mathrm{e} 1$ & $2.03 \mathrm{e} 5$ & 1 & $4.92 \mathrm{e}-6$ & 11 & $9.38 \mathrm{e} 1$ & $1.04 \mathrm{e} 2$ & $1.76 \mathrm{e} 5$ & 1 & $5.68 \mathrm{e}-6$ \\
\hline 12 & $8.11 \mathrm{e} 1$ & $9.01 \mathrm{e} 1$ & $2.03 \mathrm{e} 5$ & & & 12 & $9.38 \mathrm{e} 1$ & $1.04 \mathrm{e} 2$ & $1.76 \mathrm{e} 5$ & & \\
\hline \multicolumn{5}{|c|}{ Creep damage fraction per cycle } & $5.91 e-5$ & \multicolumn{5}{|c|}{ Creep damage fraction per cycle } & $6.82 e-5$ \\
\hline
\end{tabular}

Table 21: Sample calculation to determine creep damage fraction, $D_{c}$ per cycle from stress-time history according to Method 1. 


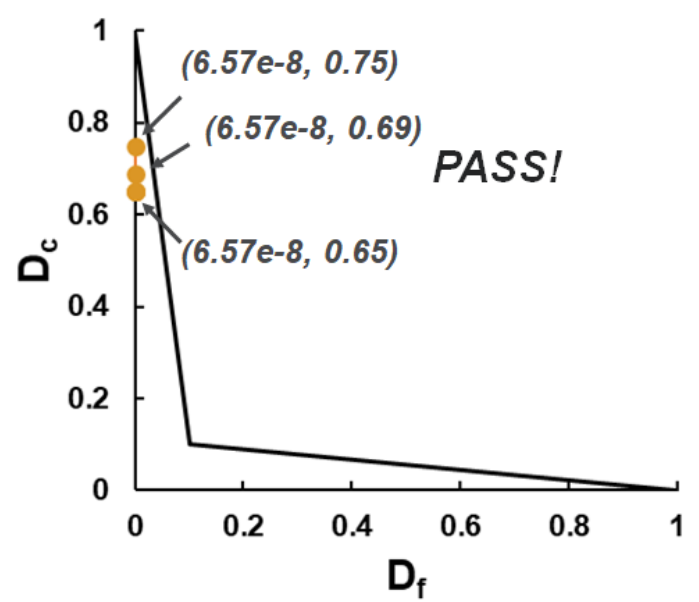

Figure 31: Illustration of creep-fatigue design check. Plotted data are results from analysis according to Method 1.

Step 6: Strain-controlled time-independent buckling check

This design check was not performed as buckling is not expected under these loading conditions.

\section{Design calculations based on Method 2}

Steps 1, 2, 3, 4, and 6 in Method 2 are same as in Method 1 and therefore only Step 5 is discussed here.

Step 5: Creep-fatigue damage check

Method 2 is applicable only if the primary plus secondary stress intensity $(P+Q)$ remains less than $S_{y}$ for all service loading and if peak stresses are minimal.

For a design to be acceptable, the following relation must be satisfied:

$\sum_{j}\left(\frac{n}{N_{d}}\right)_{j}+\sum_{k}\left(\frac{\Delta t}{T_{d}}\right)_{k} \leq D$

where $\mathrm{D}$ is the total creep-fatigue damage and the first and second terms on the left side are fatigue damage, $D_{f}$ and creep damage, $D_{o}$, respectively. In the fatigue damage term, $(n)_{j}$ is the number of repetitions of cycle type $\mathrm{j}$ and $\left(N_{d}\right)_{j}$ is the number of design allowable cycles for respective cycle type; while in the creep damage term, $\left(T_{d}\right)_{k}$ is the allowable time duration for a given stress at the maximum temperature occurring in the time interval $\mathrm{k}$ and $(\Delta t)_{k}$ is the duration of the time interval $\mathrm{k}$.

The design allowable cycles for fatigue damage is determined by entering fatigue curves at total strain range, $\epsilon_{t}$. Total strain range, $\epsilon_{t}$ is calculated using equation HBB-T-1432-16:

$\Delta \varepsilon=\Delta \epsilon_{1}+\Delta \epsilon_{2}$

where $\Delta \epsilon_{1}$ is the maximum equivalent strain range calculated from the elastic analysis of under primary and secondary loading together, according to Section III, Division 5, HBB-T-1413. $\Delta \epsilon_{2}$ is the creep strain increment per stress cycle. $\Delta \epsilon_{2}$ can be determined by entering the isochronous stress-strain curves at the O'Donnell-Porowski core stress, $\sigma_{c}$ (determined in Method 1, Step 4) and maximum metal temperature for the stress cycle time, including hold times between transient (instead of total service life). Alternatively, $\Delta \epsilon_{2}$ can be calculated by dividing the creep strain accumulated during the entire service life by the number of stress cycles during the entire service life. We used the latter option. 
Creep damage for each service load cycle is evaluated from the von Mises stress profile, determined from elastically calculated stresses, versus time profile for this load cycle. Using the stress-time profile and the hold time temperature, $T_{H T}$ during the cycle, creep damage fraction can be calculated according to the illustration in Figure 32. As mentioned before, we only considered the start-up/shut-down service load cycle and the day time (12 hr) during the cycle for creep damage fraction calculation.

Table 22 and 23 shows few sample calculations of determining creep damage fraction, $D_{c}$ and fatigue damage fraction, $D_{f}$, respectively, according to Method -2. Similar to Method 1, Method 2 also uses creep-fatigue interaction diagram to determine whether a design passes creep-fatigue damage check. Comparing $\left(D_{f}, D_{c}\right)$ with the damage envelop in creep-fatigue interaction diagram the design is found to be passed according to Method 2.

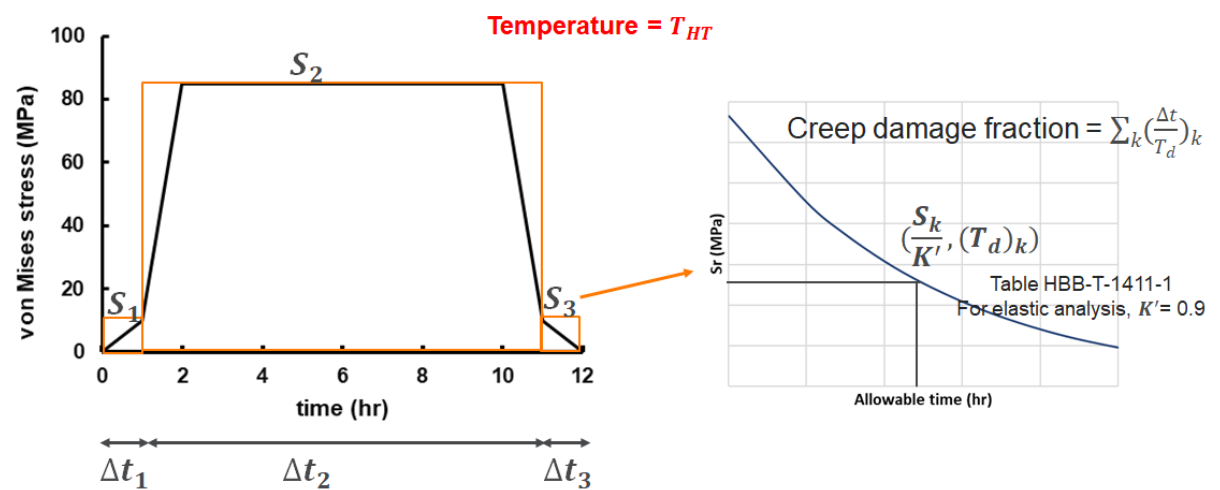

Figure 32: Illustration of calculating creep damage fraction in Method 2. 
Creep-fatigue Behavior and Damage Accumulation of a Candidate Structural Material for Concentrating Solar Power Solar Thermal Receiver Michael McMurtrey

\begin{tabular}{|c|c|c|c|c|c|c|c|c|c|c|c|}
\hline \multicolumn{6}{|c|}{ At OD on stress classification line-1 shown in Figure 28} & \multicolumn{6}{|c|}{ At OD on stress classification line -2 shown in Figure 28} \\
\hline \multicolumn{6}{|c|}{$\begin{array}{l}T_{H T}=770^{\circ} \mathrm{C} \\
S_{y} \text { at } T_{H T}=490 \mathrm{MPa}(\text { Method } 2 \text { is applicable! })\end{array}$} & \multicolumn{6}{|c|}{$\begin{array}{l}T_{H T}=767.3^{\circ} \mathrm{C} \\
S_{y} \text { at } T_{H T}=492.3 \mathrm{MPa}(\text { Method } 2 \text { is applicable! })\end{array}$} \\
\hline $\begin{array}{c}\text { Time } \\
(\mathrm{hr})\end{array}$ & $\begin{array}{c}S_{k_{k}} \\
(M P a)\end{array}$ & $\frac{S_{k}}{K_{(=0.9)}^{T_{(}}}$ & $\begin{array}{c}\left(T_{d}\right]_{k} \\
(h r)\end{array}$ & $\begin{array}{l}\mathbb{B} t_{k} \\
(h r)\end{array}$ & $\left(\frac{D L}{T_{d}}\right)_{k}$ & $\begin{array}{c}\text { Time } \\
(\mathrm{hr})\end{array}$ & $\begin{array}{c}S_{k} \\
(M P a)\end{array}$ & $\frac{3_{k}}{K_{(=0.9)}}$ & $\begin{array}{c}\left(T_{d}\right)_{k} \\
(h r)\end{array}$ & $\begin{array}{l}\mathbb{\Delta} t_{k} \\
(h r)\end{array}$ & $\frac{d r}{T_{d}} \eta_{k}$ \\
\hline 0 & 0 & - & - & - & - & 0 & 0 & - & - & - & - \\
\hline 1 & 7.88 & 8.76 & 390230 & 1 & $2.56 \mathrm{e}-6$ & 1 & 9.05 & 10.06 & 385957 & 1 & $2.59 \mathrm{e}-6$ \\
\hline 2 & 57.17 & 63.52 & 195295 & 10 & $5.12 \mathrm{e}-4$ & 2 & 59.93 & 66.59 & 212754 & 10 & $4.70 \mathrm{e}-5$ \\
\hline 10 & 57.17 & - & - & - & - & 10 & 59.93 & - & - & - & - \\
\hline 11 & 7.88 & 8.76 & 390230 & 1 & $2.56 \mathrm{e}-6$ & 11 & 9.05 & 10.06 & 385957 & 1 & $2.59 \mathrm{e}-6$ \\
\hline 12 & 0 & - & - & - & - & 12 & 0 & - & - & - & - \\
\hline \multicolumn{5}{|c|}{ Creep damage fraction per cycle } & $5.63 e-5$ & \multicolumn{5}{|c|}{ Creep damage fraction per cycle } & $5.21 e-5$ \\
\hline \multicolumn{5}{|c|}{ Creep damage fraction, $D_{c}$} & 0.62 & \multicolumn{5}{|c|}{ Creep damage fraction, $D_{c}$} & 0.57 \\
\hline \multicolumn{6}{|c|}{ At ID on stress classification line-1 shown in Figure 28} & \multicolumn{6}{|c|}{ At ID on stress classification line-2 shown in Figure 28} \\
\hline \multicolumn{6}{|c|}{$\begin{array}{l}T_{H T}=740^{\circ} \mathrm{C} \\
\left.S_{y} \text { at } T_{H T}=512 \mathrm{MPa} \text { (Method } 2 \text { is applicable! }\right)\end{array}$} & \multicolumn{6}{|c|}{$\begin{array}{l}T_{H T}=737.3^{\circ} \mathrm{C} \\
S_{y} \text { at } T_{H T}=513 \mathrm{MPa}(\text { Method } 2 \text { is applicable! })\end{array}$} \\
\hline $\begin{array}{c}\text { Time } \\
(\mathrm{hr})\end{array}$ & $\begin{array}{c}S_{k_{k}} \\
(M P a)\end{array}$ & $\frac{S_{k}}{K_{(=0.9)}^{T}}$ & $\begin{array}{c}\left(T_{d}\right)_{k} \\
(h r)\end{array}$ & $\begin{array}{l}\Delta t_{k_{k}} \\
(h r)\end{array}$ & $\left.\frac{\pi t}{T_{d}}\right)_{k}$ & $\begin{array}{c}\text { Time } \\
(\mathrm{hr})\end{array}$ & $\begin{array}{c}S_{k_{k}} \\
(M P a)\end{array}$ & $\frac{S_{k}}{K_{(=0.9)}}$ & $\begin{array}{c}\left(T_{d}\right)_{k} \\
(h r)\end{array}$ & $\begin{array}{l}\Delta t_{k} \\
(h r)\end{array}$ & $\left(\frac{\omega t}{T_{d}}\right)_{k}$ \\
\hline 0 & 0 & - & - & - & - & 0 & 0 & - & - & - & - \\
\hline 1 & 9.72 & 10.8 & 394482 & 1 & $2.53 \mathrm{e}-6$ & 1 & 10.55 & 11.7 & 395103 & 1 & $2.53 \mathrm{e}-6$ \\
\hline 2 & 74.01 & 82.23 & 200011 & 10 & $4.50 \mathrm{e}-5$ & 2 & 86.03 & 95.59 & 196367 & 10 & $5.09 \mathrm{e}-5$ \\
\hline 10 & 74.01 & - & - & - & - & 10 & 86.03 & - & - & - & - \\
\hline 11 & 9.72 & 10.8 & 394482 & 1 & $2.53 \mathrm{e}-6$ & 11 & 10.55 & 11.7 & 395103 & 1 & $2.53 \mathrm{e}-6$ \\
\hline 12 & 0 & - & - & - & - & 12 & 0 & - & - & - & - \\
\hline \multicolumn{5}{|c|}{ Creep damage fraction per cycle } & $5.51 e-5$ & \multicolumn{5}{|c|}{ Creep damage fraction per cycle } & $5.60 e-5$ \\
\hline \multicolumn{5}{|c|}{ Creep damage fraction, $D_{c}$} & 0.60 & \multicolumn{5}{|c|}{ Creep damage fraction, $D_{c}$} & 0.61 \\
\hline
\end{tabular}

Table 22: Sample calculation to determine creep damage fraction, $D_{c}$ per cycle from stress-time history according to Method 2.

\begin{tabular}{|c|c|c|c|c|}
\hline & \multicolumn{2}{|c|}{$\begin{array}{l}\text { At OD on stress classification line-1 shown } \\
\text { in Figure } 28\end{array}$} & \multicolumn{2}{|c|}{$\begin{array}{l}\text { At OD on Stress classification line-2 shown } \\
\text { in Figure } 28\end{array}$} \\
\hline & $\begin{array}{l}\text { Start-up/shut-down } \\
\text { cycle }\end{array}$ & Cloud event & $\begin{array}{l}\text { Start-up/shut-down } \\
\text { cycle }\end{array}$ & Cloud event \\
\hline$T^{\max }$ & $770^{\circ} \mathrm{C}$ & $770^{\circ} \mathrm{C}$ & $767.3^{\circ} \mathrm{C}$ & $767.3^{\circ} \mathrm{C}$ \\
\hline$\Delta \varepsilon_{1}$ & $0.0356 \%$ & $0.0360 \%$ & $0.0377 \%$ & $0.0376 \%$ \\
\hline$\Delta \epsilon_{2}$ & $2.23 \mathrm{e}-12 \%$ & 0 & $6.05 \mathrm{e}-13 \%$ & 0 \\
\hline$\Delta \varepsilon$ & $0.0356 \%$ & $0.0360 \%$ & $0.0387 \%$ & $0.0386 \%$ \\
\hline $\begin{array}{l}\text { Design allowable } \\
\text { cycles, } N_{\delta}\end{array}$ & $>1 \mathrm{e} 12$ & $>1 \mathrm{e} 12$ & $>1 \mathrm{e} 12$ & $>1 \mathrm{e} 12$ \\
\hline Design cycles, $n$ & $30 * 365=10950$ & $30 * 365 * 5=54750$ & $30 * 365=10950$ & $30 * 365 * 5=54750$ \\
\hline $\begin{array}{l}\text { Fatigue damage } \\
\text { fraction, } D_{f}\end{array}$ & \multicolumn{2}{|l|}{$6.57 e-8$} & \multicolumn{2}{|l|}{$6.57 e-8$} \\
\hline
\end{tabular}

Table 23: Sample calculations of determining fatigue damage fraction, $D_{f}$ according to Method 2.

\section{Design calculations based on Method 3}

This method is applicable only if the elastically-calculated stresses remain below the material yield stress, $S_{y}$. In the discussion of design calculation based on Method 2, it is shown that the 
elastically-calculated stress for this sample problem is always less than $S_{y}$ and therefore Method 3 is applicable.

For primary load design, Method 3 uses the same procedures in Method 1 which is based on elastic analysis. For ratcheting and creep-fatigue design checks, however, this method uses inelastic analysis where material's constitutive response is described by an elastic-creep model. The description of the elastic-creep material model is provided above. Design calculations related to ratcheting and creep-fatigue damage are discussed for Method 3.

Step 1a: Defining service loads and design loads (for primary load design check)

Same as in Method 1 Step 1.

Step 1b: Defining service loads and design loads (for ratcheting and creep-fatigue evaluation)

In this method, separate weather related load cannot be separated from a standard daily load cycle. For this sample problem, therefore, the design load, shown in Figure 21, is considered as the service load.

Step 2a: Transient elastic thermo-mechanical analysis for each service load case (for primary load design check)

Same as in Method 1 Step 2.

Step 2b: Transient elastic-creep thermo-mechanical analysis for each service load case (for ratcheting and creep-fatigue evaluation)

We used MOOSE (Multiphysics Object Oriented Simulation Environment), an open source finite element solver to perform the transient elastic-creep thermo-mechanical analyses under the loading conditions mentioned in Step 1b. The analysis was repeated until a steady state cyclic response was achieved.

Step 3: Primary load design check

Same as in Method 1 Step 3.

Step 4: Ratcheting check

To determine ratcheting strain Method 3 requires to run the analysis using elastic-creep material model, described above, and monitor the maximum effective strain, $\sqrt{\frac{2}{3} \varepsilon: \varepsilon}$ at the beginning and end of the cycle. The criterion is that the ratcheting strain does not exceed $2 \%$ at any point of the structure for base metal. Figure 33 plots the maximum effective strain at the critical tube location as a function of cycle count. Extrapolating the maximum effective strain out to design life of the tube, i.e. 30 years $(=30 * 365$ cycles), gives the ratcheting strain of $0.00565 \%$ which is less than $2 \%$.

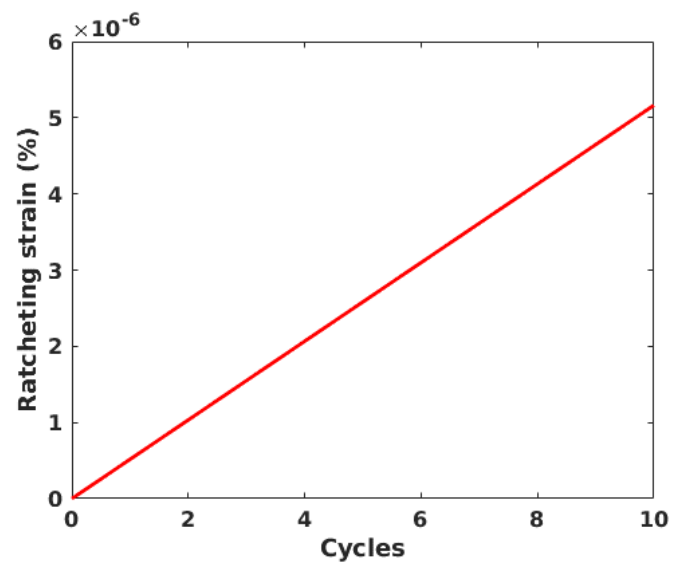


Figure 33 Maximum ratcheting strain in the structure versus number of cycles determined from elastic-creep thermo-mechanical analysis.

Step 5: Creep-fatigue damage check

Once steady cyclic response was achieved in the analysis, the temperature, stress, strain, time history for a single cycle of the periodic loading were extracted. To determine fatigue damage fraction, the effective strain range, $\Delta \varepsilon$ was first computed from the strain history according to Section III, Division 5, HBB-T-1413 with $v^{*}=0.5$ for inelastic analysis. Fatigue damage fraction, $D_{f}$ was then calculated from $\Delta \varepsilon$ using rainflow counting and Miner's rule. Figure 34 plots temperature, von Mises stress, and effective strain range profiles at four critical locations of the tube after a steady cyclic response was achieved. Table 24 shows details of the fatigue damage fraction calculation according to Method 3. The von Mises effective stress, $\sigma_{\text {eff }}(t)$ was used to determine the creep damage fraction. Figure 35 illustrates the method of creep damage fraction, $D_{c}$ calculation and Table 25 reports details of the calculation for four critical locations in the structure. All four sets of $\left(D_{f}, D_{c}\right)$ fall inside the damage envelop in the creep-fatigue interaction diagram which means according to Method 3 the design passes creep-fatigue damage check.

According to Table HBB-1411-1 in Section III, Division 5 of ASME Code, a design margin (i.e, $K^{\prime}$ ) is applied to the effective stress while determining the allowable rupture time from the design rupture table. ASME Code recommends to use $K^{\prime}=0.9$ for elastic analysis and $K^{\prime}=0.67$ for inelastic analysis. However, he creep damage fraction calculation is repeated in Table 26 with $K^{\prime}=0.9$. The history behind the ASME stress factors is somewhat murky, but given the lower consequences of failure we recommend a stress factor of 0.9 for all analysis, including inelastic analysis. 

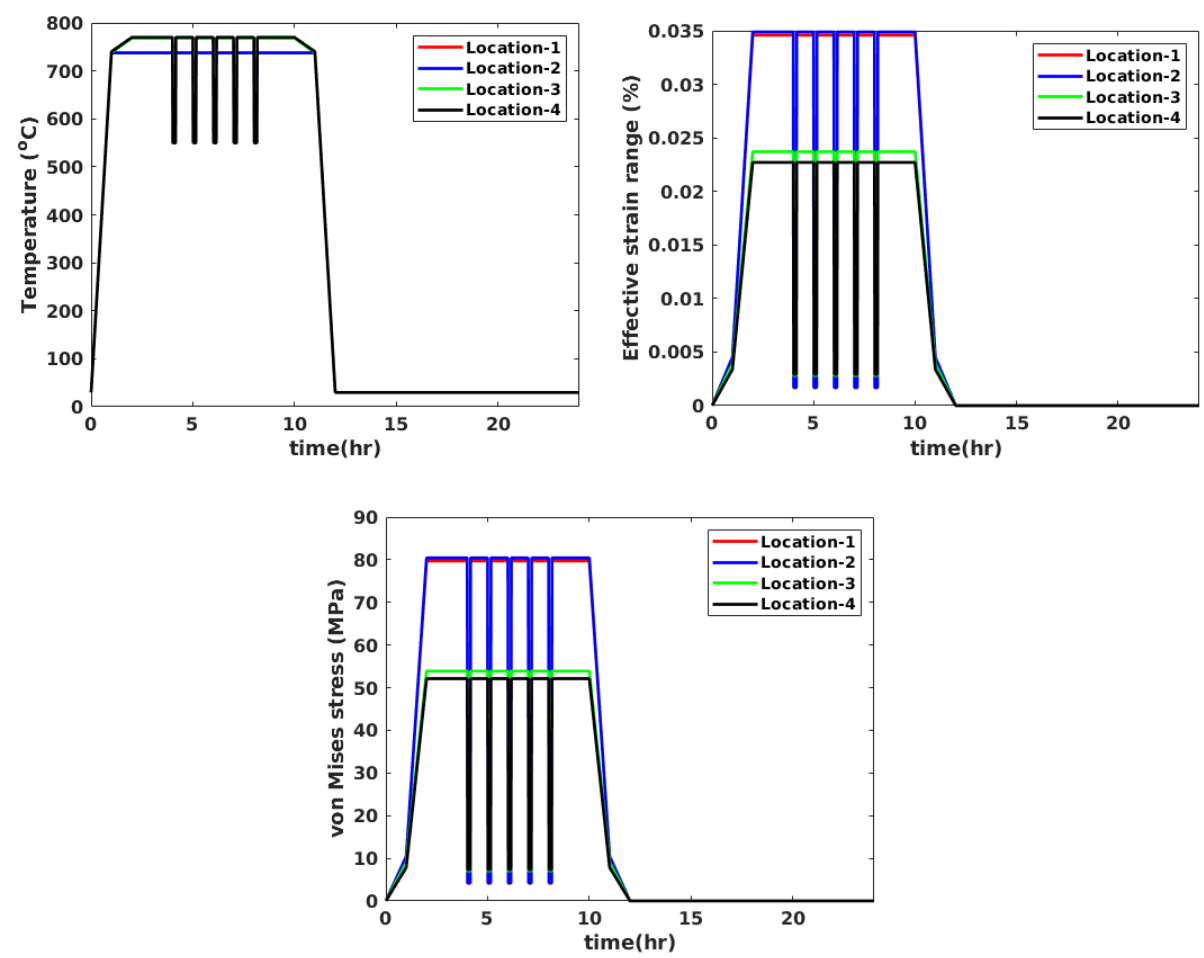

Figure 34 Temperature, effective strain range, and von Mises stress profiles at four critical location of the tube after a steady cyclic response is achieved in the elastic-creep thermo-mechanical analysis.

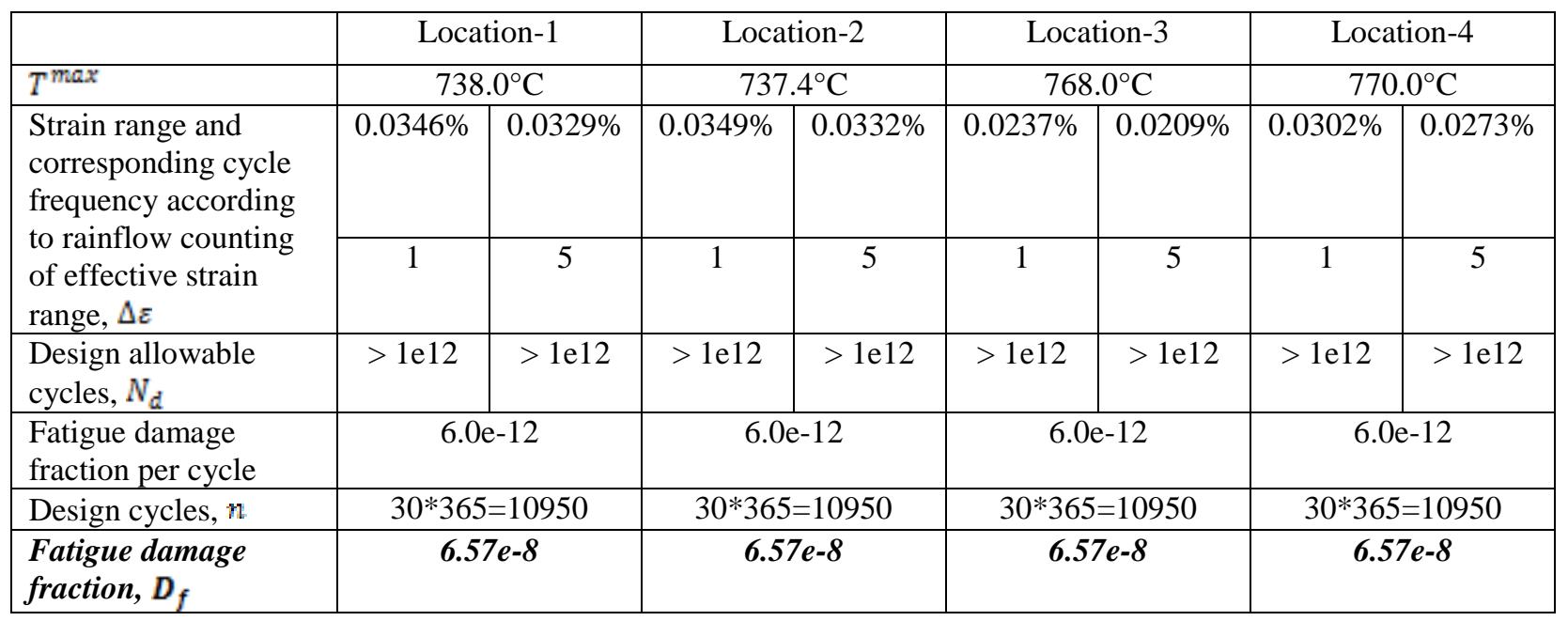

Table 24: Sample calculation of determining fatigue damage fraction, $D_{f}$ according to Method 3. 


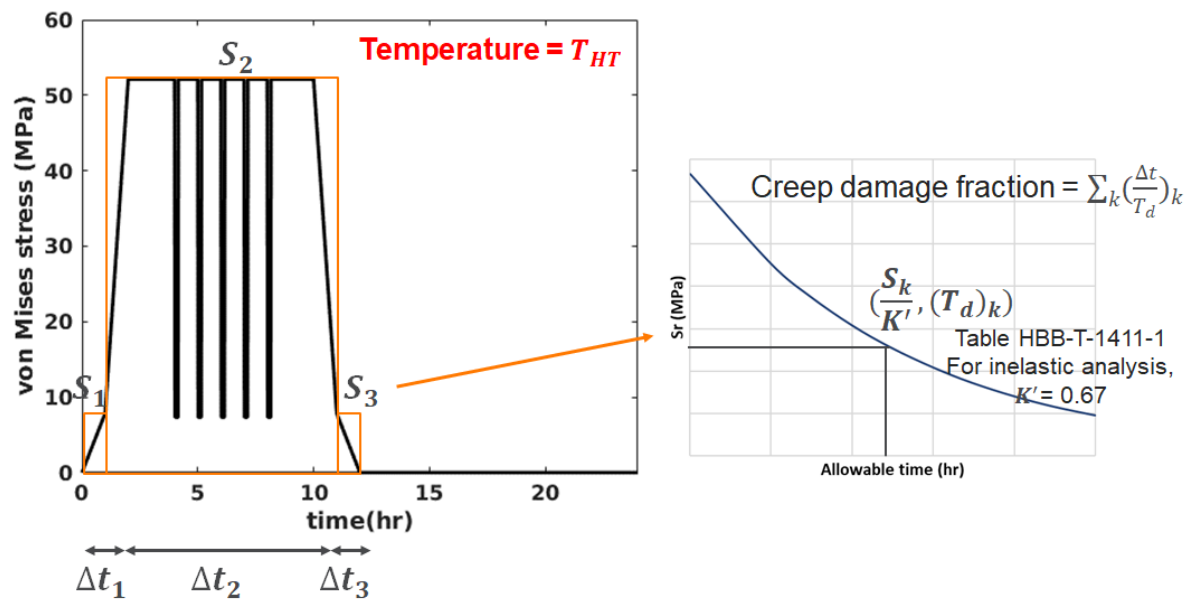

Figure 35: Illustration of calculating creep damage fraction in Method 3.

\begin{tabular}{|c|c|c|c|c|c|c|c|c|c|c|c|c|}
\hline & \multicolumn{3}{|c|}{ Location-1 } & \multicolumn{3}{|c|}{ Location-2 } & \multicolumn{3}{|c|}{ Location-3 } & \multicolumn{3}{|c|}{ Location-4 } \\
\hline Temperature during hold, $T_{M T}$ & \multicolumn{3}{|c|}{$738.0^{\circ} \mathrm{C}$} & \multicolumn{3}{|c|}{$737.4^{\circ} \mathrm{C}$} & \multicolumn{3}{|c|}{$768.0^{\circ} \mathrm{C}$} & \multicolumn{3}{|c|}{$770.0^{\circ} \mathrm{C}$} \\
\hline \multirow{2}{*}{$\begin{array}{l}\text { von Mises effective stress, } \sigma_{t / f f} \\
(\mathrm{MPa}) \text { and corresponding time } \\
\text { interval, } \Delta t_{t_{k}}(\mathrm{hr})\end{array}$} & 10.5 & 79.7 & 10.5 & 10.4 & 80.4 & 10.4 & 8.9 & 53.9 & 8.9 & 7.8 & 52.1 & 7.8 \\
\hline & 1 & 10 & 1 & 1 & 10 & 1 & 1 & 10 & 1 & 1 & 10 & 1 \\
\hline 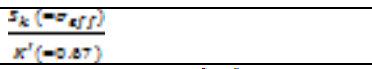 & 15.7 & 119.0 & 15.7 & 15.5 & 120.0 & 15.5 & 13.3 & 80.4 & 13.3 & 11.6 & 77.8 & 11.6 \\
\hline Allowable time, $\left(T_{d}\right)_{k}(h r)$ & $3.8 \mathrm{e} 5$ & $1.4 \mathrm{e} 5$ & $3.8 \mathrm{e} 5$ & $3.9 \mathrm{e} 5$ & $1.4 \mathrm{e} 5$ & $3.9 \mathrm{e} 5$ & $3.8 \mathrm{e} 5$ & $1.7 \mathrm{e} 5$ & $3.8 \mathrm{e} 5$ & $3.8 \mathrm{e} 5$ & $1.7 \mathrm{e} 5$ & $3.8 \mathrm{e} 5$ \\
\hline$\left(\frac{b_{k}}{x_{2}}\right)_{k}$ & $\begin{array}{l}2.6 e- \\
6\end{array}$ & $\begin{array}{l}7.2 \mathrm{e}- \\
5\end{array}$ & $\begin{array}{l}2.6 \mathrm{e}- \\
6\end{array}$ & $\begin{array}{l}2.6 \mathrm{e}- \\
6\end{array}$ & $\begin{array}{l}7.2 \mathrm{e}- \\
5\end{array}$ & $\begin{array}{l}2.6 \mathrm{e}- \\
6\end{array}$ & $\begin{array}{l}2.7 \mathrm{e}- \\
6\end{array}$ & $\begin{array}{l}5.9 \mathrm{e}- \\
5\end{array}$ & $\begin{array}{l}2.7 \mathrm{e}- \\
6\end{array}$ & $\begin{array}{l}2.6 e- \\
6\end{array}$ & \begin{tabular}{|l}
$5.8 \mathrm{e}-$ \\
5
\end{tabular} & $\begin{array}{l}2.6 e- \\
6\end{array}$ \\
\hline Creep damage fraction per cycle & \multicolumn{3}{|c|}{$7.71 e-5$} & \multicolumn{3}{|c|}{$7.75 \mathrm{e}-5$} & \multicolumn{3}{|c|}{$6.45 \mathrm{e}-5$} & \multicolumn{3}{|c|}{$6.32 \mathrm{e}-5$} \\
\hline Design cycles, $n$ & \multicolumn{3}{|c|}{$30 * 365=10950$} & \multicolumn{3}{|c|}{$30 * 365=10950$} & \multicolumn{3}{|c|}{$30 * 365=10950$} & \multicolumn{3}{|c|}{$30 * 365=10950$} \\
\hline Creep damage fraction, $D_{\varepsilon}$ & \multicolumn{3}{|c|}{0.84} & \multicolumn{3}{|c|}{0.85} & \multicolumn{3}{|c|}{0.71} & \multicolumn{3}{|c|}{0.69} \\
\hline
\end{tabular}

Table 25: Sample calculation of determining creep damage fraction, $D_{c}$ according to Method 3.

\begin{tabular}{|c|c|c|c|c|c|c|c|c|c|c|c|c|}
\hline & \multicolumn{3}{|c|}{ Location-1 } & \multicolumn{3}{|c|}{ Location-2 } & \multicolumn{3}{|c|}{ Location-3 } & \multicolumn{3}{|c|}{ Location-4 } \\
\hline Temperature during hold, $T_{m r}$ & \multicolumn{3}{|c|}{$738.0^{\circ} \mathrm{C}$} & \multicolumn{3}{|c|}{$737.4^{\circ} \mathrm{C}$} & \multicolumn{3}{|c|}{$768.0^{\circ} \mathrm{C}$} & \multicolumn{3}{|c|}{$770.0^{\circ} \mathrm{C}$} \\
\hline \multirow{2}{*}{$\begin{array}{l}\text { von Mises effective stress, } \sigma_{t / f f} \\
(M P a) \text { and corresponding time } \\
\text { interval, } \Delta t_{k}(h r)\end{array}$} & 10.5 & 79.7 & 10.5 & 10.4 & 80.4 & 10.4 & 8.9 & 53.9 & 8.9 & 7.8 & 52.1 & 7.8 \\
\hline & 1 & 10 & 1 & 1 & 10 & 1 & 1 & 10 & 1 & 1 & 10 & 1 \\
\hline 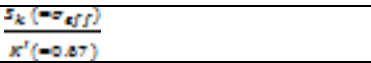 & 11.7 & 88.6 & 11.7 & 11.6 & 89.3 & 11.6 & 9.9 & 59.9 & 9.9 & 8.7 & 57.9 & 8.7 \\
\hline Allowable time, $\left(T_{d}\right)_{k}(h r)$ & $3.9 \mathrm{e} 5$ & $2.1 \mathrm{e} 5$ & $3.9 \mathrm{e} 5$ & $4.0 \mathrm{e} 5$ & $2.1 \mathrm{e} 5$ & $4.0 \mathrm{e} 5$ & $3.9 \mathrm{e} 5$ & $2.3 \mathrm{e} 5$ & $3.9 \mathrm{e} 5$ & $3.9 \mathrm{e} 5$ & $2.4 \mathrm{e} 5$ & $3.9 \mathrm{e} 5$ \\
\hline$\left(\frac{b_{F}}{x_{4}}\right)_{k}$ & $\begin{array}{l}2.5 \mathrm{e}- \\
6\end{array}$ & $\begin{array}{l}4.7 e- \\
5\end{array}$ & $\begin{array}{l}2.5 \mathrm{e}- \\
6\end{array}$ & $\begin{array}{l}2.5 \mathrm{e}- \\
6\end{array}$ & \begin{tabular}{|l|}
$4.7 e-$ \\
5
\end{tabular} & $\begin{array}{l}2.6 e- \\
6\end{array}$ & $\begin{array}{l}2.6 e- \\
6\end{array}$ & $\begin{array}{l}4.3 e- \\
5\end{array}$ & $\begin{array}{l}2.6 \mathrm{e}- \\
6\end{array}$ & $\begin{array}{l}2.6 \mathrm{e}- \\
6\end{array}$ & $\begin{array}{l}4.6 e- \\
5\end{array}$ & $\begin{array}{l}2.6 \mathrm{e}- \\
6\end{array}$ \\
\hline Creep damage fraction per cycle & \multicolumn{3}{|c|}{$5.24 \mathrm{e}-5$} & \multicolumn{3}{|c|}{$5.24 \mathrm{e}-5$} & \multicolumn{3}{|c|}{$4.82 \mathrm{e}-5$} & \multicolumn{3}{|c|}{$4.76 \mathrm{e}-5$} \\
\hline Design cycles, $n$ & \multicolumn{3}{|c|}{$30 * 365=10950$} & \multicolumn{3}{|c|}{$30 * 365=10950$} & \multicolumn{3}{|c|}{$30 * 365=10950$} & \multicolumn{3}{|c|}{$30 * 365=10950$} \\
\hline Creep damage fraction, $D_{\varepsilon}$ & \multicolumn{3}{|c|}{0.57} & \multicolumn{3}{|c|}{0.57} & \multicolumn{3}{|c|}{0.53} & \multicolumn{3}{|c|}{0.52} \\
\hline
\end{tabular}

Table 26: Repeat of calculations in Table 10 by changing $K^{y}=0.67$ to $K^{s}=0.9$.

\section{Sample problem 2}

For sample problem 2 we considered a tube in an external tubular receiver. The receiver has parabolic reflectors at the back of the tubes which help reduce the variation in the circumferential heat flux distribution on the tube. Figure 36 shows the schematic of the tubular receiver. The tube is $10.5 \mathrm{~m}$ long, $42.2 \mathrm{~mm}$ diameter, and $1 \mathrm{~mm}$ thick. Heat flux on the tube is non uniform 
both along the length and circumference. We considered only one type of cycle for this problem which represent heat flux on the day of spring equinox. Figure 37 plots the loading profiles of maximum flux incident, salt inlet and outlet temperature, and salt pressure during day (10 hrs). The salt considered for this problem is $\mathrm{MgCl}_{2} / \mathrm{KCl}$ binary molten salt. The mass flow rate of the salt is $44.5 \mathrm{~kg} / \mathrm{s}$. Salt inlet and outlet temperatures are $700^{\circ} \mathrm{C}$ and $720^{\circ} \mathrm{C}$, respectively. The tube can freely expand both in radial and axial direction, however warping is not allowed in the axial direction. Figure 38 shows the heat flux and tube outer wall temperature distribution at noon. The design life of the tube is considered to be 4.4 years. Design calculations according all three methods are provided below without detailed discussion.

This sample problem quickly runs through the design checks for all three methods. See problem 1 for a more detailed walk through of each method.

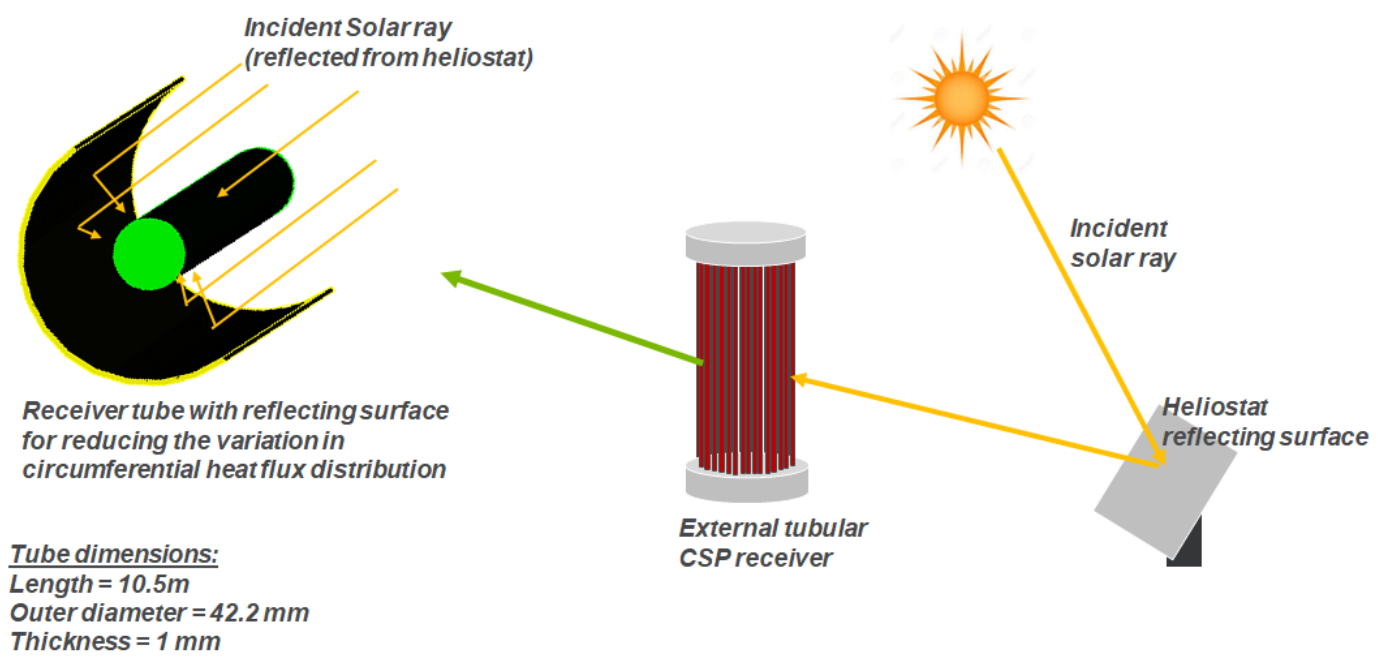

Figure 36: Schematic of an external tubular receiver (Sample problem 2). 

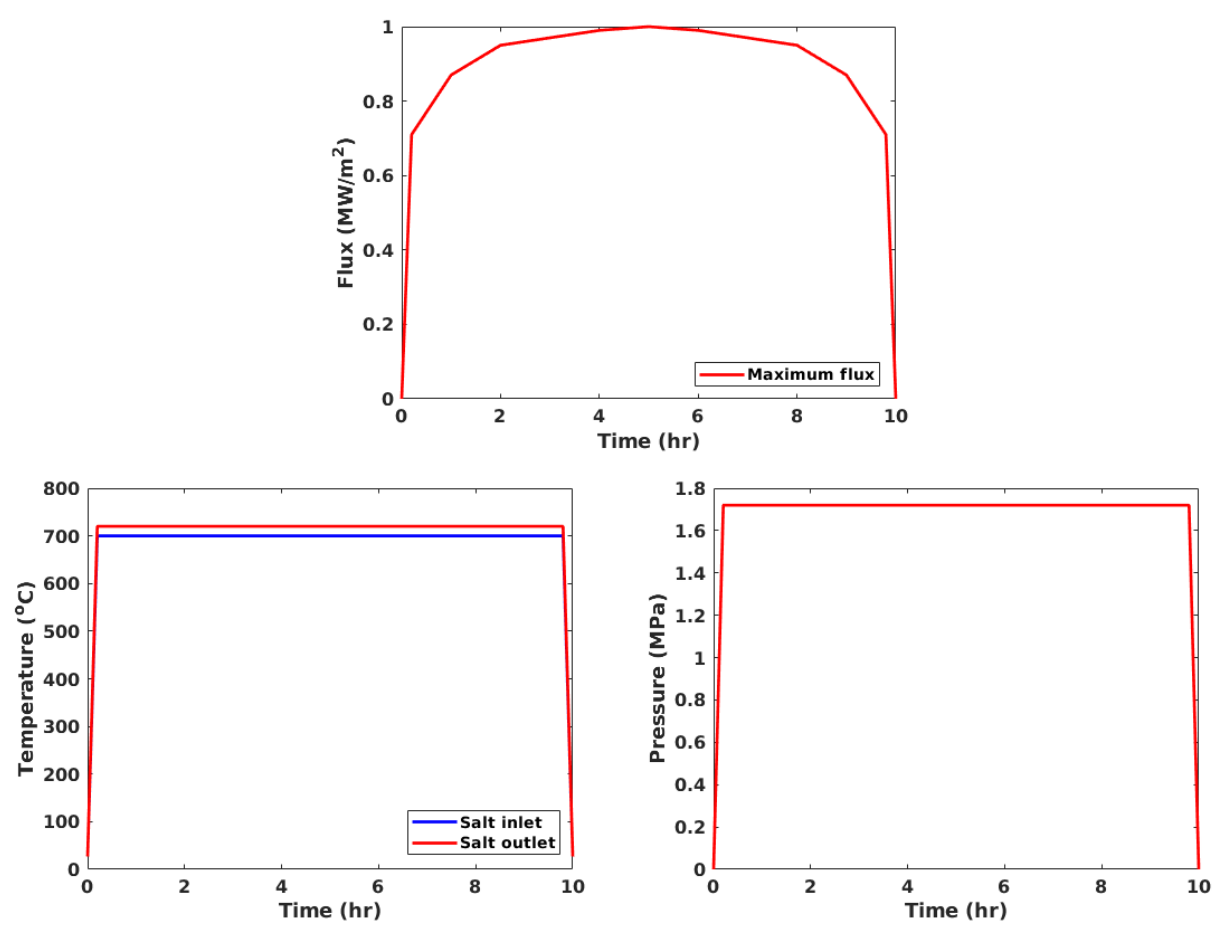

Figure 37: (Sample problem 2) Loading profiles of maximum flux incident, salt inlet and outlet temperature, and salt pressure during day. Only one type of cycle is considered. Receiver operation time per day is 10 hours. Loading profiles shown are only for the tube considered for design study.

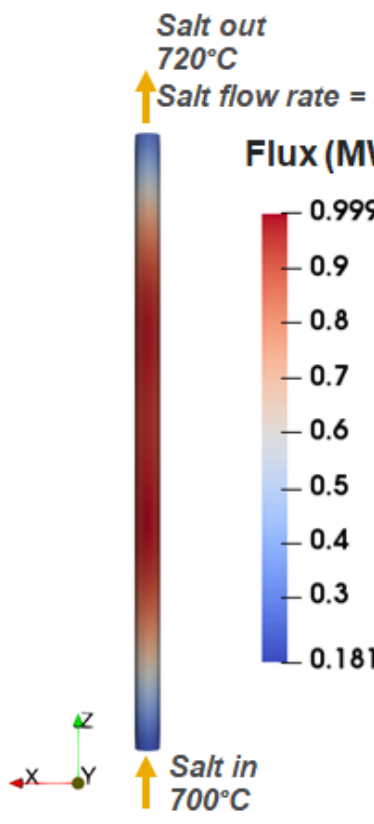

Facing heliostat

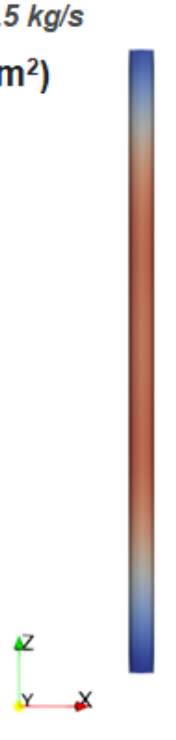

Facing reflector

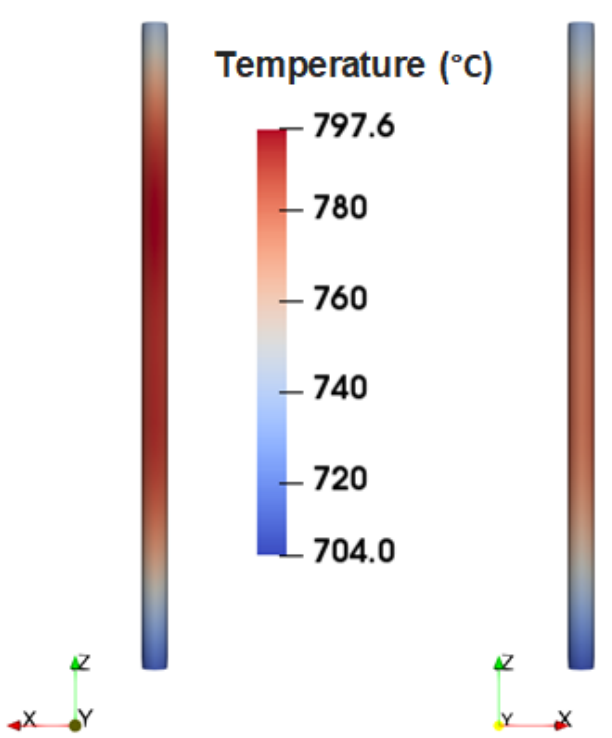

Facing heliostat
Facing reflector

Figure 38: (Sample problem-2) Contour plot of flux incident on tube and tube outer wall temperature at noon. 


\section{Design calculations based on Method 1}

Step 1: Defining service loads and design loads

As we considered only one type of loading condition, the loading profile shown in Figure 37 can be considered as both the design load and service load.

Step 2: Transient elastic thermo-mechanical analysis for each service load case and stress classification

We used MOOSE (Multiphysics Object Oriented Simulation Environment), an open source finite element solver to perform the transient elastic thermo-mechanical analyses. We classify pressure as primary load and temperature gradient as secondary load. There is no peak load. Figure 39 shows elastic stresses at noon at a critical location of the tube.
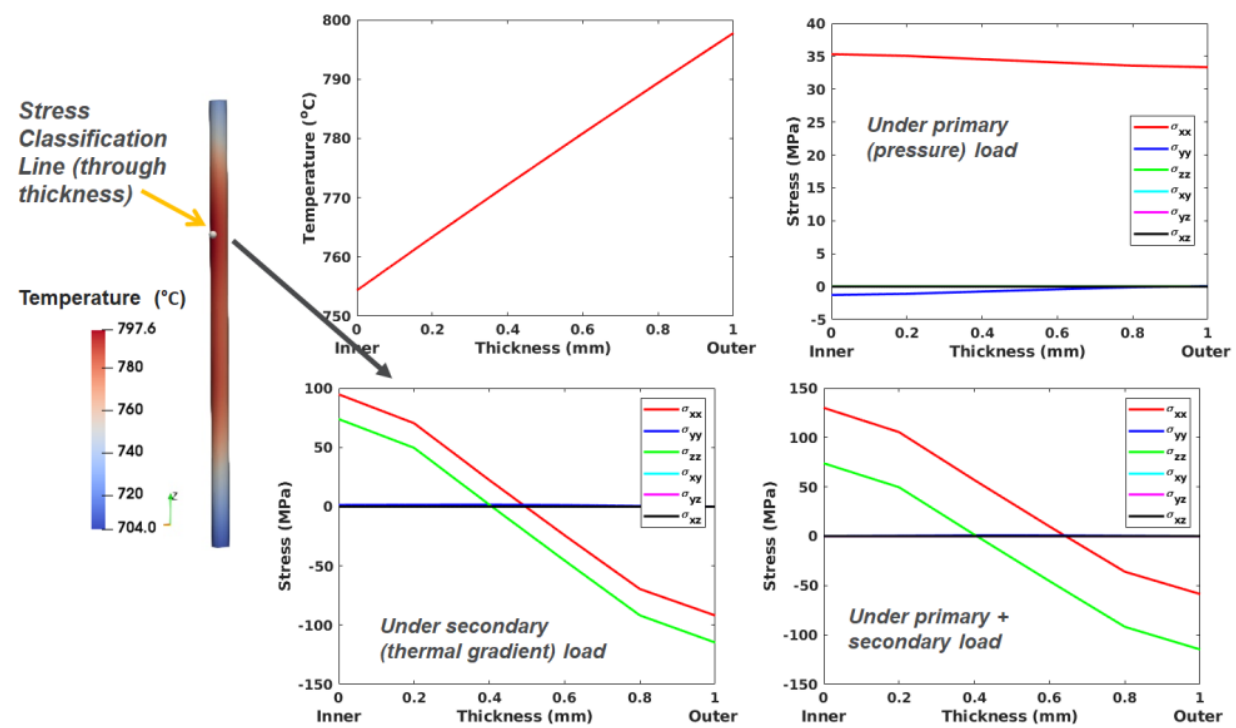

Figure 39: (Sample problem-2) Through thickness temperature and elastic stresses at a critical location of the tube at noon.

Step 3: Primary load design check

See Table 27.

\begin{tabular}{|l|c|}
\hline Max. General primary membrane stress intensity, $P_{m}$ & $34.90 \mathrm{MPa}$ \\
\hline Max. Combined primary membrane plus bending stress intensity, $P_{L}+P_{b}$ & $36.76 \mathrm{MPa}$ \\
\hline Maximum metal temperature, $T_{\max }$ & $797.6{ }^{\circ} \mathrm{C}$ \\
\hline Allowable stress, $S_{0}$ at $T_{\max }$ & $36.89 \mathrm{MPa}$ \\
\hline Design criteria $-1: P_{m} \leq S_{0}$ & $\boldsymbol{P A S S} !$ \\
\hline Design criteria $-2: P_{L}+P_{b} \leq 1.5 S_{0}$ & $\boldsymbol{P A S S} !$ \\
\hline
\end{tabular}

Table 27: (Sample problem-2) Primary load design checks along the stress classification line shown in Figure 39, according to Method 1,2, \&3.

Step 4: Ratcheting check

See Table 28. 


\begin{tabular}{|c|c|}
\hline & Stress classification line shown in Figure 39 \\
\hline$T_{\text {Wrall aweraged }}^{\text {Max }}$ & $776.4^{\circ} \mathrm{C}$ \\
\hline$T_{\text {wail averaged }}^{\text {min }}$ & $30^{\circ} \mathrm{C}$ \\
\hline$T^{\max }$ & $797.6^{\circ} \mathrm{C}$ \\
\hline$S_{y H}\left(\right.$ at $\left.T_{\text {wail averaged }}^{\text {max }}\right)$ & $451.16 \mathrm{MPa}$ \\
\hline$S_{y L}\left(\right.$ at $\left.T_{\text {wall }}^{\text {ming averaged }}\right)$ & $621.0 \mathrm{MPa}$ \\
\hline$S_{y}=\left(S_{y H}+S_{y L}\right) / 2$ & $536.08 \mathrm{MPa}$ \\
\hline K & 1.5 \\
\hline$K_{\mathrm{t}}=(K+1) / 2$ & 1.25 \\
\hline$\left(P_{L}+\frac{P_{b}}{K_{t}}\right)_{\max }$ & $36.39 \mathrm{MPa}$ \\
\hline$\left(Q_{R}\right)_{\max }$ & $114.76 \mathrm{MPa}$ \\
\hline$X=\left(P_{L}+\frac{P_{b}}{K_{k}}\right)_{\max } / S_{y}$ & 0.0679 \\
\hline$Y=\left(Q_{R}\right)_{\max } / S_{y}$ & 0.2147 \\
\hline$Z$ using Section III, Division 5, Figure HBB-T-1332-1 & 0.0679 \\
\hline$\sigma_{c}$ from $Z=\frac{\sigma_{c}}{s_{y z}}$ & 42.17 \\
\hline Service life (considering whole day as service time per day) & 4.4 years $=38544$ hours \\
\hline Ratcheting strain at the end of service life & $0.151 \%$ \\
\hline Ratcheting design criteria: $2 \%$ for base metal & PASS! \\
\hline
\end{tabular}

Table 28: (Sample problem-2) Ratcheting design checks according to Method-1\&2.

Step 5: Creep-fatigue damage check

See Table 29 for fatigue damage fraction calculation, Tables 30 and 31 for creep damage calculation, and Figure 40 for creep-fatigue damage check. 
Creep-fatigue Behavior and Damage Accumulation of a Candidate Structural Material for Concentrating Solar Power Solar Thermal Receiver Michael McMurtrey

\begin{tabular}{|c|c|c|}
\hline & $\begin{array}{l}\text { At OD on stress classification line shown } \\
\text { in Figure } 39\end{array}$ & $\begin{array}{l}\text { At ID on stress classification line shown } \\
\text { in Figure } 39\end{array}$ \\
\hline$T^{\max }$ & $797.6^{\circ} \mathrm{C}$ & $754.4^{\circ} \mathrm{C}$ \\
\hline Hot temperature & $797.6^{\circ} \mathrm{C}$ & $754.4^{\circ} \mathrm{C}$ \\
\hline Cold temperature & $30^{\circ} \mathrm{C}$ & $30^{\circ} \mathrm{C}$ \\
\hline Hot time & $10 \mathrm{hr} *(4.4 * 365)=16060 \mathrm{hr}$ & $10 \mathrm{hr} *(4.4 * 365)=16060 \mathrm{hr}$ \\
\hline Cold time & $14 \mathrm{hr} *(30 * 365)=22484 \mathrm{hr}$ & $14 \mathrm{hr} *(30 * 365)=22484 \mathrm{hr}$ \\
\hline$S_{Y H}$ & $78.4 \mathrm{MPa}$ & $126.4 \mathrm{MPa}$ \\
\hline$S_{r L}$ & Not required & Not required \\
\hline$S_{m}$ at $T^{\max }$ & $218.9 \mathrm{MPa}$ & $253.5 \mathrm{MPa}$ \\
\hline $3 \bar{S}_{\mathrm{m}}$ & $406.8 \mathrm{MPa}$ & $506.7 \mathrm{MPa}$ \\
\hline$\Delta \epsilon_{\max }$ & $0.0583 \%$ & $0.0659 \%$ \\
\hline$K$ & 1 (no peak stress) & 1 (no peak stress) \\
\hline$K \Delta \epsilon_{\max }$ & $0.0582 \%$ & $0.0659 \%$ \\
\hline$E$ & $169216 \mathrm{MPa}$ & $173104 \mathrm{MPa}$ \\
\hline $3 \bar{S}_{\mathrm{m} / E}$ & $0.240 \%$ & $0.293 \%$ \\
\hline$K_{\theta}$ & 1 & 1 \\
\hline$K_{V}^{s}$ & 1 & 1 \\
\hline$\overline{K_{\mathrm{W}}}$ & 1 & 1 \\
\hline$\frac{5^{2}}{5}$ & 1 & 1 \\
\hline$\Delta e_{\text {mod }}$ & $0.0582 \%$ & $0.0659 \%$ \\
\hline$\Delta \varepsilon_{c}$ & $0.094 \mathrm{e}-3 \%$ & 0 \\
\hline$\epsilon_{t}$ & $0.0583 \%$ & $0.0659 \%$ \\
\hline $\begin{array}{ll}\text { Design } & \text { allowable } \\
\text { cycles, } N_{d} & \\
\end{array}$ & $>1 \mathrm{e} 12$ & $>1 \mathrm{e} 12$ \\
\hline Design cycles, $n$ & $4.4 * 365=1602$ & $4.4 * 365=1606$ \\
\hline $\begin{array}{ll}\text { Fatigue } & \text { damage } \\
\text { fraction, } D_{f} & \end{array}$ & $1.60 e-9$ & $1.60 e-9$ \\
\hline
\end{tabular}

Table 29: (Sample problem-2) Sample calculation of determining fatigue damage fraction, $D_{f}$ according to Method 1.

\begin{tabular}{|l|l|l|}
\hline & $\begin{array}{l}\text { At OD on stress classification line } \\
\text { shown in Figure 39 }\end{array}$ & $\begin{array}{l}\text { At ID on stress classification line } \\
\text { shown in Figure 39 }\end{array}$ \\
\hline$\Delta \epsilon_{t}$ & $0.0583 \%$ & $0.0659 \%$ \\
\hline$T_{H T}$ & $797.6^{\circ} \mathrm{C}$ & $754.4^{\circ} \mathrm{C}$ \\
\hline$S_{L B}=\sigma_{c}$ & $42.17 \mathrm{MPa}$ & $42.17 \mathrm{MPa}$ \\
\hline $\begin{array}{l}K^{s} \text { (Table HBB-T-1411-1) for } \\
\text { elastic analysis }\end{array}$ & 0.9 & 0.9 \\
\hline $\begin{array}{l}\text { Creep damage fraction per cycle } \\
\text { (from Table 31) }\end{array}$ & $6.16 \mathrm{e}-4$ & $1.42 \mathrm{e}-4$ \\
\hline Design cycles, $n$ & $4.4 * 365=1602$ & $4.4^{*} 365=1602$ \\
\hline Creep damage fraction, $\boldsymbol{D}_{c}$ & $\mathbf{0 . 9 9}$ & $\mathbf{0 . 2 8}$ \\
\hline
\end{tabular}

Table 30: (Sample problem-2) Sample creep damage fraction, $D_{c}$ calculation according to Method 1. 


\begin{tabular}{|c|c|c|c|c|c|c|c|c|c|c|c|}
\hline \multicolumn{6}{|c|}{ At OD on stress classification line shown in Figure 39} & \multicolumn{6}{|c|}{ At ID on stress classification line shown in Figure 39} \\
\hline $\begin{array}{c}\text { Time } \\
(\mathrm{hr})\end{array}$ & $\begin{array}{c}S_{k}^{S_{k}} \\
(M P a)\end{array}$ & $\begin{array}{c}\frac{3_{k}}{K^{s}} \\
(M P a)\end{array}$ & $\begin{array}{c}\left(T_{d}\right)_{k} \\
(h r)\end{array}$ & $\begin{array}{l}\Delta t_{k} \\
(h r)\end{array}$ & $\left(\frac{\Delta r}{T_{d}}\right)_{k}$ & $\begin{array}{c}\text { Time } \\
(\mathrm{hr})\end{array}$ & $\begin{array}{c}S_{k} \\
(M P a)\end{array}$ & $\begin{array}{c}\frac{3_{k}}{K^{s}} \\
(M P a)\end{array}$ & $\begin{array}{c}\left(T_{d)_{k}}\right. \\
(\boldsymbol{h r})\end{array}$ & $\begin{array}{l}\Delta t_{k} \\
(h r)\end{array}$ & $\left(\frac{\Delta T}{T_{a}}\right)_{k}$ \\
\hline 0 & $9.87 \mathrm{E}+01$ & $1.10 \mathrm{E}+02$ & $1.62 \mathrm{E}+04$ & 1 & $6.16 \mathrm{E}-05$ & 0 & $1.14 \mathrm{E}+02$ & $1.27 \mathrm{E}+02$ & $7.04 \mathrm{E}+04$ & 1 & $1.42 \mathrm{E}-05$ \\
\hline 1 & $9.87 \mathrm{E}+01$ & $1.10 \mathrm{E}+02$ & $1.62 \mathrm{E}+04$ & 1 & $6.16 \mathrm{E}-05$ & 1 & $1.14 \mathrm{E}+02$ & $1.27 \mathrm{E}+02$ & $7.04 \mathrm{E}+04$ & 1 & $1.42 \mathrm{E}-05$ \\
\hline 2 & $9.87 \mathrm{E}+01$ & $1.10 \mathrm{E}+02$ & $1.62 \mathrm{E}+04$ & 1 & $6.16 \mathrm{E}-05$ & 2 & $1.14 \mathrm{E}+02$ & $1.27 \mathrm{E}+02$ & $7.04 \mathrm{E}+04$ & 1 & $1.42 \mathrm{E}-05$ \\
\hline 3 & $9.87 \mathrm{E}+01$ & $1.10 \mathrm{E}+02$ & $1.62 \mathrm{E}+04$ & 1 & $6.16 \mathrm{E}-05$ & 3 & $1.14 \mathrm{E}+02$ & $1.27 \mathrm{E}+02$ & $7.04 \mathrm{E}+04$ & 1 & $1.42 \mathrm{E}-05$ \\
\hline 4 & $9.87 \mathrm{E}+01$ & $1.10 \mathrm{E}+02$ & $1.62 \mathrm{E}+04$ & 1 & $6.16 \mathrm{E}-05$ & 4 & $1.14 \mathrm{E}+02$ & $1.27 \mathrm{E}+02$ & $7.04 \mathrm{E}+04$ & 1 & $1.42 \mathrm{E}-05$ \\
\hline 5 & $9.87 \mathrm{E}+01$ & $1.10 \mathrm{E}+02$ & $1.62 \mathrm{E}+04$ & 1 & $6.16 \mathrm{E}-05$ & 5 & $1.14 \mathrm{E}+02$ & $1.27 \mathrm{E}+02$ & $7.04 \mathrm{E}+04$ & 1 & $1.42 \mathrm{E}-05$ \\
\hline 6 & $9.87 \mathrm{E}+01$ & $1.10 \mathrm{E}+02$ & $1.62 \mathrm{E}+04$ & 1 & $6.16 \mathrm{E}-05$ & 6 & $1.14 \mathrm{E}+02$ & $1.27 \mathrm{E}+02$ & $7.04 \mathrm{E}+04$ & 1 & $1.42 \mathrm{E}-05$ \\
\hline 7 & $9.87 \mathrm{E}+01$ & $1.10 \mathrm{E}+02$ & $1.62 \mathrm{E}+04$ & 1 & $6.16 \mathrm{E}-05$ & 7 & $1.14 \mathrm{E}+02$ & $1.27 \mathrm{E}+02$ & $7.04 \mathrm{E}+04$ & 1 & $1.42 \mathrm{E}-05$ \\
\hline 8 & $9.87 \mathrm{E}+01$ & $1.10 \mathrm{E}+02$ & $1.62 \mathrm{E}+04$ & 1 & $6.16 \mathrm{E}-05$ & 8 & $1.14 \mathrm{E}+02$ & $1.27 \mathrm{E}+02$ & $7.04 \mathrm{E}+04$ & 1 & $1.42 \mathrm{E}-05$ \\
\hline 9 & $9.87 \mathrm{E}+01$ & $1.10 \mathrm{E}+02$ & $1.62 \mathrm{E}+04$ & 1 & $6.16 \mathrm{E}-05$ & 9 & $1.14 \mathrm{E}+02$ & $1.27 \mathrm{E}+02$ & $7.04 \mathrm{E}+04$ & 1 & $1.42 \mathrm{E}-05$ \\
\hline 10 & $9.87 \mathrm{E}+01$ & $1.10 \mathrm{E}+02$ & $1.62 \mathrm{E}+04$ & & & 10 & $1.14 \mathrm{E}+02$ & $1.27 \mathrm{E}+02$ & $7.04 \mathrm{E}+04$ & & \\
\hline \multicolumn{5}{|c|}{ Creep damage fraction per cycle } & $6.16 e-4$ & \multicolumn{5}{|c|}{ Creep damage fraction per cycle } & $1.42 e-4$ \\
\hline
\end{tabular}

Table 31: (Sample problem-2) Sample calculation of creep damage fraction, $D_{c}$ per cycle from stress-time history according to Method 1.

(1.60e-9, 0.99)

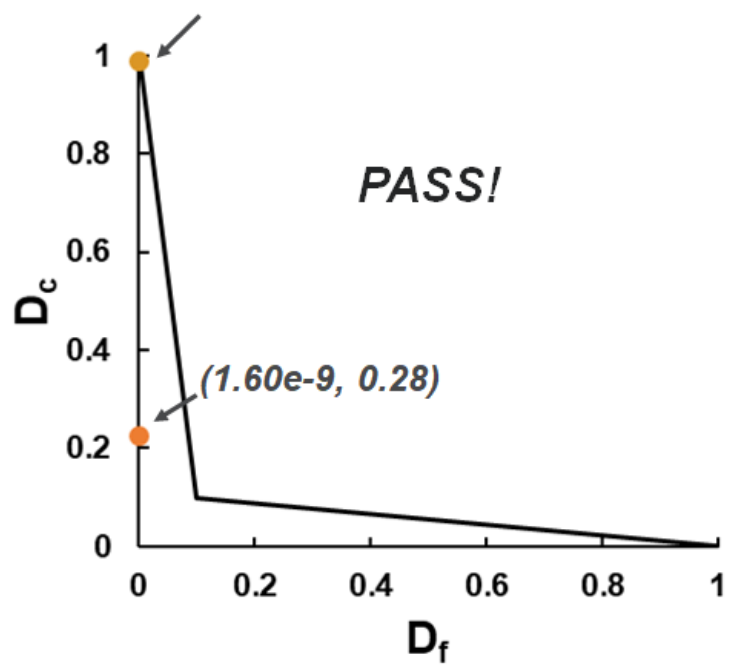

Figure 40: (Sample problem-2) Illustration of creep-fatigue design check. Plotted data are results from analysis according to Method 1.

Step 6: Strain-controlled time-independent buckling check

This design check was not performed as buckling is not expected for this loading condition.

\section{Design calculations based on Method 2}

Steps 1, 2, 3, 4, and 6 in Method 2 are same as in Method 1.

Step 5: Creep-fatigue damage check

See Figure 41 and Table 32 for creep damage fraction calculation, Table 33 for fatigue damage calculation, and Figure 42 for creep-fatigue damage check. 


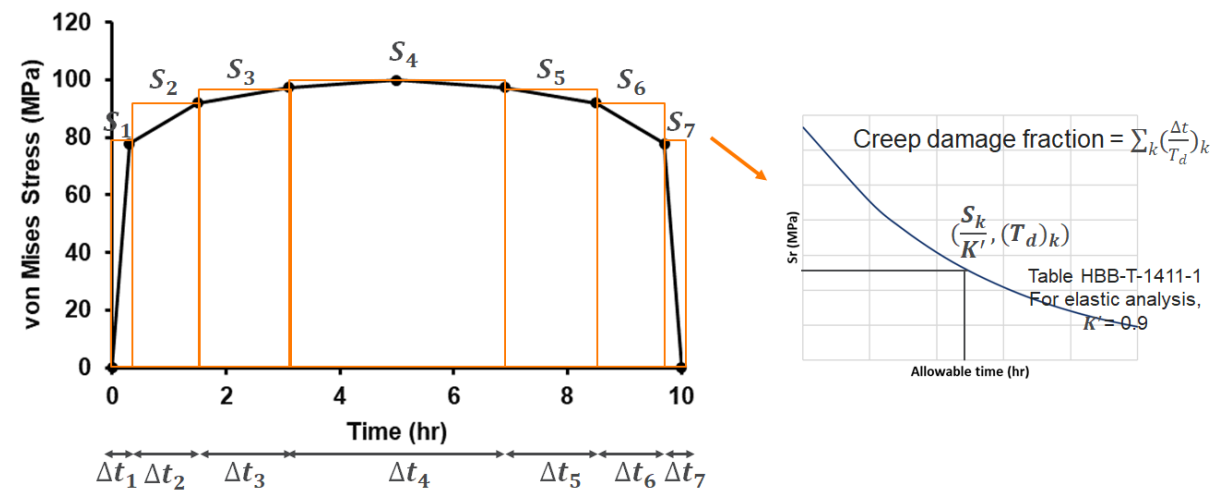

Figure 41: (Sample problem-2) Illustration of calculating creep damage fraction in Method 2.

\begin{tabular}{|c|c|c|c|c|c|}
\hline \multicolumn{6}{|c|}{ At OD on stress classification line shown in Figure 39} \\
\hline \multicolumn{6}{|c|}{$\begin{array}{l}T_{H T}=797.6^{\circ} \mathrm{C} \\
S_{y} \text { at } T_{H T}=465.2 \mathrm{MPa}(\text { Method } 2 \text { is applicable!) }\end{array}$} \\
\hline Time $(\mathrm{hr})$ & $\begin{array}{c}S_{k} \\
(M P a)\end{array}$ & $\begin{array}{c}\frac{S_{k}}{K^{v}(=0.9)} \\
(M P a)\end{array}$ & $\begin{array}{c}\left(T_{d}\right)_{k} \\
(h r)\end{array}$ & $\begin{array}{l}\Delta t_{k} \\
(h r)\end{array}$ & $\left(\frac{\Delta t}{T_{d}}\right)_{k}$ \\
\hline 0.3 & 77.84 & 86.49 & 67197 & 0.3 & $4.46 \mathrm{E}-06$ \\
\hline 1.5 & 91.83 & 102.03 & 24022 & 1.2 & $5.00 \mathrm{E}-05$ \\
\hline 3.1 & 97.4 & 108.22 & 17667 & 1.6 & $9.06 \mathrm{E}-05$ \\
\hline 5 & 99.84 & 110.93 & 14885 & 3.8 & $2.55 \mathrm{E}-04$ \\
\hline 6.9 & 97.4 & 108.22 & 17667 & 1.6 & $9.06 \mathrm{E}-05$ \\
\hline 8.5 & 91.83 & 102.03 & 24022 & 1.2 & $5.00 \mathrm{E}-05$ \\
\hline 9.7 & 77.84 & 86.49 & 67197 & 0.3 & $4.46 \mathrm{E}-06$ \\
\hline 10 & 0 & 0 & & & \\
\hline \multicolumn{5}{|c|}{ Creep damage fraction per cycle } & $5.45 e-3$ \\
\hline \multicolumn{5}{|c|}{ Creep damage fraction, $D_{c}$} & 0.87 \\
\hline
\end{tabular}

Table 32: (Sample problem-2) Sample calculation of creep damage fraction, $D_{c}$ per cycle from stress-time history according to Method 2.

\begin{tabular}{|l|l|}
\hline & At OD on stress classification line shown in Figure 39 \\
\hline$T^{\max }$ & $797.6^{\circ} \mathrm{C}$ \\
\hline$\Delta \varepsilon_{1}$ & $0.0583 \%$ \\
\hline$\Delta \varepsilon_{2}$ & $0.094 \mathrm{e}-3 \%$ \\
\hline$\Delta \varepsilon$ & $0.0583 \%$ \\
\hline Design allowable cycles, $N_{d}$ & $>1 \mathrm{e} 12$ \\
\hline Design cycles, $n$ & $4.4 * 365=1602$ \\
\hline Fatigue damage fraction, $\boldsymbol{D}_{f}$ & $\mathbf{1 . 6 0 e - 9}$ \\
\hline
\end{tabular}

Table 33: (Sample problem-2) Sample calculation of fatigue damage fraction, $D_{f}$ according to Method 2. 


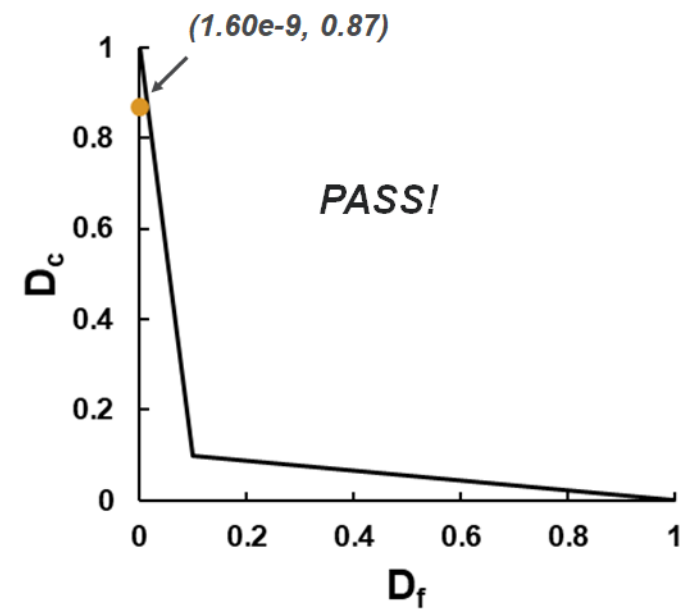

Figure 42: (Sample problem-2) Illustration of creep-fatigue design check. Plotted data are results from analysis according to Method 2.

\section{Design calculations based on Method 3}

Step 1: Defining service loads and design loads (for primary load design check)

Same as in Method 1 Step 1.

Step 2a: Transient elastic thermo-mechanical analysis for each service load case (for primary load design check)

Same as in Method 1 Step 2.

Step 2b: Transient elastic-creep thermo-mechanical analysis for each service load case (for ratcheting and creep-fatigue evaluation)

We used MOOSE (Multiphysics Object Oriented Simulation Environment), an open source finite element solver to perform the transient elastic-creep thermo-mechanical analyses under the loading conditions mentioned in Step 1. The analysis was repeated until a steady state cyclic response was achieved.

Step 3: Primary load design check

Same as in Method 1 Step 3.

Step 4: Ratcheting check

See Figure 43.

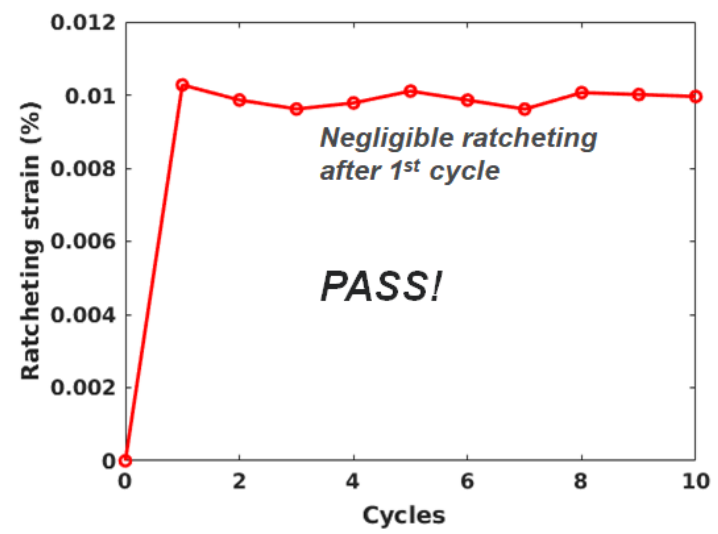

Figure 43: (Sample problem-2) Maximum ratcheting strain in the structure versus number of cycles determined from elastic-creep thermo-mechanical analysis. 
Step 5: Creep-fatigue damage check

Once steady cyclic response was achieved in the analysis, the temperature, stress, and strain-time history for a single cycle of the periodic loading were extracted. Figure 44 plots the temperature, and the steady cyclic effective strain range and von Mises effective stress at the critical location of the tube. Details of the fatigue damage fraction calculation is provided in Table 20. The tube experiences negligible fatigue damage.

Figure 45 illustrates creep damage fraction evaluation from the steady cyclic von Mises effective stress profile. Detail calculation of creep damage fraction is provided in Table 21. Using a stress factor of 0.67 the creep damage fraction at the critical location of the tube is found to be more than 1 , which means the design of the tube does not pass the creep-fatigue damage check according to Method 3.However, as discussed in sample problem 1 a factor of 0.67 is too conservative for CSP systems. Therefore, the creep damage fraction calculation is repeated in Table 22 with $K^{\prime}=0.9$. This gives much lower creep damage fraction and the design passes the creep-fatigue damage check.
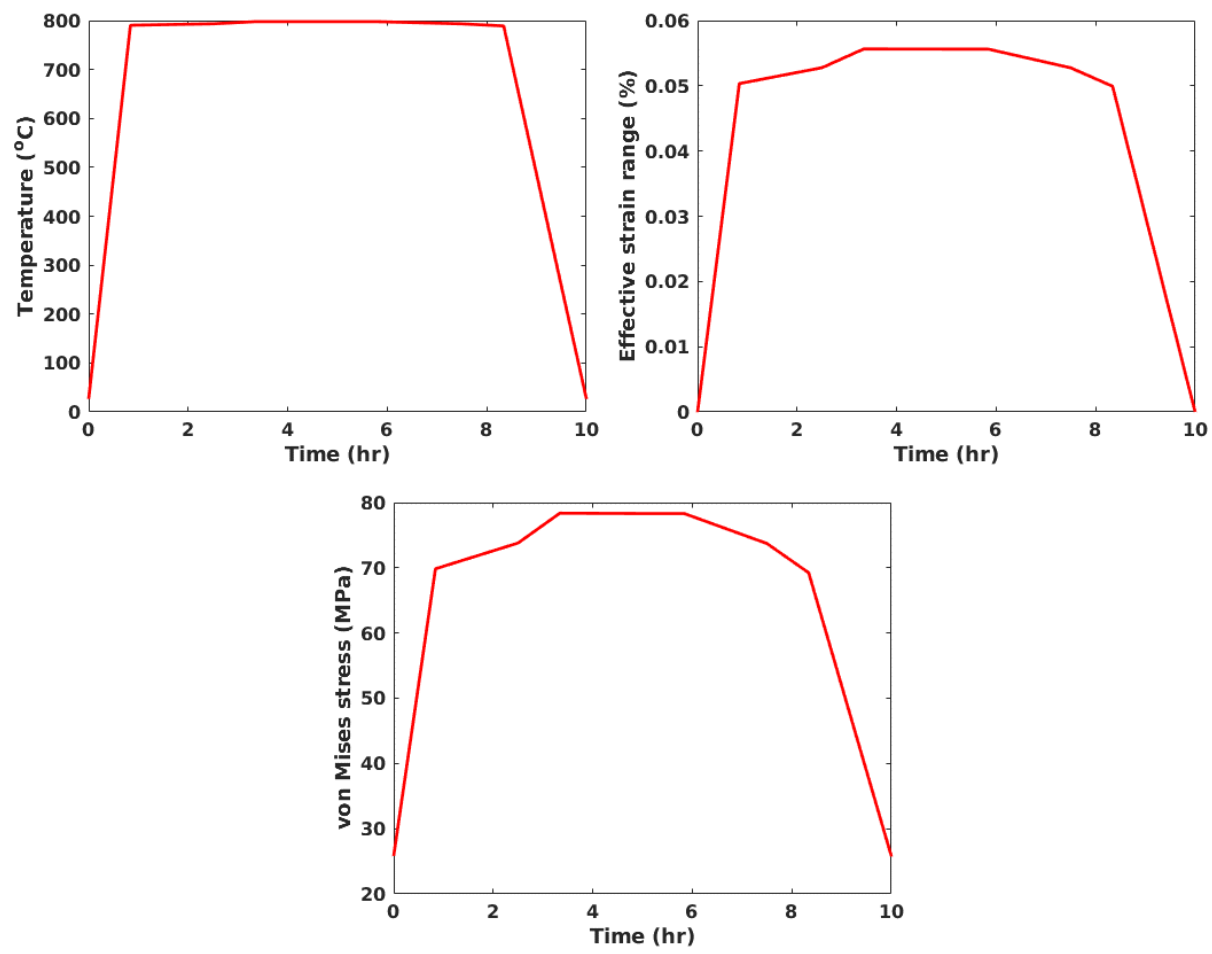

Figure 44: (Sample problem-2) Temperature, effective strain range, and von Mises stress profiles at the critical location of the tube after a steady cyclic response is achieved in the elastic-creep thermo-mechanical analysis. 


\begin{tabular}{|l|c|}
\hline & At the critical location \\
\hline$T^{\max }$ & $797.6^{\circ} \mathrm{C}$ \\
\hline $\begin{array}{l}\text { Strain range and corresponding cycle frequency according to rainflow } \\
\text { counting of effective strain range, } \Delta \varepsilon\end{array}$ & $0.0557 \%$ \\
\hline Design allowable cycles, $N_{\mathbb{d}}$ & 1 \\
\hline Design cycles, $n$ & $>1 \mathrm{e} 12$ \\
\hline Fatigue damage fraction, $D_{f}$ & $4.4 * 365=1606$ \\
\hline
\end{tabular}

Table 34: (Sample problem-2) Sample calculation of fatigue damage fraction, $D_{f}$ according to Method 3.
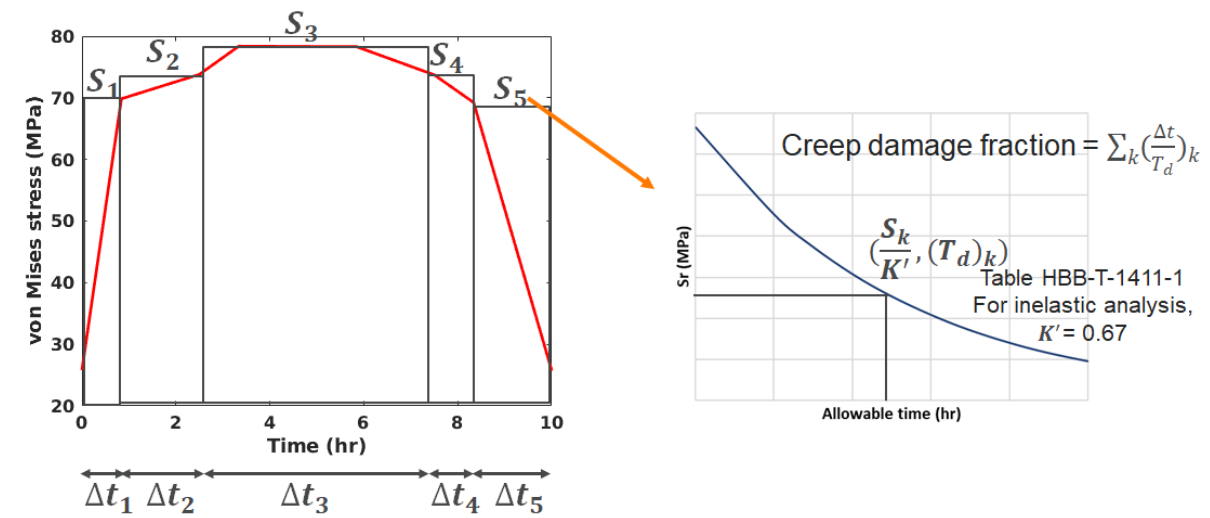

Figure 45: (Sample problem-2) Illustration of calculating creep damage fraction in Method 3.

\begin{tabular}{|c|c|c|c|c|c|}
\hline & \multicolumn{5}{|c|}{ At the critical location } \\
\hline Temperature during hold, $T_{H T}$ & \multicolumn{5}{|c|}{$797.6^{\circ} \mathrm{C}$} \\
\hline \multirow{2}{*}{$\begin{array}{l}\text { von Mises effective stress, } \sigma_{a f f}(M P a) \text { and } \\
\text { corresponding time interval, } \Delta t_{k}(h r)\end{array}$} & 69.8 & 73.8 & 78.3 & 73.7 & 69.2 \\
\hline & 0.84 & 1.66 & 5 & 0.84 & 1.66 \\
\hline $\begin{array}{l}S_{\mathrm{k}}\left(=\sigma_{\text {gfff }}\right) \\
R^{f}(=0.67)\end{array}$ & 104.2 & 110.1 & 116.9 & 110.0 & 103.3 \\
\hline Allowable time, $\left(T_{d d}\right)_{k} \quad(h r)$ & 21794 & 15737 & 9691 & 15839 & 22718 \\
\hline$\left(\frac{\mathbb{d i t}}{T_{d}}\right)_{k}$ & $3.85 \mathrm{E}-05$ & $1.05 \mathrm{E}-04$ & $5.16 \mathrm{E}-04$ & $5.30 \mathrm{E}-05$ & $7.31 \mathrm{E}-05$ \\
\hline Creep damage fraction per cycle & \multicolumn{5}{|c|}{$7.86 \mathrm{e}-4$} \\
\hline Design cycles, $n$ & \multicolumn{5}{|c|}{$4.4 * 365=1606$} \\
\hline Creep damage fraction, $D_{c}$ & \multicolumn{5}{|c|}{$\begin{array}{c}1.26(F A I L !) \\
D_{c} \text { is more than } 1 .\end{array}$} \\
\hline
\end{tabular}

Table 35: (Sample problem-2) Sample calculation of creep damage fraction, $D_{c}$ according to Method 3. 


\begin{tabular}{|c|c|c|c|c|c|}
\hline & \multicolumn{5}{|c|}{ At the critical location } \\
\hline Temperature during hold, $T_{H T}$ & \multicolumn{5}{|c|}{$797.6^{\circ} \mathrm{C}$} \\
\hline \multirow{2}{*}{$\begin{array}{l}\text { von Mises effective stress, } \sigma_{\text {eff }}(M P a) \text { and } \\
\text { corresponding time interval, } \Delta t_{k}(h r)\end{array}$} & 69.8 & 73.8 & 78.3 & 73.7 & 69.2 \\
\hline & 0.84 & 1.66 & 5 & 0.84 & 1.66 \\
\hline$\frac{S_{k}\left(=\sigma_{\text {sfff }}\right)}{K^{f}(=0,9)}$ & 77.6 & 82.0 & 87.0 & 81.9 & 76.9 \\
\hline Allowable time, $\left(T_{d}\right)_{k}(h r)$ & 101224 & 84383 & 65244 & 84765 & 103904 \\
\hline$\left(\frac{\Delta t}{T_{d}}\right)_{k}$ & 8.30E-06 & $1.97 \mathrm{E}-05$ & $7.66 \mathrm{E}-05$ & $9.91 \mathrm{E}-06$ & $1.60 \mathrm{E}-05$ \\
\hline Creep damage fraction per cycle & \multicolumn{5}{|c|}{$1.30 \mathrm{e}-4$} \\
\hline Design cycles, $n$ & \multicolumn{5}{|c|}{$4.4 * 365=1606$} \\
\hline Creep damage fraction, $D_{c}$ & \multicolumn{5}{|c|}{$\begin{array}{c}0.21(\text { PASS! }) \\
\left(D_{f}, D_{c}\right) \text { falls inside the damage envelop in the creep- } \\
\text { fatigue interaction diagram }\end{array}$} \\
\hline
\end{tabular}

Table 36: (Sample problem-2) Repeat of calculations in Table 21 by changing $K^{s}=0.67$ to $K^{s}=0.9$.

\section{Comparison of the design methods}

In general, Method 1 requires the most designer effort, followed by Method 2, and Method 3. So generally designers will prefer 2 and 3, depending on if they want to use elastic analysis (2) or are comfortable with a simple inelastic analysis (3).

All methods predict fatigue damage in the two sample components is negligible. However, the relative conservative of the three approaches can be assessed by comparing the creep damage fractions for each method for the two sample problems. Table 37 provides this comparison, using a stress factor of 0.9 for Method 3.

\begin{tabular}{llll}
\hline & Method 1 & Method 2 & Method 3 \\
\hline Sample Problem 1 & 0.75 & 0.61 & 0.57 \\
Sample Problem 2 & 0.99 & 0.87 & 0.21 \\
\hline
\end{tabular}

Table 37: Creep damage fraction for each problem and for each design method

Methods 1 and 2 produce comparable creep damage fractions, which makes sense as they are fundamentally both the ASME design by elastic analysis method, with simplifications for Method 1. Full inelastic analysis, at least with a stress factor of 0.9, produces much less over conservative results. With a factor of 0.67 the results of inelastic analysis are comparable to the damage fractions predicted by the elastic analysis methods.

\section{Summary}

These sample problems, along with the current design allowables, will be distributed to the project design expert and three CSP system vendors for evaluation. This will fulfill our project Q6 deliverable. We will request they use sample problem 1 (the simple linear gradient tube) as the reference problem for the round robin, but will provide sample problem 2 as well, as it is a more realistic geometry. 
Our final milestone is the complete, finalized design method. We are on track to provide this at the start of Q7 (November 2019). For the design data only the creep-fatigue diagram is not final. This diagram will be finalized when the remaining INL creep-fatigue tests are completed.

The design methods presented here will be recommended in the final report. The only remaining item to address, which will be completed in Q7, is a method for assessing buckling in receiver structures. As long as the receiver design provides axial strain relief, the thermomechanical loading is unlikely to cause buckling. However, the combination of the thermomechanical loading plus an external wind load does have the potential to buckle a receiver tube. ANL has developed a buckling method based on the isochronous curves developed in this project. The Q7 report will detail this method and provide example calculations. The method will also be provided in our final report.

Additional work will focus on interpreting the INL sheet tests to provide modified design constants for very thin structures and on finalizing the design methods and preparing the final, detailed design method report.

\section{Task 3}

\section{Force controlled testing}

Task 3 will examine the effect of different material forms on the design models (particularly fatigue). Specifically, we will be looking at Alloy $740 \mathrm{H}$ sheet in this task. Due to the nature of sheet fatigue testing, it is not feasible to do fully reversed, strain controlled testing, as the material would buckle during the compression. Furthermore, it is more difficult to measure strain directly from the sheet specimens without causing deformation from the pressure imposed by the extensometers onto the specimen. As a result, the sheet metal testing will be performed in load control, with an $\mathrm{R}=0.1$ (minimum stress will be $10 \%$ of maximum stress). To allow for a more direct comparison of tests, several force controlled, $\mathrm{R}=0.1$ tests were performed on plate material. The results of the three tests run this quarter are shown below in Figure 46. Loads were chosen based on strain controlled test results. Initially the force was chosen to match the peak stress achieved during the $1 \%$ delta strain tests. This resulted in too short of a fatigue life, so a force was chosen to match the near-steady state stress after the initial peak. Additional tests at $750^{\circ} \mathrm{C}$ will be performed in the next quarter. A machine and grips have been identified for sheet testing, and these tests will also begin shortly. 


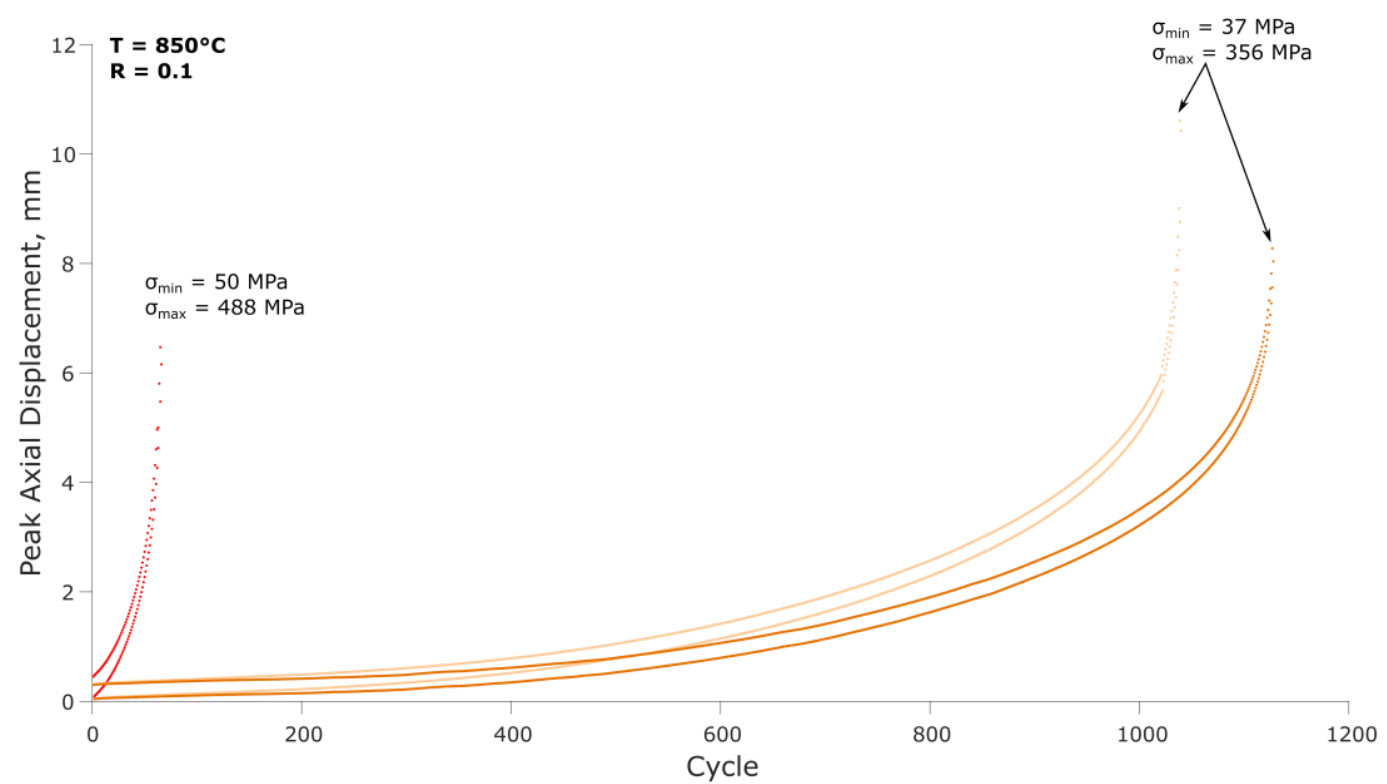

Figure 46. Displacement vs cycle of load controlled tests.

\section{Summary}

Testing performed on the plate material will provide a basis for expectation of the sheet metal testing. These tests will also be included in the Argonne design models moving forward. A summary of the load controlled, Alloy $740 \mathrm{H}$ plate tests is shown in Table 38.

\begin{tabular}{|c|c|c|c|c|c|c|c|c|c|c|}
\hline Temp. & Hold time & $\mathrm{R}$ & $\sigma_{\min }$ & $\sigma_{\max }$ & \multicolumn{2}{|c|}{ At Cycle 10} & \multicolumn{3}{|c|}{ Midlife } & Machine \\
\hline & & & & & $\begin{array}{c}\text { axial } \\
\text { disp }\end{array}$ & $\begin{array}{c}\text { axial } \\
\text { disp }\end{array}$ & $\begin{array}{c}\text { cycle } \\
\text { used }\end{array}$ & $\begin{array}{c}\text { axial } \\
\text { disp }_{\text {max }}\end{array}$ & $\begin{array}{c}\text { axial } \\
\text { disp } \\
\text { Cycles }\end{array}$ \\
to Failure \\
\hline$\left({ }^{\circ} \mathrm{C}\right)$ & $(\mathrm{min})$ & & $\mathrm{MPa}$ & $\mathrm{MPa}$ & $\mathrm{mm}$ & $\mathrm{mm}$ & & $\mathrm{mm}$ & $\mathrm{mm}$ & \\
\hline 850 & 0 & 0.1 & 50 & 488 & 0.642 & 0.256 & 33 & 1.496 & 1.082 & 66 \\
\hline 850 & 0 & 0.1 & 37 & 356 & 0.327 & 0.064 & 500 & 1.050 & 0.780 & 1040 \\
\hline 850 & 0 & 0.1 & 37 & 356 & 0.314 & 0.053 & 550 & 0.920 & 0.652 & 1128 \\
\hline
\end{tabular}

Table 38. Results of load controlled, Alloy $740 \mathrm{H}$ plate material tested during Q6.

\section{References}

[1] Special Metals,

http://www.specialmetals.com/assets/smc/documents/alloys/inconel/inconel-alloy-740-h.pdf.

[2] American Society of Mechanical Engineers Boiler \& Pressure Vessel Code Case 2702, 2011.

[3] Purgert, R. et al. Boiler materials for ultra supercritical coal power plants. DOE technical report, 2015.

[4] Jena, P. S. M., et al. "Low cycle fatigue behavior of nickel base superalloy IN $740 \mathrm{H}$ at $760^{\circ}$ C: Influence of fireside corrosion atmosphere." International Journal of Fatigue 116: pp. 623-633, 2018. 
[5] Zhang, S. and Takahashi, Y. "Evaluation of high temperature strength of a Ni-based Alloy $740 \mathrm{H}$ for advanced ultra-supercritical power plant." In Advances in Materials Technology for Fossil Power Plants: Proceedings from the Seventh International Conference, Waikoloa, Hawaii, USA, 2014.

[6] Kocks, U. "Realistic constitutive relations for metal plasticity." Materials Science and Engineering A 317:, pp. 181-187, 2001.

[7] Mecking, H., Nicklas, B., Zarubova, N., et al. "A 'universal' temperature scale for plastic flow.” Acta Metallurgica 34(3): pp. 527-535, 1986.

[8] Zhang, Shengde, and Yukio Takahashi. "Creep and Creep-Fatigue Deformation and Life Assessment of Ni-Based Alloy 740H and Alloy 617." In ASME 2018 Pressure Vessels and Piping Conference, pp. V06AT06A060-V06AT06A060. American Society of Mechanical Engineers, 2018. 